UNIVERSIDADE DE SÃO PAULO

ESCOLA DE ENFERMAGEM

LUANA PRADO FIGUEREDO

COMPLICAÇÕES DA TERAPIA NUTRICIONAL ENTERAL (TNE) E

FATORES ASSOCIADOS EM PACIENTES HOSPITALIZADOS

SÃo PAULO

2011 


\title{
LUANA PRADO FIGUEREDO
}

COMPLICAÇÕES DA TERAPIA NUTRICIONAL ENTERAL (TNE) E FATORES ASSOCIADOS EM PACIENTES HOSPITALIZADOS

\author{
Dissertação apresentada à Escola de \\ Enfermagem da Universidade de São \\ Paulo para obtenção do título de \\ Mestre em Ciências, pelo Programa de \\ Pós-Graduação em Enfermagem na \\ Saúde do Adulto.
}

Orientadora:

Prof $^{a}$ Dra $^{a}$ Ana Maria Kazue Miyadahira

\section{SÃO PAULO}




\section{DEDICATÓRIA}

A Deus, pela benção da vida e sustentação. Por ser meu maior inspirador e amigo confidencial, em tudo.

A minha querida mamãe Maria de Fátima Prado, por sua sutil presença e ternura, auxiliou-me com discernimento, força e amor para continuar. Suas inestimáveis orientações, ensinamentos e confiança foram fundamentais para minha formação e para que os sonhos se tornassem realidade. Seguiu a meu lado todos os momentos com cumplicidade e determinação, para que mais este trabalho fosse finalizado.

Ao Cesar Chagas Barbosa, por seu apoio, atenção e presença em todos os momentos desta trajetória. Pelas suas incessantes orações, juntos a nós, para que todos os obstáculos fossem ultrapassados.

Ao Wendell Leme da Silva, meu namorado que foi companheiro em todas as fases desta experiência, pela compreensão de meu distanciamento, estímulo e amor. 


\section{AGRADECIMENTOS ESPECIAIS}

À Profa Dra Ana Maria Kazue Miyadahira, pela orientação deste estudo e compreensão, ensinando- me a admirar suas competências, além de ter compartilhado suas experiências e oferecido-me uma oportunidade impar de crescimento.

À querida $\operatorname{Prof}^{\mathrm{a}} \mathrm{Dr}^{\mathrm{a}}$ Miako Kimura pelo estímulo e conversas que me despertaram na busca de um novo pensar com base no dizer intencional:

"Não podemos ser como borboletas".

Às Professoras Doutoras Kazuko Uchikawa Graziano e Suely Itsuko Ciosak, pela rica contribuição em meu Exame de Qualificação e apoio no decorrer desta caminhada.

À querida Lilia de Souza Nogueira, minha amiga por toda colaboração e incentivo no decorrer desta caminhada.

A todas as colegas do grupo de pesquisa "Habilidades Psicomotoras em Emergência e Terapia Intensiva", da EEUSP.

À Prof ${ }^{\mathrm{a}} \mathrm{Dr}^{\mathrm{a}}$ Kátia Grillo Padilha pelas suas instigantes conversas que irrigaram minha forma de pensar.

Às enfermeiras Ligia Fumiko Minami e Flávia de Oliveira Motta Maia, que acreditaram nessa ideia e apoiaram a realização desta pesquisa com suas sugestões acertadas e enriquecedoras. 
À equipe do Sed e do SAME, pela colaboração e disponibilidades em vários momentos no período de coleta de dados.

Ao Dr Ricardo Luís Barbosa (Laboratório de Estatística da EEUSP), pela colaboração no processamento dos dados.

À Profa Ivone Borelli, pela correção gramatical do projeto de pesquisa submetido ao exame de qualificação e da dissertação.

Ao Jamil Abuyagui Vieira e Juliana Akie Takahashi, funcionários da biblioteca "Wanda de Aguiar Horta" da EEUSP, pelas orientações nas buscas bibliográficas e auxílios na organização das referências bibliográficas.

Aos queridos amigos $\mathrm{Dr}^{\circ}$ Cesar Brant e a Nutricionista Clara Pedrosa Rodrigues, pela oportunidade de crescimento profissional e troca de experiências na equipe de terapia nutricional.

A todos os Pacientes que passaram pela experiência da Terapia Nutricional Enteral. Não apenas os ensinei nas conversas com minhas orientações, mas aprendi muito com suas histórias, sofridas complicações e evoluções. A todos, minha eterna gratidão.

A todos que direta ou indiretamente colaboraram na realização desta dissertação. 
"Encontrei inúmeros vendedores de sonhos pelo caminho. Através de suas inteligências e seus gestos generosos, eles me inspiraram, me ensinaram e me fizeram ver a minha pequenez. Interromperam sua trajetória em algumas curvas da existência para pensar nos outros e se doar sem pedir nada em troca”.

(Cury, Augusto, 2008) 
Figueredo LP. Complicações da Terapia Nutricional Enteral (TNE) e fatores associados em pacientes hospitalizados. [dissertação]. São Paulo: Escola de Enfermagem, Universidade de São Paulo; 2011.

\section{RESUMO}

Trata-se de um estudo observacional, retrospectivo, cujo objetivo foi descrever o perfil dos pacientes e características da Terapia Nutricional Enteral (TNE) bem como analisar as complicações dessa terapia e os fatores associados em pacientes adultos hospitalizados. O estudo constituiuse de uma amostra de 214 pacientes internados, no período de 2008 e 2009, em um hospital universitário do Município de São Paulo. Os dados foram coletados dos prontuários e das fichas de avaliação nutricional, em um formulário elaborado para o estudo. Os resultados permitiram verificar que: 1 a-) em relação ao perfil dos pacientes e terapia nutricional enteral, houve predominância do sexo masculino (55,6\%), com média de idade de 64,8 anos; internados em unidades de semi-intensiva e UTI $(66,8 \%)$. b-) Referente à terapia nutricional enteral, a média de dias de nutrição enteral foi de 13,2 dias, e $43,5 \%$ dos pacientes receberam-na em até uma semana. Quanto à via de acesso enteral, predominaram as sondas nasoenterais $(96,3 \%)$ e o método de administração contínuo da dieta (67,3\%). 2-) em relação às complicações da TNE e os eventos observados - dos 214 pacientes da amostra, em 200 deles houve complicações durante o uso da nutrição enteral. Verificou-se a ocorrência de complicações: gastrointestinal $(90,5 \%)$, metabólica $(55,0 \%)$, mecânica $(41,5 \%)$ e pulmonar $(13,0 \%)$. Os eventos observados mais frequentes da complicação gastrointestinal foram: distensão abdominal $(33,4 \%)$, constipação $(17,5 \%)$ e alto volume residual gástrico $(14,6 \%)$. Na complicação metabólica, o evento observado foi hiperglicemia $(55,0 \%)$, com valor médio de $174,2 \mathrm{mg} / \mathrm{dL}$. Os eventos observados predominantes da complicação mecânica foram: saída não programada da sonda enteral $(70,5 \%)$, seguida de obstrução da sonda enteral (19,0\%). Na complicação pulmonar, a aspiração pulmonar $(13,0 \%)$ foi o evento observado. 5-) Quanto ao método de infusão houve associação significativa da infusão contínua com os seguintes eventos observados na complicação gastrointestinal: alto VRG $(p=0,000)$, constipação $(p=0,010)$, distensão abdominal $(p=0,037)$. Na complicação mecânica, houve associação significativa com a infusão intermitente nos seguintes eventos: saída não programada da sonda enteral $(p=0,005)$ e deslocamento da sonda enteral $(p=0,040)$. 6-) Quanto à terapia medicamentosa, houve associação significativa da complicação metabólica (hiperglicemia) e o uso de sedativos/opioides $(p=0,000)$ e drogas vasoativas $(p=0,000)$. Este estudo demonstrou que as complicações coexistentes com a TNE são muito prevalentes nesta população (93,5\%). Além disso, verificou-se que existe elevada ocorrência de eventos observados (617), sendo as complicações (400) que apresentaram intersecções significativas com outras variáveis acima descritas. Portanto, investigações das condições clínicas, as 
terapêuticas e os cuidados no uso da sonda enteral devem ser reiteradamente indicadas, sobretudo para os enfermeiros que são responsáveis pela administração e monitoramento da nutrição enteral.

Palavras-chave: Alimentação enteral, intubação gastrointestinal, complicações, pacientes internados. 
Figueredo LP. Complications of Enteral Nutrition Therapy (ENT) and associated factors in hospitalized patients. [Thesis]. São Paulo: School of Nursing, University of São Paulo, 2011.

\begin{abstract}
This observational and retrospective study aimed to describe the profile of patients and the characteristics of the Enteral Nutrition Therapy (ENT), as well as to analyze the complications of this therapy and the associated factors in hospitalized adult patients. The study consisted of a sample of 214 patients, hospitalized between 2008 and 2009 at a university hospital in the city of São Paulo. Data were collected from medical records and of nutritional assessment sheets, using a form developed for the study. Results showed that: 1 a-) in relation to patient profiles and enteral nutrition therapy participants were predominantly male $(55.6 \%)$, with an average age of 64.8 years, hospitalized in semi-intensive and intensive care units (66.8\%); b-) Concerning enteral nutrition therapy, the average days of enteral nutrition was 13.2 days, and $43.5 \%$ of the patients received it for up to one week. As for the route of enteral access, nasoenteric feeding tube $(96.3 \%)$ and continuous feeding administration (67.3\%) were the most common. 2 -) regarding the complications of ENT and the observed events - of the 214 patients of the sample, 200 had complications during the use of enteral nutrition. There was occurrence of gastrointestinal (90.5\%), metabolic $(55.0 \%)$, mechanical $(41.5 \%)$ and pulmonary $(13.0 \%)$ complications. The most frequently observed events among gastrointestinal complication were: abdominal distention $(33.4 \%)$, constipation $(17.5 \%)$ and high gastric residual volume (GRV) (14.6\%). Among the metabolic complication, hyperglycemia $(55.0 \%)$ was observed, with average of $174.2 \mathrm{mg} / \mathrm{dL}$. The predominant events resulting from mechanical complication were unexpected withdrawal of enteral feeding tube $(70.5 \%)$, followed by obstruction of enteral feeding tube $(19.0 \%)$. As for pulmonary complication, pulmonary aspiration $(13.0 \%)$ was the observed event. 5-) Concerning the method of infusion, there was significant association of continuous infusion with the following events observed in gastrointestinal complication: high GRV $(p=0.000)$, constipation $(p=0.010)$ and abdominal distension $(p=0.037)$. Among the mechanical complication, there was significant association with intermittent infusion at the following events: unexpected withdrawal of enteral feeding tube $(p=0.005)$ and displacement of enteral feeding tube $(p=0.040)$. 6-) Regarding drug therapy, there was significant association of metabolic complication (hyperglycemia) and use of sedatives/opioids $(p=0.000)$ and vasoactive drugs $(p=0.000)$. This study evidenced that complications concomitant with ENT are very prevalent in this population (93.5\%). Moreover, it was found that there is a high occurrence of observed events (617), with complications (400) presenting significant intersections with other variables described above. Therefore, research on the clinical conditions, treatments and care to the use of enteral feeding tubes should be constantly indicated, particularly
\end{abstract}


for nurses who are responsible for the administration and monitoring of enteral nutrition.

Keywords: $\quad$ Enteral nutrition, intubation gastrointestinal, complications, inpatients. 


\section{LISTA DE ILUSTRAÇÕES}

Figura 1 - Distribuição dos pacientes submetidos à TNE $(n=214)$ em um hospital universitário, no período de 2008/2009, segundo o local de internação. São Paulo, 2010

Figura 2 - Distribuição dos pacientes submetidos à TNE $(n=214)$ em um hospital universitário, no período de 2008/2009, segundo o uso de ventilação mecânica. São Paulo, 2010

Figura 3 - Distribuição dos pacientes submetidos à TNE em um hospital universitário, no período de 2008/2009, segundo o tipo de acesso enteral. São Paulo, 2010

Figura 4 - Distribuição dos pacientes submetidos à TNE com complicações $(n=200)$ em um hospital universitário, no período de 2008/2009, segundo os tipos de complicações. São Paulo, 2010 


\section{LISTA DE TABELAS}

Tabela 1 - Distribuição dos pacientes submetidos à TNE em um hospital universitário, no período de 2008/2009, segundo a faixa etária. São Paulo, 2010.

Tabela 2 - Distribuição dos pacientes submetidos à TNE em um hospital universitário, no período de 2008/2009, segundo o sexo. São Paulo, 2010.

Tabela 3 - Distribuição das comorbidades apresentadas pelos pacientes submetidos à TNE em um hospital universitário, no período de 2008/2009. São Paulo, 2010

Tabela 4 - Distribuição das terapias medicamentosas utilizadas pelos pacientes submetidos à TNE em um hospital universitário, no período de 2008/2009. São Paulo, 2010

Tabela 5 - $\quad$ Distribuição dos pacientes submetidos à TNE $(n=214)$ em um hospital universitário, no período de 2008/2009, segundo o tempo de TNE em semanas. São Paulo, 2010

Tabela 6 - Distribuição dos pacientes submetidos à TNE em um hospital universitário, no período de 2008/2009, segundo o método de infusão da TNE. São Paulo, 2010 ... 57

Tabela 7 - Distribuição dos pacientes submetidos à TNE em um hospital universitário, no período de 2008/2009, com complicações: metabólica, mecânica e pulmonar $(n=200)$ segundo a ocorrência ou não da complicação gastrointestinal. São Paulo, 2010

Tabela 8 - Distribuição dos pacientes submetidos à TNE em um hospital universitário, no período de 2008/2009, com complicações: mecânica e metabólica $(n=200)$, segundo a ocorrência ou não de complicação pulmonar. São Paulo, 2010

Tabela 9 - $\quad$ Frequência de eventos observados nas complicações encontradas nos pacientes submetidos à TNE em um hospital universitário, no período de 2008/2009. São Paulo, 2010 
Tabela 10 - Frequência dos eventos observados nos 181 casos de complicação gastrointestinal em pacientes submetidos à TNE em um hospital universitário, no período de 2008/2009. São Paulo, 2010

Tabela 11 - Frequência dos eventos observados nos 83 casos de complicação mecânica em pacientes submetidos à TNE em um hospital universitário, no período de 2008/2009. São Paulo, 2010

Tabela 12 - Distribuição dos casos com complicação gastrointestinal (eventos observados), segundo a complicação pulmonar nos pacientes submetidos à TNE em um hospital universitário, no período de 2008/2009. São Paulo, 2010

Tabela 13 - Distribuição dos casos com complicação gastrointestinal (eventos observados) nos pacientes submetidos à TNE em um hospital universitário, no período de 2008/2009, segundo o método de infusão da TNE. São Paulo, 2010.

Tabela 14 - Distribuição dos casos com complicação metabólica (hiperglicemia), segundo o método de infusão da nutrição enteral nos pacientes submetidos à TNE em um hospital universitário, no período de 2008/2009, São Paulo, 2010

Tabela 15 - Distribuição dos casos com complicação mecânica (eventos observados), segundo o método de infusão da nutrição enteral nos pacientes submetidos à TNE em um hospital universitário, no período de 2008/2009. São Paulo, 2010

Tabela 16 - Distribuição dos casos com complicação pulmonar (evento observado) nos pacientes submetidos à TNE em um hospital universitário, no período de 2008/2009, segundo o método de infusão da TNE. São Paulo, 2010 ... 69

Tabela 17 - Distribuição dos pacientes que receberam terapia medicamentosa e foram submetidos à TNE em um hospital universitário, no período de 2008/2009, segundo a ocorrência de complicações: gastrointestinal e metabólica. São Paulo, 2010.

Tabela 18 - Distribuição dos pacientes que receberam terapia medicamentosa e foram submetidos à TNE em um hospital universitário, no período de 2008/2009, segundo a ocorrência de complicações mecânica e pulmonar. São Paulo, 2010 



\section{SUMÁRIO}

1.1 Paciente hospitalizado e terapia nutricional enteral ....................................... 19

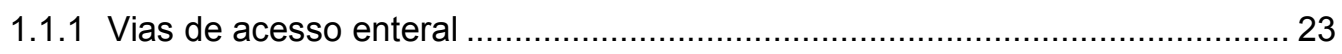

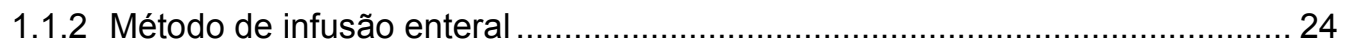

1.2 Suportes terapêuticos: medicamentoso e ventilatório..................................... 25

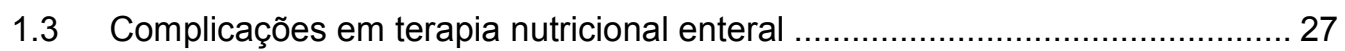

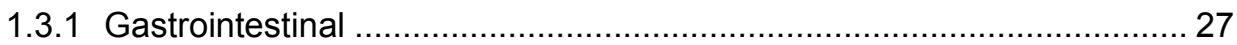

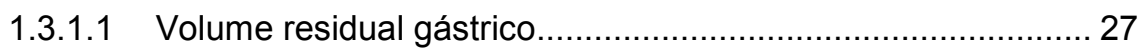

1.3.1.2 Náuseas, Vômitos e Refluxos.................................................. 28

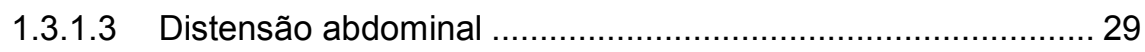

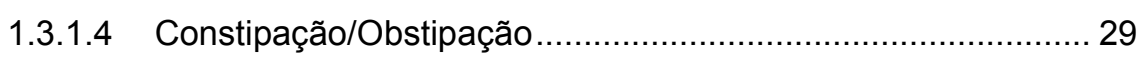

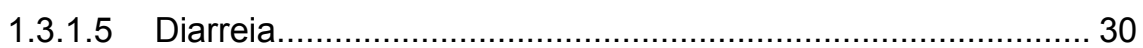

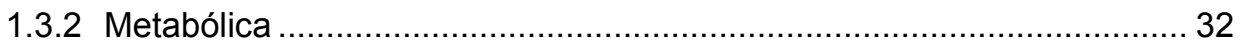

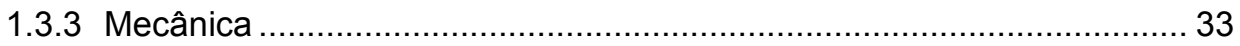

1.3.3.1 Deslocamento e saída não programada da sonda enteral...... 33

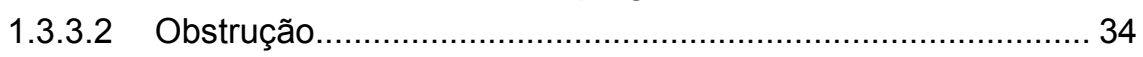

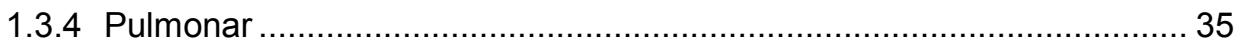

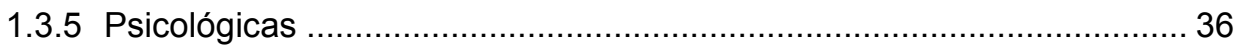

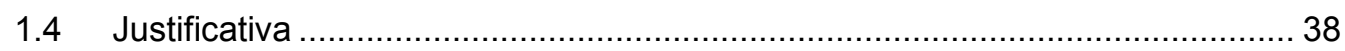

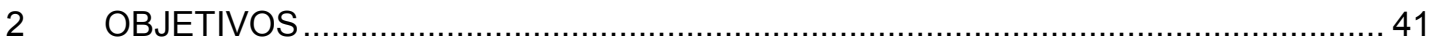

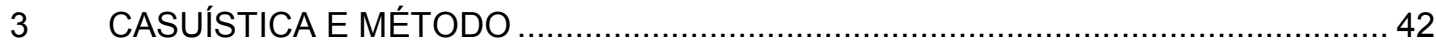

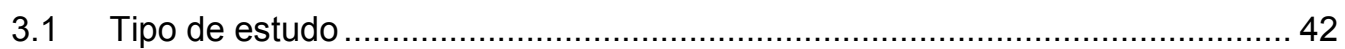

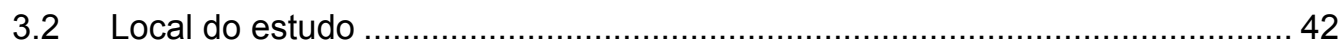

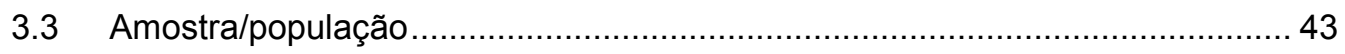

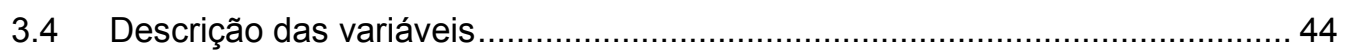

3.4.2 Fatores associados às complicações da TNE foram considerados: ...... 45

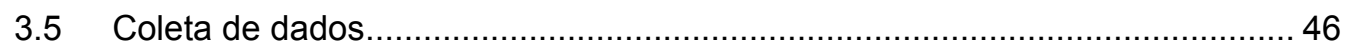

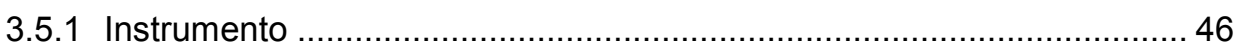

3.5.2 Operacionalização da coleta dos dados ............................................ 46

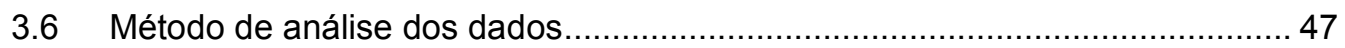

3.6.1 Análise do tipo de complicação............................................................ 47

3.6.2 Análise da associação entre as complicações ...................................... 47

3.6.3 Análise da influência dos fatores associados às complicações ............. 48

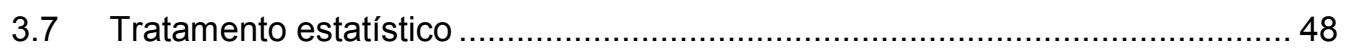

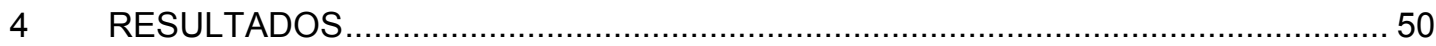

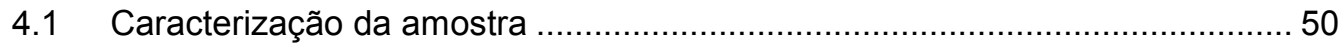

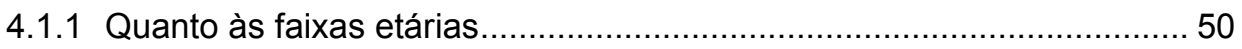

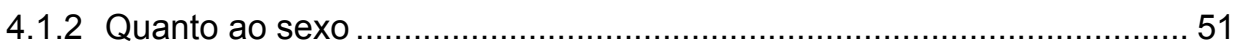


4.1.3 Quanto ao local de internação ........................................................ 52

4.1.4 Quanto às comorbidades e tipo de tratamento recebido ....................... 52

4.1.5 Quanto à necessidade de ventilação mecânica ..................................... 54

4.1.6 Quanto ao tipo de terapia medicamentosa ........................................... 54

4.1.7 Quanto ao tempo de internação.......................................................... 55

4.2 Terapia nutricional enteral: tempo de TNE, vias de acesso e métodos de

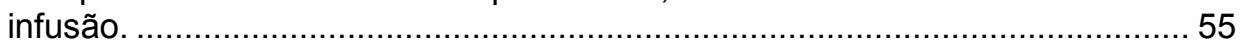

4.2.1 Terapia nutricional enteral, segundo o tempo de administração ............. 56

4.2.2 Terapia nutricional enteral, segundo o tipo de acesso .......................... 56

4.2.3 Terapia nutricional enteral, segundo o método de infusão: contínuo

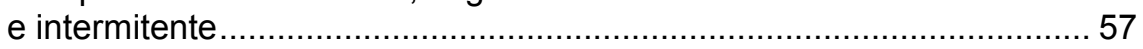

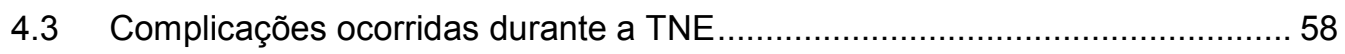

4.4 Análise da associação entre as complicações ocorridas durante a TNE ......... 59

4.4.1 Associação entre as complicações ocorridas durante a TNE, segundo a ocorrência de complicações gastrointestinais........................ 59

4.4.2 Associação entre as complicações mecânica e metabólica segundo a ocorrência de complicação pulmonar .................................... 60

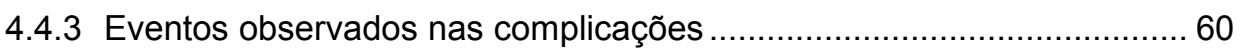

4.4.4 Complicação gastrointestinal e eventos observados ............................. 62

4.4.5 Complicação metabólica e evento observado ......................................... 63

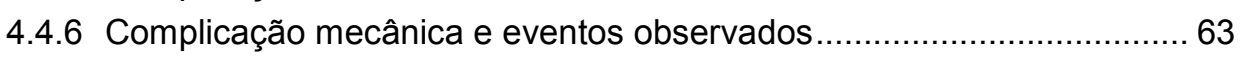

4.4.7 Complicação pulmonar e evento observado........................................... 64

4.5 Eventos observados nas complicações e métodos de infusão da nutrição

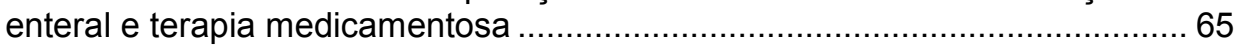

4.5.1 Eventos observados nas complicações gastrointestinais e forma

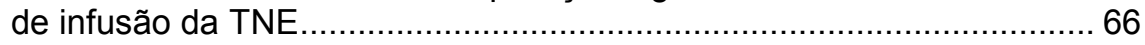

4.5.2 Evento observado na complicação metabólica e método de infusão

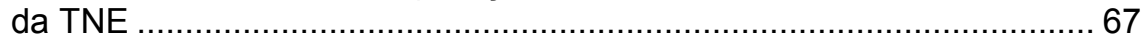

4.5.3 Eventos observados na complicação mecânica e método de

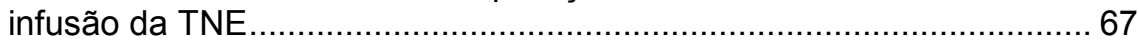

4.5.4 Evento observado na complicação pulmonar e método de infusão

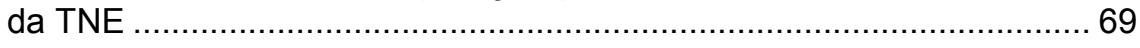

4.5.5 Terapia medicamentosa e complicações: gastrointestinal e

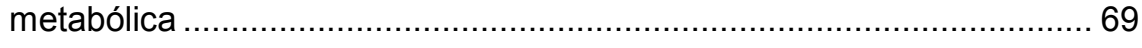

4.5.6 Terapia medicamentosa e complicações: mecânica e pulmonar ........... 71

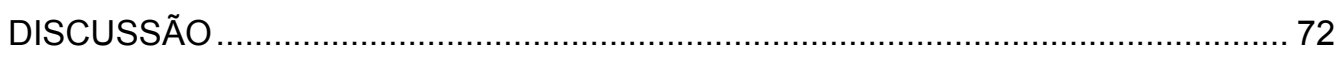

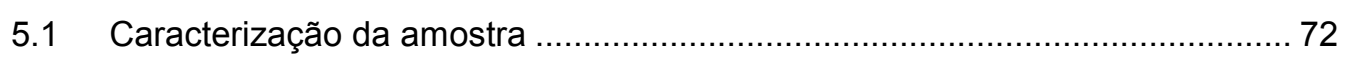

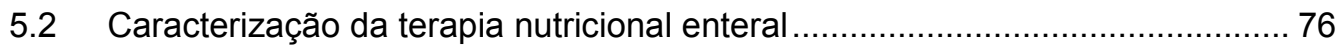

5.3 Complicação gastrointestinal e eventos observados ...................................... 77

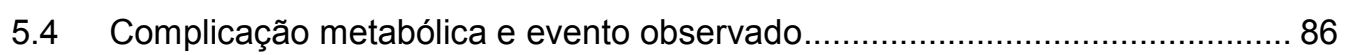

5.5 Complicação mecânica e eventos observados .............................................. 87

5.6 Complicação pulmonar e evento observado ................................................. 94

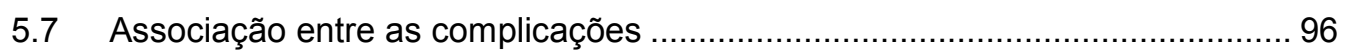

5.8 Influência dos eventos observados nas complicações: gastrointestinal e mecânica na complicação pulmonar 
5.9 Eventos observados nas complicações: métodos de infusão da nutrição

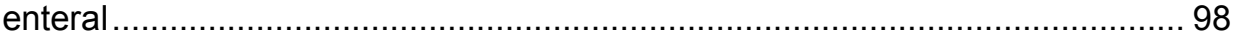

5.10 Eventos observados nas complicações: terapia medicamentosa...................... 99

5.11 À guisa de sinopse, limitações e perspectivas ........................................... 100

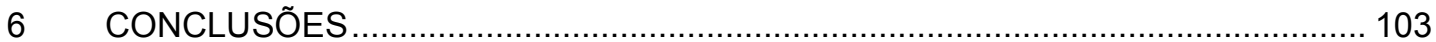

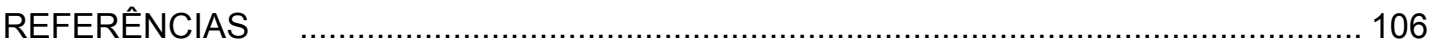

APÊNDICE

ANEXO 


\section{INTRODUÇÃO}

A terapia nutricional enteral (TNE) é uma prática usual no âmbito hospitalar e domiciliar, utilizada em pacientes impossibilitados de se alimentarem por via oral. Difundi-se rápida e progressivamente, como método excelente para oferecer nutrientes necessários a pacientes com alto catabolismo, constituindo-se na primeira escolha para prevenção da desnutrição hospitalar, nesse tipo de doentes. A adesão a essa forma de terapia ocorre em razão do aprimoramento nas formulações dos nutrientes, no controle do padrão microbiológico, no emprego de bombas de infusão para administração controlada do volume da nutrição enteral, assim como em virtude da alta qualidade das sondas que reduz as intercorrências, tanto na introdução como em sua manutenção $0^{(1)}$.

A prática da TNE requer atuação sistematizada dos profissionais, sobretudo do enfermeiro que presta a assistência integral à beira do leito e monitora sua administração. Apesar de seus amplos e reconhecidos benefícios, a ocorrência de complicações nos pacientes durante o uso dessa forma de terapia nutricional é uma realidade que ainda necessita de estudos profundos para melhor equacioná-la.

Em TNE, as complicações são relatadas pela literatura, que também lista as mais frequentes (gastrointestinal, mecânica, metabólica e pulmonar) entre seus usuários ${ }^{(2)}$. Sobre o assunto, são muito ilustrativos os relatos de complicações observadas pelo Grupo de Apoio Nutricional Enteral e Parenteral (GANEP), no Brasil, que analisou 80 pacientes que fizeram uso de drogas vasoativas: $45 \%$ deles apresentaram alguma complicação digestiva e, em $21 \%$, a complicação esteve associada ao débito pela sonda e, em $10 \%$, à diarreia ${ }^{(2)}$. Em outro estudo, realizado nos Estados Unidos da América em cinco UTIs de trauma, com casuística de 360 pacientes submetidos à ventilação mecânica recebendo TNE, verificou-se que a aspiração, a mais importante complicação pulmonar, presente em $88 \%$ dos casos, esteve relacionada ao vômito em 20 pacientes $(p=0,007)$, VRG 
$(\geq 200 \mathrm{ml})$ em $182(p=0,058)$ e ao refluxo em 30 pacientes $(p=0,033)$. Além disso, os pesquisadores observaram que, em 322 dos 360 casos, havia conteúdo alimentar na secreção traqueal, sendo em maior quantidade nos pacientes com a sonda enteral localizada em região pré-pilórica em relação às pós-pilórica $(56 \% \text { VS } 43 \%)^{(3)}$.

Com enfoque a respeito de outros aspectos clínicos, outra investigação demonstrou que as complicações podem estar atreladas ao estado nutricional depauperado, que é prejudicial às funções cardíaca, respiratória, renal, intestinal e imunológica, o que acarreta acréscimo na gravidade do quadro clínico desses pacientes ${ }^{(4)}$. Esse cenário clínico pode, ainda, influenciar na redução da ingesta alimentar ou na tolerância nutricional e comprometer a evolução dos pacientes, levando-os à desnutrição que aumenta progressivamente com o tempo de hospitalização. O fato foi identificado em um estudo realizado com 4.000 pacientes de hospitais públicos, cujo resultado mostrou que, após 48hs de admissão, 31\% dos pacientes mostraram algum grau de desnutrição, elevando para $61 \%$ naqueles internados por mais de 15 dias $^{(5)}$.

Após estas considerações preliminares que ilustram, de forma sinóptica, a importância das complicações da TNE e de suas relações com variáveis clínicas e terapêuticas, a seguir, serão expostos os dados de literatura sobre o tema.

\subsection{PACIENTE HOSPITALIZADO E TERAPIA NUTRICIONAL ENTERAL}

O processo de hospitalização associado à idade avançada, condição sócioeconômica desfavorável e desnutrição preexistente podem intensificar as agressões ao $\operatorname{organismo}^{(6)}$ e prejudicar a qualidade da ingestão alimentar, comprometendo o estado nutricional fatos que predispõem à piora do prognóstico do paciente ${ }^{(7)}$. 
A desnutrição em pacientes hospitalizados é uma possibilidade que deve ser considerada, pois pode ocorrer entre $19 \%$ a $80 \%$ deles, em razão de mudanças sofridas no metabolismo em decorrência da própria doença ou do tratamento de que necessitam ${ }^{(4)}$, sobretudo, em Unidade de Terapia Intensiva (UTI), onde o índice de infecção é elevado, as cicatrizações são mais lentas e as complicações diversas. Geralmente, esses pacientes são dependentes de ventilação mecânica, além de alguns terem alterações da mucosa intestinal ${ }^{(8-10)}$ e mudança da microbiota, local que é uma condição preditora de altas taxas de morbidade e mortalidade ${ }^{(8)}$. Desafortunadamente, pacientes desnutridos hospitalizados que evoluem com piora do quadro clínico sob os aspectos nutricionais vêm sendo uma realidade documentada nas últimas três décadas ${ }^{(4)}$. Por essa razão, a terapia nutricional (TN) deve ser encarada como prioridade no tratamento desses pacientes ${ }^{(11)}$.

No Brasil, o Inquérito Brasileiro de Avaliação Nutricional Hospitalar (IBRANUTRI), realizou um estudo multicêntrico, transversal e epidemiológico, em 12 estados brasileiros e no Distrito Federal, em 1996, que analisou 4.000 pacientes. Os achados da investigação revelaram a presença de desnutrição em $48 \%$ dos pacientes internados e sua progressão durante a internação, chegando a $61 \%$, quando a permanência no hospital foi maior que 15 dias $^{(5)}$. Esta estimativa é confirmada em outro estudo, chegando a $50 \%$ dos pacientes hospitalizados, e o déficit nutricional pode levar a complicações clínicas em diferentes órgãos. Os autores da pesquisa atribuem essa realidade à falta de registros dos profissionais médicos, enfermeiros e nutricionistas sobre os aspectos do estado nutricional do paciente, além da baixa utilização de terapia nutricional e outras origens multifatoriais, como aspectos socioeconômicos e outros relacionados às doenças ${ }^{(12)}$.

A terapia nutricional, quando bem indicada e adequada às necessidades nutricionais do paciente, auxilia na redução da morbidade e mortalidade, pois permite restabelecer o perfil nutricional, assim como suprir as necessidades nutricionais específicas. Entretanto, a falta de 
conhecimento e a inabilidade de seu manejo podem acarretar riscos e complicações aos pacientes ${ }^{(13)}$.

Por conseguinte, a TNE tem sido considerada, sempre que possível, como o método de escolha para pacientes internados, sem condições de se alimentar por via oral de forma suficiente, para atingir o mínimo de suas necessidades energéticas, habitualmente aumentadas pelo estresse fisiológico ${ }^{(14)}$.

A TNE apresenta vantagens importantes, sobretudo, quando introduzida precocemente (primeiras 24 a 48h), pois tem mostrado ser um importante preditor para diminuição de complicações ${ }^{(1)}$, por proporcionar melhor função imunitária intestinal, redução na produção de hormônios catabólicos, manutenção da integridade do trato gastrointestinal e preservação do estado nutricional ${ }^{(13,15)}$. Essas vantagens têm permitido que sua prática seja rotineiramente empregada como alternativa bem sucedida para o restabelecimento de pacientes hospitalizados ${ }^{(14)}$, desde que haja funcionalidade do trato gastrointestinal ${ }^{(1,14)}$ e aporte suficiente de nutrientes para as necessidades nutricionais diárias ${ }^{(14,16)}$.

Entre as contraindicações relacionadas ao uso da TNE, destacam-se as situações em que o trato gastrointestinal apresenta alterações funcionais graves, comprometendo a capacidade de absorção. A diarreia grave $(>1500 \mathrm{ml} / 24 \mathrm{~h})$, fístula digestiva com alto débito, vômitos incoercíveis, síndrome do intestino curto do tipo maciço ou em fase inicial de reabilitação intestinal são algumas das situações que contraindicam a TNE. Além disso, podem-se incluir as obstruções mecânicas por tumor ou pseudoobstrução com ausência total ou parcial do trânsito intestinal, bridas, fecaloma, isquemia mesentérica (comum em pacientes graves sépticos e com disfunção de múltiplos órgãos), peritonite grave, doença inflamatória intestinal, pancreatite aguda grave, hemorragia digestiva, má perfusão periférica, graves alterações metabólicas e instabilidade hemodinâmica (Pressão Arterial Média $<65 \mathrm{mmHg})^{(16)}$. Nos casos de contraindicação temporária, opta-se pela reintrodução da nutrição enteral o mais precoce 
possível, visando a prevenir perdas acentuadas de nutrientes e repor as deficiências já existentes ${ }^{(17,18)}$.

Para a instituição da nutrição enteral, é necessário verificar se a mesma terá uma previsão mínima de manutenção de 5 a 7 dias ${ }^{(6,19)}$, devendo ser precedida de avaliação periódica no máximo a cada 10 dias $^{(20)}$, incluindo a correção de nutrientes ofertados, de acordo com a resposta clínica do paciente, a fim de evitar risco que propicie outros distúrbios de ordem física $^{(21)}$.

$\mathrm{Na}$ avaliação do paciente que se beneficiará da TNE, torna-se circunstancial a escolha da formulação e da via de acesso enteral. A diversidade de fórmulas enterais disponíveis no mercado possibilita a indicação da TNE aos pacientes em suas diversas condições clínicas ${ }^{(1)}$. 0 conhecimento e a análise criteriosa das propriedades e características das fórmulas enterais são aspectos importantes para prevenir as complicações. A dieta selecionada deve ser completa e adequada para períodos variados, a fim de suprir as exigências nutricionais do paciente e ser bem tolerada(22).

A seleção da formulação enteral também dependerá do calibre e do posicionamento da sonda, dos horários de administração da dieta, do volume a ser infundido, além do método para infusão (intermitente ou contínuo) e do tipo de gotejamento (gravitacional, em bolus ou por bomba de infusão) $)^{(23)}$.

A manifestação de intolerância digestiva nem sempre está relacionada diretamente à formulação enteral, mas, sim, à osmolaridade dos medicamentos. Geralmente, os medicamentos com pH ácido são propensos a interagir com fórmulas que contêm proteínas intactas como as poliméricas $^{(24)}$. A capacidade de interação entre nutrientes e fármacos pode levar à potencialização ou minimização do efeito de ambos e as alterações que ocorrem com a estrutura molecular dos nutrientes podem alterar a capacidade de absorção ${ }^{(25)}$. 
$\mathrm{Na}$ formulação enteral, os complementos alimentares utilizados têm baixa viscosidade e alta solubilidade, para auxiliar na regulação da função intestinal e não promover impacto negativo na motilidade antroduodenal. Mas, seu uso não é isento de intercorrências, pois pode causar distensão abdominal, flatulência e obstrução da sonda. Em decorrência desses eventos, a presença de fibras na formulação enteral exige atenção no calibre da sonda e do equipo. Nesse caso, as sondas com diâmetros maiores de 8Fr são mais adequadas para formulação que contém fibras $^{(1,23)}$.

Embora o enfermeiro não seja o responsável pelo preparo da nutrição enteral é de suma importância que seus conhecimentos estejam voltados aos aspectos relacionados à constituição da formulação enteral e dos meios que possam alterá-la.

\subsubsection{Vias de acesso enteral}

A via de acesso enteral pode estar disposta no estômago, duodeno ou no jejuno, sua escolha da via deve ser fundamentada no tempo previsto para TNE e na necessidade nutricional dos pacientes, de acordo com sua condição clínica ${ }^{(6)}$. Considerando que cada via requer um cuidado específico e uma indicação para seu posicionamento, seja ele pré ou póspilórico $^{(24)}$. A escolha das fórmulas enterais e da estrutura medicamentosa também dependerão do estabelecimento do posicionamento para viabilizar a melhor prescrição ${ }^{(26)}$.

Para a TNE a curto prazo ( $\leq 4$ semanas) ${ }^{(27)}$, recomenda-se o uso da sonda nasoenteral (SNE). A partir desse período, a SNE é contraindicada, pois seu emprego por tempo prolongado está associado às complicações tardias, como migração, aspiração pulmonar da dieta ocasionando infecções de vias aéreas e do trato respiratório superior, lesão da mucosa do trato gastrointestinal, estenose esofágica e paralisia das cordas vocais. Já para TNE de longo prazo (> 4 semanas) ${ }^{(20)}$, recomenda-se 
a realização de ostomia alimentar, denominada gastrostomia ou jejunostomia $^{(20,28)}$.

As sondas para ostomia alimentar têm maior durabilidade ${ }^{(29)}$ e são indicadas para TNE a longo prazo, evitam complicações, como irritação nasal, decorrente do uso prolongado de sonda nasoenteral, estresse psicossocial em razão da autoimagem e podem ser introduzidas por via laparoscópica ou percutânea ${ }^{(27)}$. O monitoramento dos sinais e sintomas das complicações imediatas ou tardias, tais como traumas por perfuração, sangramento, infecção e migração ${ }^{(30)}$, obstrução, extravasamento de conteúdo alimentar e gástrico é voltado à equipe multidisciplinar, sobretudo, a médicos e enfermeiros ${ }^{(28,31)}$.

\subsubsection{Método de infusão enteral}

Os métodos de infusão são classificados em intermitente ou contínuo $^{(15,19)}$, no intermitente, a dieta é administrada em períodos fracionados. Essa modalidade subdivide-se em duas categorias: em bolus, utilizando seringa ou gravitacional, na qual a dieta é infundida pela força da gravidade, por meio de um equipo em períodos fracionados (de 4 a 6 vezes/dia) $)^{(15)}$.

Para o método contínuo usa-se a bomba de infusão para infundir continuamente a dieta por 12 ou $24 \mathrm{~h}^{(19)}$. Este é o mais utilizado para pacientes institucionalizados, pois o fluxo é mais preciso e seguro, permitindo que a dieta seja infundida em volumes menores e mais lentamente, acarretando redução de complicação gastrointestinal, como a distensão abdominal e diarreia ${ }^{(32)}$, além de otimizar o tempo da equipe de enfermagem, responsável pela administração da nutrição enteral ${ }^{(33)}$.

Para o emprego de ambos os métodos, recomenda-se que o paciente esteja em posição Fowler a $45^{\circ}$, independente da região onde a sonda estiver posicionada ${ }^{(34)}$. O decúbito elevado deverá ser mantido para 
prevenir acidentes decorrentes de refluxos e vômitos, com consequente aspiração pulmonar, sobretudo em pacientes inconscientes, idosos e neurológicos ${ }^{(35)}$.

\subsection{SUPORTES TERAPÊUTICOS: MEDICAMENTOSO E VENTILATÓRIO}

Alguns fatores podem contribuir indiretamente para ocorrência de complicações aos pacientes em TNE, como o uso de terapias medicamentosas que reduzem a motilidade gastrointestinal, além da terapia ventilatória mecânica. Geralmente, os pacientes internados em Unidades de Terapia Intensiva necessitam de atenção rigorosa quanto à motilidade gástrica, especialmente, quando associada ao uso de ventilação mecânica ${ }^{(1)}$.

A ventilação mecânica pode intensificar os efeitos negativos ao trato gastrointestinal, em especial, em pacientes graves, cuja doença preexistente já causa complicação gastrointestinal ${ }^{(36)}$.

O intestino não é autoregulado. Por isso, em determinados casos de gravidade, a função da barreira intestinal é comprometida. $O$ prejuízo potencial da ventilação mecânica para o desenvolvimento de complicação gastrointestinal não se limita a seus efeitos diretos sobre o trato gastrointestinal, sendo potencializado pelos medicamentos que são utilizados amiúde para facilitar a ventilação mecânica, como os opioides e sedativos, em especial, os benzodiazepínicos, que podem diminuir a motilidade gastrointestinal e prejudicar o retorno venoso em virtude da venodilatação e/ou diminuição da capacidade de resposta aos agentes vasoconstritores. Outros medicamentos, como os vasopressores e antibióticos, são comumente utilizados e muito associados à complicação gastrointestinal em pacientes com ventilação mecânica ${ }^{(36)}$. 
Os medicamentos podem interagir direta e indiretamente com a nutrição enteral em razão da acidez, osmolaridade, presença de vitaminas, eletrólitos, dentre outros. É difícil predizer quando ocorrerá interação fármaco-nutriente, entretanto é importante conhecer previamente as possíveis incompatibilidades da formulação enteral e dos medicamentos a serem administrados ${ }^{(37,38)}$. Estas poderão contribuir para a obstrução da sonda. Assim, recomenda-se utilizar formas líquidas do medicamento ou selecionar uma via alternativa para sua administração ${ }^{(37)}$.

Já a incompatibilidade fisiológica corresponde à ação medicamentosa que altera a tolerância da TNE, como os medicamentos hipertônicos que alteram a capacidade absortiva do intestino, resultando no quadro de diarreia ${ }^{(9)}$. A absorção das drogas ocorre, sobretudo na parte superior do intestino delgado, de modo que a velocidade do esvaziamento gástrico poderá determinar como a droga irá atuar na absorção. Assim o metabolismo de nutrientes pode ser modificado pelos medicamentos com alteração do estado nutricional e seu uso prolongado no tratamento de doenças crônicas pode provocar a perda de nutrientes ${ }^{(25)}$.

Frequentemente, os pacientes em UTI fazem uso de drogas vasoativas, antibioticoterapia, sedativos, analgésicos e pró-cinéticos que exercem efeitos medicamentosos disseminados, sobretudo nos sistemas nervoso central e no gastrointestinal ${ }^{(39,40)}$. Um dos primeiros sinais é a hipomotilidade gástrica, em consequência do retardo no esvaziamento gástrico, diminuição de ruídos hidroaéreos, podendo promover sinais de desconforto e distensão abdominal, náuseas e vômitos. Esta ocorrência pode resultar na necessidade de suspensão ou redução da infusão da nutrição enteral e na verificação do volume residual gástrico (VRG) frequentemente ${ }^{(41)}$. 


\subsection{COMPLICAÇÕES EM TERAPIA NUTRICIONAL ENTERAL}

Durante o uso da TNE, as complicações ocorridas podem ser classificadas em gastrointestinal, mecânica, metabólica, infecciosa, respiratória e psicológica. São recorrentes e podem ser ocasionadas por alguns fatores predisponentes que retardam à TNE. Mesmo sendo bem conhecidas, podem ser prevenidas ou tratadas, quando monitoradas adequadamente nos pacientes ${ }^{(2)}$.

\subsubsection{Gastrointestinal}

A complicação gastrointestinal é descrita, como a mais comum em pacientes com TNE, com etiologia multifatorial ${ }^{(2)}$. Dentre os eventos observados, destacam-se a estase gástrica, diarreia, cólicas abdominais, flatulências, distensão abdominal e constipação ${ }^{(42)}$, vômitos, refluxo, regurgitação. Atribuem-se os sintomas à TNE, quando estão relacionados ao tipo da fórmula enteral, velocidade da infusão, a contaminação microbiana e a incompatibilidade medicamentosa ${ }^{(37)}$. Todavia, o uso de drogas vasoativas e os analgésicos opioides contribuem para as disfunções gastrointestinais, por alterarem o fluxo intestinal, comprometendo a oferta nutricional enteral por intolerância ${ }^{(43,44)}$, pelas anormalidades como náuseas, vômitos, estase gástrica $^{(37)}$, distensão abdominal e constipação ${ }^{(9,39)}$.

\subsubsection{Volume residual gástrico}

O alto volume residual gástrico (VRG) é outra anormalidade importante da $\operatorname{TNE}^{(45,46)}$. Estudos demonstram que volume gástrico acima de 150 e $300 \mathrm{ml}$ é considerado alto VRG, e outros quando o volume alcança de 200 a $400 \mathrm{ml}^{(46,47)}$. Outro parâmetro é o volume que corresponda a $50 \%$ do volume da dieta, após 2 horas de administração ${ }^{(2)}$, considerando intolerância alimentar $^{(13,48)}$. 
$\mathrm{Na}$ ocorrência de alto VRG, a nutrição enteral deverá ter o fluxo diminuído ou interrompido, até que essa disfunção intestinal seja avaliada ou que haja melhora da motilidade gastrointestinal ${ }^{(47,48)}$. Recomenda-se que esse volume seja mensurado, antes de cada dieta, quando o método for intermitente e, a cada 4 horas, para o método contínuo, pois o acúmulo do conteúdo gástrico pode induzir a vômito e aspiração pulmonar ${ }^{(15)}$. Outros sinais de alto VRG são distensão abdominal, náusea e ausência de ruídos hidroaéreos ${ }^{(49)}$.

Diferentes nutrientes podem favorecer o retardo do esvaziamento gástrico, dentre eles, os carboidratos, proteínas, gorduras, minerais e vitaminas, promovendo distúrbio intestinal e redução da absorção dos nutrientes $^{(2)}$. O aumento da pressão intracraniana, ventilação mecânica, sepse, hipotensão, estresse metabólico, instabilidade hemodinâmica, dispepsia funcional, gastroparesia idiopática e diabética, estados pósoperatórios, dentre outros, prejudicam a motilidade gastrointestinal, assim como as drogas vasoativas, opioides, relaxantes musculares ${ }^{(49)}$, analgésicos, anticolinérgicos e antiácidos, contendo alumínio e narcóticos ${ }^{(48)}$, pois agem nos receptores gastrointestinais. O quadro é de difícil diagnóstico e controle, sobretudo, em pacientes diabéticos ${ }^{(2)}$.

O uso de agentes pró-cinéticos é bem indicado nos casos de retardamento do esvaziamento gástrico, porque eleva a amplitude das contrações peristálticas e acelera o esvaziamento gástrico ${ }^{(41)}$, assim como o controle da velocidade da infusão da fórmula. Caso essas medidas não apresentem resultados, deve-se optar pelo posicionamento pós-pilórico da sonda ${ }^{(50)}$ para melhor tolerância da dieta ${ }^{(8)}$.

\subsubsection{Náuseas, Vômitos e Refluxos}

As náuseas e vômitos são eventos da disfunção intestinal que ocorrem entre $10 \%$ a $25 \%$ dos pacientes em $\operatorname{TNE}^{(2)}$ e, geralmente, estão relacionadas à alta taxa de infusão ou retenção gástrica ${ }^{(41)}$, que ocorre pela 
diminuição da motilidade e pode ser desencadeada pelo uso de medicamentos $^{(51)}$.

A ocorrência de náuseas e/ou vômitos torna-se um desafio, quando o paciente estiver vulnerável à desnutrição aguda, necessitando de aporte nutricional rigoroso. Entretanto, podem ser controladas com a redução do fluxo de infusão, com fórmulas de baixa osmolaridade (<350 osm e/ou menor teor de gordura), mudanças de decúbito, deambulação e uso de agentes pró-cinéticos. O exame físico é outra medida eficaz, que deve ser realizada com o controle do VRG e do refluxo gastroesofágico ${ }^{(42)}$.

\subsubsection{Distensão abdominal}

A distensão abdominal pode estar associada a outras anormalidades que predispõe ao retardo no trânsito intestinal. Na vigência de TNE, pode estar acompanhada ou não de dor abdominal, empachamento, borborigmo e diarreia. Quando estes sintomas estão associados a oferta de dieta à base de lactose é necessária substituição da fórmula enteral, avaliação do paciente e, em alguns casos, a suspensão da dieta e de medicamentos que alterem o trânsito intestinal ${ }^{(2)}$, reintroduzindoos, após descartar quaisquer alterações significativas ${ }^{(45)}$.

\subsubsection{Constipação/Obstipação}

A constipação é definida, como eliminação de fezes menor que três vezes por semana, sensação de esvaziamento retal incompleto, fezes endurecidas e necessidade de esforço para evacuação ${ }^{(52)}$. A constipação altera o hábito intestinal normal e leva à diminuição do tônus muscular do intestino ${ }^{(53)}$. Podendo ser decorrente da inadequada ingesta hídrica e de dieta sem fibras, repouso prolongado no leito e uso de narcótico ${ }^{(13)}$ ou de problemas inerentes ao próprio intestino. Além disso, pode decorrer de causas secundárias, como estenoses isquêmicas, inflamatórias, pseudo- 
obstrução intestinal, síndrome do intestino irritável, Diabetes mellitus, insuficiência renal crônica, distúrbios eletrolíticos, acidente vascular cerebral, insuficiência cardíaca congestiva, desidratação e distúrbios psiquiátricos. Da mesma forma, o uso de medicamentos analgésicos (codeína, morfina, tramadol), anti-inflamatórios não esteroides, antidepressivos tricíclicos, diuréticos (furosemida, hidroclorotiazida), bloqueadores de canal de cálcio (verapamil), suplementos de cálcio e ferro, anticolinérgicos, antipsicóticos (derivados de fenotiazina), anti-histamínicos (difenidramina), antihipertensivos, opioides e antiácidos com alumínio e ferro podem contribuir para ocorrência dessa complicação ${ }^{(53)}$.

A incidência de constipação varia de $2 \%$ a $28 \%$ na população geral da América Ocidental e, na América do Norte, atinge, aproximadamente, $15 \%$ da população com mais de 65 anos. No Brasil, não há estudos epidemiológicos que apontem dados exatos sobre a constipação $^{(53)}$.

Para pacientes internados em terapia intensiva, a incidência é ainda mais elevada, variando de $5 \%$ a $83 \%{ }^{(54,55)}$.

\subsubsection{Diarreia}

Em pacientes com TNE, a diarreia ocupa uma posição de destaque na complicação gastrointestinal, nos criticamente enfermos parece, ser muito comum, e isso pode ser justificado pela falta de padronização para definir, o que seja diarreia ${ }^{(56)}$.

A diarreia é definida como "evacuação frequente de fezes líquidas ou semilíquida”"(57), acima de três episódios nas $24 \mathrm{~h}^{(58)}$. Quando está associada ao uso da nutrição enteral pode ser resultante da contaminação bacteriana da fórmula, dieta sem fibra, intolerância à lactose, deficiência de lactase, absorção inadequada de gordura, intolerância à soja, uso de antiácidos e antibióticos ${ }^{(2,45)}$. 
Pacientes com desnutrição grave podem ter prejuízo com a absorção alimentar, visto que a microvilosidade intestinal é alterada e diminuída nessa situação. A hipoalbuminemia é um sinalizador que auxilia no diagnóstico de desnutrição, entretanto é comum em pacientes graves com estresse metabólico, sendo um fator de mau prognóstico que associa se significantemente com a diarreia ${ }^{(2,49)}$.

Os pacientes em uso de TNE e antibioticoterapia podem desenvolver quadro diarréico infeccioso causado, eventualmente, pelo Clostridium Difficile, que produz enterotoxina associada à colite e diarreia intensa ${ }^{(40,59)}$. Dentre os principais fatores de risco associados à diarreia nosocomial em pacientes internados em unidades de terapia intensiva, é a duração da antibioticoterapia e a quantidade de antimicrobianos utilizados $^{(60)}$. Um dia a mais do previsto de antibioticoterapia eleva em $16 \%$ o risco de ocorrência de diarreia, e a inclusão adicional de outro antibiótico a determinado esquema antimicrobiano aumenta este risco em até $65 \%{ }^{(61)}$.

Outros fatores de risco são: a gravidade clínica do paciente, o número de dias de internação e o uso de nutrição enteral ${ }^{(62)}$. O efeito isolado de cada um desses fatores ainda não é claro, todavia, dentre os medicamentos, os antibióticos aumentam de duas para quatro vezes o risco de diarreia ${ }^{(60)}$. Os efeitos colaterais de medicamentos, como antiácidos com magnésio, digitais, lactulose, laxativos, aminofilina, propranolol e suplementos contendo potássio e fósforo também predispõem à diarreia ${ }^{(49)}$.

$\mathrm{Na}$ vigência de diarreia, as características das fezes devem ser quantificadas, analisadas e registradas devidamente para pesquisar as possíveis causas, pois nem sempre está diretamente relacionada à administração da dieta enteral. A suspensão da dieta enteral deverá ocorrer apenas mediante avaliação de uma equipe de terapia nutricional, não devendo suspendê-la no primeiro episódio de fezes semilíquidas ou líquidas ${ }^{(40)}$. 
A incidência de diarreia varia de $2 \%$ a $68 \%$ em pacientes hospitalizados, sobretudo nas UTI, onde esta variação é mais ampla, chegando a $95 \%{ }^{(56,63)}$.

\subsubsection{Metabólica}

Na complicação metabólica, os eventos observados são menos frequentes entre os descritos em $\operatorname{TNE}^{(2)}$. Os mais comuns são a hipernatremia, hiponatremia, hipercalemia, hipercalcemia, hipercapnia, hipofosfatemia e hiperglicemia. Além da atenção para a desidratação e a hiper-hidratação, a prevenção reside no monitoramento do balanço hídrico, tratamento da hiperglicemia e diurese osmótica ${ }^{(64)}$. O evento menos observado na complicação metabólica é a hipoglicemia, seguida das alterações de eletrólitos, elementos-traços e das funções hepáticas ${ }^{(2)}$. A hipoglicemia apresenta sinais precoces de difícil controle em pacientes graves, quando prolongada e aguda, pode causar convulsões, coma, danos cerebrais irreversíveis, bem como arritmias cardíacas ${ }^{(65)}$.

A hiperglicemia que se manifesta nas doenças críticas também em pacientes que não eram previamente diabéticos, reflete o desenvolvimento adaptativo de resistência à insulina. O evento predispõe os pacientes a muitas complicações durante o tratamento intensivo, como: sepse, inflamação, insuficiência de múltiplos órgãos e morte ${ }^{(66)}$. Em TNE, a hiperglicemia ocorre em torno de $10 \%$ a $30 \%$ dos pacientes ${ }^{(67)}$ e estes podem necessitar de agentes hipoglicemiantes antes e durante a terapia ${ }^{(67)}$, para controlar o aumento da hiperglicemia que agrava e prolonga as fases da doença, incrementando a gravidade do paciente ${ }^{(68)}$.

O monitoramento dos eventos observados na complicação metabólica auxilia na redução da incidência de infecção, complicações, desenvolvimento de disfunção orgânica, além de proporcionar a diminuição nos dias de internação na UTI e no hospital ${ }^{(68)}$. 


\subsubsection{Mecânica}

A complicação mecânica está relacionada à manipulação direta com a sonda, aos diferentes calibres, à qualidade dos dispositivos acoplados à sonda, à administração de medicamentos e à manipulação do paciente. Sua incidência em pacientes adultos crônicos pode variar de $3 \%$ a $41 \%{ }^{(69,70)}$. A literatura também aponta incidência entre $0,14 \%$ e $62 \%$ em pacientes adultos hospitalizados ${ }^{(71)}$. Aproximadamente, dois terços desses pacientes são agitados e removem a sonda em 2 semanas de TNE. Geralmente, esses eventos estão relacionados à alteração do nível de consciência e ocasionam problemas, tanto de ordem mecânica como pulmonar ao paciente ${ }^{(72)}$.

\subsubsection{Deslocamento e saída não programada da sonda enteral}

O deslocamento da sonda e a saída não programada (acidental) são intercorrências que predispõem algumas complicações, que podem ser causadas pela fixação inadequada da sonda, pela agitação dos pacientes, tosse, vômito, manipulação da sonda e do paciente ${ }^{(73)}$. Entretanto, essas intercorrências são consideradas evitáveis desde que sejam implementadas medidas eficazes de segurança ao paciente. O controle radiológico do posicionamento da sonda e a demarcação da sonda próxima à narina podem assegurar seu posicionamento ${ }^{(27)}$, pois facilitam a vigilância ${ }^{(74)}$.

Estudos brasileiros indicam que o índice de mobilização indevida da sonda varia entre $25 \%$ a $29 \%^{(15,44)}$, contribuindo para o atraso da administração de medicamentos e complementos alimentares, com possível fornecimento inadequado das calorias previstas. Além do gasto de tempo na checagem desse evento e da possível repassagem da sonda que pode levar a traumas acidentais no sistema traqueopulmonar ${ }^{(1,75)}$. 


\subsubsection{Obstrução}

A obstrução da sonda enteral pode ocorrer em função de uma variedade de circunstâncias, seja por fragmentos dos medicamentos triturados, incompatibilidade de fármaco-nutriente de fármaco-fármaco ou pelo acúmulo de resíduo alimentar ou gástrico ${ }^{(15,76)}$.

O posicionamento da sonda pré ou pós-pilórica é um aspecto para ser observado e monitorado, pois, quando localizada na posição pré-pilórica torna-se mais suscetível à oclusão do que as que estão no jejuno ou no duodeno ${ }^{(77)}$, visto que $\circ \mathrm{pH}$ gástrico é mais ácido e favorece a interação droga-nutriente ${ }^{(73)}$.

O tipo e a quantidade de medicamentos administrados associados ao tipo de formulação da dieta (alto conteúdo de proteínas, alta viscosidade, baixo $\mathrm{pH}$ ) podem levar à coagulação da fórmula enteral. $\mathrm{O}$ método de administração (intermitente ou contínuo) e o tamanho da sonda enteral podem ocasionar a obstrução da sonda enteral. Estas obstruções podem ser evitadas quando são utilizados medicamentos em estrutura líquida. Medicamentos em apresentação sólida devem ser devidamente triturados, se isto for apropriado. Devem-se utilizar técnicas de lavagem da sonda, após a infusão da dieta e dos medicamentos e considerar o tamanho da sonda de nutrição, para que este procedimento seja realizado ${ }^{(37)}$.

A primeira intervenção e a mais segura para manter livre o lúmen da sonda é a irrigação, antes e após a administração de medicamentos e da dieta, independente da composição ou forma ${ }^{(37)}$. A irrigação pode ser a cada 4 horas $^{(19)}$ ou no intervalo de cada dieta e após administração de medicamentos $^{(25)}$. O atraso na desobstrução pode conduzir atraso na administração dos medicamentos, de nutrientes ingeridos e até na troca de sonda ${ }^{(37)}$.

Ainda que as sondas sejam, frequentemente, desobstruídas com sucesso, a remoção da oclusão requer tempo adicional da enfermagem e 
retarda a provisão da $\operatorname{TNE}^{(37)}$. No caso, de obstrução, em que a sonda, não possa ser irrigada com êxito, esta deverá ser substituída e isto acarretará custo adicional, desconforto para o paciente e risco de trauma na repassagem do dispositivo, além da exposição adicional à radiação para o controle do posicionamento ${ }^{(75)}$.

\subsubsection{Pulmonar}

Os eventos observados na complicação pulmonar são temidos por serem considerados os de maior gravidade em TNE, sobretudo nos pacientes incapacitados de tolerar a alimentação gástrica, no qual o risco de aspiração pulmonar é ainda maior ${ }^{(2,45,78)}$. Esta complicação relaciona-se à aspiração de conteúdo gástrico e/ou de dieta para a árvore brônquica. Os fatores de risco, como a intubação orotraqueal, alto VRG, vômitos, retardo do esvaziamento gástrico, íleo paralítico e mau posicionamento da SNE, proporcionam maior vulnerabilidade em pacientes com doenças neurológicas, comatosos e cardíacos ${ }^{(13,79)}$.

A presença da SNE pode predispor à aspiração pelo aumento de salivação, alteração da colonização orofaríngea decorrente da ausência de alimentação oral, diminuição do reflexo de tosse, inabilidade de proteção das vias aéreas, elevação laríngea prejudicada e lesão da mucosa ${ }^{(13,79)}$. A presença da SNE é um fator de risco independente para o desenvolvimento pneumonia e a aspiração pulmonar não está somente associada à presença da SNE, mas também ao calibre do dispositivo, à velocidade da infusão da dieta e posição do paciente no leito ${ }^{(80)}$.

O desenvolvimento de pneumonia em pacientes submetidos à ventilação mecânica pode estar associado com à TNE, pois a nutrição via sonda neutraliza o suco gástrico, determinando a elevação do pH intragástrico e, consequentemente, a colonização gástrica que aumenta o risco de refluxo e aspiração. O posicionamento no leito pode ser outro fator 
de risco para aspiração pulmonar, independente do uso de ventilação

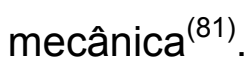

Em um estudo prospectivo, que analisou 205 pacientes submetidos à ventilação mecânica, foi verificado que, dos 56 pacientes que desenvolveram pneumonia na UTI, a nutrição enteral foi um fator de risco para tal complicação $(O R=2,89 ; p=0,001)$ em $86 \%{ }^{(81)}$.

\subsubsection{Psicológicas}

O uso da sonda enteral implica mudança na vida cotidiana para o paciente, interferindo em sua qualidade de vida e de seus familiares. Os aspectos psicológicos devem ser considerados, pois essa mudança inicia-se com o desconforto do uso da sonda enteral, sede e sensação de boca seca, que levam à falta de estímulos ao paladar ${ }^{(2)}$. Os horários fixos para se alimentar favorecem a monotonia e a autoimagem prejudicada que interfere diretamente na sociabilidade e inatividade do paciente, deixando-o ansioso e deprimido. O apoio e o acompanhamento psicológicos são fundamentais, visto que essa sobrecarga de estresse pode comprometer a qualidade de vida do doente. Dessa forma, é indispensável à avaliação dos aspectos psicológicos e da qualidade de vida para pacientes que necessitam de TNE, além de ser útil para capacitar os profissionais, orientar os pacientes e seus cuidadores, bem como acompanhar os resultados dessa mudança de hábitos de vida ${ }^{(82)}$.

\section{A atuação da Equipe Multiprofissional de Terapia Nutricional}

(EMTN) é fundamental para se assegurar a assistência qualificada aos pacientes submetidos à TNE. O trabalho em conjunto possibilita cumprir o objetivo da TNE e identificar os problemas com a sonda enteral, distúrbios clínicos e nutricionais, para que as intervenções de fato sejam precisas e monitoradas, a fim de alcançar resultados satisfatórios ao longo da TNE. 
Em face de a enfermagem desempenhar um cuidado holístico aos pacientes, é necessário o fortalecimento da atuação do enfermeiro da EMTN, coordenando a equipe de enfermagem nas atividades relacionadas à terapia nutricional ${ }^{(83)}$, cabendo-Ihe as ações de planejamento, organização, execução e avaliação dos cuidados de enfermagem. Ele deve participar e promover atividades de aprimoramento operacional em terapia nutricional e estimular a equipe de enfermagem no desenvolvimento de trabalhos científicos $^{(20,83)}$.

As ações conjuntas da equipe de enfermagem incluem um complexo rol de atividades que são embasadas em regulamentações estabelecidas para $\mathrm{TNE}^{(20)}$, a saber: orientar o uso da TNE para o paciente e família; preparar o paciente, material e local para sondagem; estabelecer o acesso enteral, conforme procedimento preestabelecido; manter a via de administração; receber e manter conservada a nutrição enteral até sua administração; promover a segurança do dispositivo de alimentação; assegurar e supervisionar a administração; registrar e comunicar qualquer intercorrência a EMTN; apresentar claramente a evolução do paciente e de suas condições gerais; auxiliar na criação e padronização de protocolos para as ações de enfermagem; além de participar do processo de seleção, avaliação e aquisição dos recursos a serem utilizados ${ }^{(20,84)}$.

As Portarias estabelecidas pela Agência de Vigilância Sanitária (ANVISA) fixaram os requisitos mínimos para segurança e qualidade relacionados à TNE. Estas normatizações são consideradas um grande avanço para utilização da terapia nutricional, pois trouxeram respaldo técnico-legal a todos que a adotaram, dando ênfase aos controles e aos processos em terapia nutricional, visando também a prover o melhor custobenefício da terapia, com o máximo benefício e mínimo risco ao paciente ${ }^{(20)}$. 


\subsection{JUSTIFICATIVA}

Do que se expôs, percebe-se a inquestionável importância do papel do enfermeiro no sucesso da terapia nutricional. Além disso, acrescenta-se também ser de sua responsabilidade analisar o cenário em que atua, isto é, cabe a ele avaliar as condições clínicas preexistentes e os procedimentos terapêuticos a que são submetidos os pacientes, como também exercer cuidadosa atenção aos sinais e sintomas que dimensionam as complicações da TNE. Em virtude disso, é fundamental que o enfermeiro protagonize e lidere a atuação em conjunto com a equipe multiprofissional, embasado em protocolos para o monitoramento de todo o processo da TNE, no propósito de manter máxima fluência e harmonia em procedimento tão complexo como esse, recheado de adversidades para o paciente.

A pesquisadora observou a presença de complicações, quando atuava em uma equipe multiprofissional, que prestava assistência a pacientes adultos em terapia nutricional enteral em um hospital público. No serviço, as complicações eram, com freqüência, verificadas e de difícil controle, pois envolviam diversos fatores relacionados direta e indiretamente à condição clínica do paciente. Entretanto, pela falha na mensuração e na investigação do problema, a real proporção dos acontecimentos era desconhecida, dificultando o monitoramento e a adoção de medidas eficazes para controlá-las ou, até mesmo, evitá-las.

Posteriormente, ao entrar em contato com o serviço de um hospital universitário, como estagiária, foi possível constatar que as características eram semelhantes às observadas anteriormente. $\mathrm{Na}$ instituição, as reformas para assistência nutricional tinham sido implantadas 2 anos antes, e uma equipe multiprofissional de terapia nutricional tinha sido formada. Os protocolos estavam em desenvolvimento, como também um sistema integrado de informação para gerenciar a assistência prestada em terapia nutricional. Todavia, a atuação dessa equipe era exercida somente nas unidades de cuidados intensivos e semi-intensivos e o perfil dos pacientes adultos em TNE atendidos nos diversos setores, como também 
das complicações apresentadas por eles, ainda não haviam sido investigados.

Por essas razões, surgiu o interesse de analisar, de forma organizada, as complicações ocorridas nos pacientes são submetidos à nutrição enteral. Mediante a proximidade da pesquisadora aos problemas com a TNE e de suas dificuldades em estabelecer o correto enfrentamento desses desvios, vários questionamentos emergiram, fornecendo estímulos a enfrentar esse desafio.

Qual é o perfil dos pacientes adultos que receberam TNE nesse hospital universitário? Quais são as complicações? Quais são os eventos observados nas complicações? Como são suas intersecções com os eventos observados? Qual a influência da terapia medicamentosa? Qual é a influência do método de administração da TNE?

Aparentemente, as complicações apresentadas por eles eram similares às mais frequentes relatadas na literatura científica e as observadas por esta pesquisadora na experiência vivida durante 4 anos, como enfermeira de uma equipe multiprofissional de terapia nutricional de um hospital público do Município de São Paulo.

Desconhecendo-se a existência dessas características na instituição local da pesquisa, quanto à identificação dos tipos de complicações e dos fatores que se associam a elas em pacientes adultos em uso da TNE, acredita-se que a presente investigação contribuirá para esse discernimento. Subsequentemente, poderá ampliar o conhecimento dos profissionais e a partir disso, fornecer subsídios ao enfermeiro, para que atue com a mais acurada atenção no monitoramento do cuidado ao paciente em nutrição enteral, a fim de que as medidas tomadas previnam e amenizem a ocorrência dessas complicações.

Frente ao exposto e considerando-se que são atenuáveis as complicações coexistentes com a TNE, ao se verificar, previamente, sua exequibilidade, julgou-se oportuna a consecução de um estudo, com 
abordagem retrospectiva, focado no problema em tela, tendo como sujeitos de pesquisa a população que foi submetida à TNE em anos anteriores. Tendo as perspectivas favoráveis, e a convicção da importância de se responder aos questionamentos acima expostos, esta pesquisa em pacientes adultos internados em um hospital universitário do Município de São Paulo, destina-se a contribuir com novos subsídios para o aprimoramento de protocolos (em curso), para a prevenção da ocorrência das adversidades acima anunciadas. 


\section{OBJETIVOS}

Esta pesquisa analisa uma população de pacientes submetidos à Terapia Nutricional Enteral (TNE) em um Hospital Universitário do Município de São Paulo com os seguintes objetivos:

1) Caracterizar a amostra quanto:

a) Ao perfil dos pacientes

b) À terapia nutricional enteral

2) Analisar os tipos de complicações relacionadas com a TNE

3) Analisar a associação das complicações entre si

4) Analisar a associação dos eventos observados na complicação gastrointestinal com a complicação pulmonar

5) Analisar a influência do método de infusão da TNE sobre os eventos observados nas complicações da TNE

6) Analisar a influência das drogas administradas sobre as complicações da TNE 


\section{CASUÍSTICA E MÉTODO}

\subsection{Tipo de estudo}

Trata-se de um estudo observacional, descritivo, retrospectivo.

\subsection{Local do estudo}

O estudo foi realizado em um Hospital Universitário, vinculado à Universidade de São Paulo e situado no Município de São Paulo, que atende pacientes do Sistema Único de Saúde (SUS).

O atendimento é prestado em diferentes especialidades médicas para tratamento clínico e cirúrgico. O acompanhamento nutricional é desenvolvido por uma Equipe Multiprofissional de Terapia Nutricional (EMTN), composta por médico nutrólogo, nutricionista, enfermeira, fonoaudióloga e farmacêutico, que tem como atribuições gerais traçar diretrizes e elaborar protocolos para evolução dos pacientes em TNE, indicação, preparo, conservação, transporte, administração, controle clínico e laboratorial.

Nos anos de 2008 e 2009, a EMTN que já era formada, exercia suas atividades somente nos pacientes em TNE que estavam internados na Unidade de Terapia Intensiva e Semi-Intensiva, dessa instituição. Os protocolos e indicadores estavam em fase de desenvolvimento, como também um Sistema Integrado de Informações, para armazenar os registros sobre as condutas e evoluções do suporte nutricional. A ferramenta, desde então, é gerenciada pelos membros da EMTN e, ao final do acompanhamento nutricional é gerado um relatório simplificado sobre as avaliações, intervenções, evoluções e resultados que fizeram parte do 
seguimento, que é anexado no prontuário do paciente. Ao longo do acompanhamento nutricional os membros da EMTN também realizam seus registros nos prontuários dos pacientes, nos mesmos formulários comumente utilizados por outras equipes.

A TNE é administrada e controlada pela equipe de enfermagem, e as intervenções e complicações são registradas nos impressos próprios de uso da equipe.

\subsection{Amostra/população}

No período de janeiro de 2008 a dezembro de 2009, foram internados $7.989^{1}$ pacientes adultos para tratamentos clínicos e cirúrgicos na instituição hospitalar de estudo, e $556^{2}$ deles foram submetidos à Terapia Nutricional Enteral em algum momento da hospitalização. Com base nessa população, realizou-se o cálculo amostral utilizando a equação $n=\frac{p q z_{1-\alpha / 2}^{2}}{m^{2}}$ (85) adotando o nível de significância de 5\%. O tamanho amostral estimado foi de 214 pacientes. A seleção dos sujeitos do estudo ocorreu por meio de amostragem aleatória simples, que é realizada quando todos os elementos da amostra têm a mesma probabilidade de serem incluídos.

Para a elegibilidade da amostra, foram obedecidos os seguintes critérios:

- Pacientes com idade acima de 14 anos e 11 meses. Na instituição de estudo é considerado paciente adulto aquele com idade superior ao citado;

- Pacientes internados entre janeiro de 2008 e dezembro de 2009;

\footnotetext{
Dados fornecidos pelo Serviço de Arquivo Médico e Estatística (SAME).

Dados Fornecidos pelo Serviço de Nutrição e Dietética (SND).
} 
- Pacientes que receberam nutrição enteral exclusiva (independente da via de acesso de alimentação enteral: sonda naso/oroenteral ou gastrostomia) ou concomitantemente ao recebimento de nutrição via oral em qualquer momento da TNE.

A introdução de nutrição parenteral associada à nutrição enteral foi o critério de exclusão adotado.

\subsection{Descrição das variáveis}

\subsubsection{Complicações ocorridas durante a Terapia Nutricional Enteral}

Para o presente estudo, foram consideradas as complicações mais frequentes citadas na literatura, bem como os eventos que as caracterizam:

- Gastrointestinal - os eventos observados foram: náusea, vômito, refluxo, alto volume residual gástrico (VRG), dor abdominal, distensão abdominal, constipação e diarreia.

Neste estudo, considerou-se o alto VRG, volume acima de $200 \mathrm{ml}^{(2,67)}$. Para a constipação, adotou-se o conceito de evacuação ausente por mais de 3 dias $^{(86)}$ e, para diarreia acima de três episódios de evacuações semilíquidas ou líquidas em um período de $24 \mathrm{~h}^{(58)}$.

- Pulmonar - o evento observado foi apenas a presença de aspiração pulmonar.

Para este estudo, considerou-se como complicação pulmonar quando observado o diagnóstico clínico de "Pneumonia Aspirativa" ou "Broncopneumonia Aspirativa", após a introdução da nutrição enteral, cuja evolução médica apresentasse alguma informação de associação deste quadro ao uso da TNE. 
- Mecânica - os eventos observados foram: obstrução, deslocamento e saída acidental da sonda enteral, lesão tissular associada ao uso da sonda enteral e infecção perigastrostomia,

- Metabólica - os eventos observados foram: hiperglicemia e hipoglicemia.

Para a complicação metabólica adotou-se como referência para hiperglicemia níveis de glicose $>110 \mathrm{mg} / \mathrm{dL}^{(87)}$ e, para hipoglicemia, $<60 \mathrm{mg} / \mathrm{dL}^{(68)}$, de controle glicêmico realizado por meio do teste de glicemia capilar.

Além dessas variáveis, foram também considerados: idade, sexo, comorbidades, uso de ventilação mecânica, local de internação, tempo de internação e de TNE: em dias e semanas, via de acesso (sonda naso/oroenteral ou gastrostomia).

\subsubsection{Fatores associados às complicações da TNE foram considerados:}

- Terapêutica medicamentosa: sedativos/opioides, drogas vasoativas, relaxantes musculares, anti-inflamatórios, antibióticos e pró-cinéticos.

- Método de infusão da TNE: intermitente ou contínuo. 


\subsection{Coleta de dados}

\subsubsection{Instrumento}

Com propósito de se obter as informações para o estudo, foi elaborado o instrumento denominado "instrumento de complicações e fatores associados" (APÊNDICE) que permitiu o registro das seguintes informações:

- Dados do perfil demográfico e clinico: registro hospitalar, idade, sexo, tempo de internação, unidade de internação, comorbidades, ventilação mecânica e terapia medicamentosa.

- Dados da terapia nutricional enteral: tempo de TNE, via de acesso e método de infusão.

- Dados das complicações e dos fatores associados: segundo o tipo e frequência.

\subsubsection{Operacionalização da coleta dos dados}

O projeto de pesquisa foi submetido ao Comitê de Ética em Pesquisa do Hospital Universitário (HU/USP 968/09 - ANEXO). Após sua aprovação, obteve-se no Serviço de Nutrição e Dietética a relação dos pacientes adultos internados, entre janeiro de 2008 a dezembro de 2009, que foram submetidos à Terapia Nutricional Enteral para a seleção dos prontuários. Posteriormente, o projeto foi apresentado para às enfermeiras do Serviço de Apoio Educacional, para que fosse possível consultar as fichas de notificação de intercorrências (formulário em que são registrados os eventos adversos e as ocorrências anormais com os pacientes durante a internação hospitalar), a fim de complementar as informações relacionadas à complicação mecânica com a sonda enteral. 
Para seleção dos prontuários, a relação dos pacientes, que compuseram a amostra, foi encaminhada ao Serviço de Arquivo Médico e Estatística (SAME) para a separação dos prontuários. Os dados foram coletados com base nos registros realizados na ficha de internação, prescrição e evolução médica, folhas de balanço e de controle, anotações e evoluções de enfermagem e de avaliação nutricional, quando presente no prontuário do paciente.

Para tanto, foi utilizado o instrumento elaborado para o presente estudo (APÊNDICE). A coleta foi realizada pela própria pesquisadora no SAME e no Serviço de Apoio Educacional, durante os meses de maio, junho e julho de 2010 .

\subsection{Método de análise dos dados}

\subsubsection{Análise do tipo de complicação}

As complicações foram agrupadas em quatro tipos: gastrointestinal, mecânica, metabólica e pulmonar. Os eventos constituintes de cada complicação foram coletados, computados e apresentados em tabelas e figuras ilustrando-se as frequências absolutas e relativas.

\subsubsection{Análise da associação entre as complicações}

Por meio de tabelas de contingências $(2 \times 2)$, foram estudadas as possíveis associações entre as complicações observadas.

Para esse procedimento, as variáveis foram:

a) Dependentes: as complicações que foram consideradas em rodízio de acordo com o objetivo da análise. 
b) Independentes: as complicações e os eventos observados, com ênfase para os eventos constituintes da complicação gastrointestinal.

\subsubsection{Análise da influência dos fatores associados às complicações}

O método de infusão da TNE e a terapêutica medicamentosa, foram considerados, como possíveis fatores associados às complicações:

Da forma diferente que, no item anterior, para este procedimento as variáveis foram:

a) Dependentes: os eventos constituintes das complicações com ênfase para a complicação gastrointestinal para análise da influência da infusão da TNE e as complicações: gastrointestinal, mecânica, metabólica e pulmonar para análise da influência das drogas.

b) Independentes: o método de infusão da TNE e os grupos de drogas administradas.

\subsection{Tratamento estatístico}

Ao término da coleta, os dados obtidos foram inseridos em uma planilha Exce/® e, posteriormente tratados no Statistical Package or Social Science (SPSS) versão 18.0 for Windows.

Para a descrição e apresentação das variáveis qualitativas, foram utilizadas as frequências absolutas ( $n$ ) e relativas (\%) para as classes de cada variável. Para as variáveis quantitativas, empregaram-se as médias, medianas, desvio-padrão, valores mínimos e máximos para indicar a variabilidade dos resultados. 
Para verificar os fatores associados aos eventos observados nas complicações, utilizou-se o teste de Qui-Quadrado de Pearson. O teste Exato de Fisher foi usado nos casos em que os valores esperados foram inferiores a $5^{(88)}$.

Em todas as análises, foi considerado um nível de significância de $5 \%(p \leq 0,05)$. 


\section{RESULTADOS}

A população do estudo constituiu-se de 214 pacientes adultos internados em um hospital universitário do Município de São Paulo que foram submetidos à terapia nutricional enteral (TNE), no período de 2008 e 2009.

\subsection{Caracterização da amostra}

A seguir serão apresentadas as características dos pacientes que foram submetidos à TNE.

\subsubsection{Quanto às faixas etárias}

Quanto à idade dos pacientes, verifica-se nos dados da Tabela 1 a distribuição por faixa etária desses pacientes. 
Tabela 1 - Distribuição dos pacientes submetidos à TNE em um hospital universitário, no período de 2008/2009, segundo a faixa etária. São Paulo, 2010

\begin{tabular}{ccc}
\hline Faixa etária (anos) & $\mathbf{n}$ & $\%$ \\
\hline$<20$ & 06 & 2,8 \\
$20 \mid--30$ & 10 & 4,7 \\
$30 \mid--40$ & 09 & 4,2 \\
$40 \mid--50$ & 21 & 9,8 \\
$50 \mid--60$ & 30 & 14,0 \\
$60 \mid--70$ & 34 & 15,9 \\
$70 \mid--80$ & 58 & 27,1 \\
$\geq 80$ & 46 & 21,5 \\
Total & $\mathbf{2 1 4}$ & $\mathbf{1 0 0 , 0}$ \\
\hline
\end{tabular}

Em relação à faixa etária (Tabela 1), verifica-se que a maioria dos pacientes tinha 60 anos ou mais, totalizando 138 (64,5\%). Existe um predomínio no intervalo dos 70 anos a 79 anos de idade, 58 (27,1\%).

A idade dos pacientes variou de 15 a 108 anos, sendo a média de $64,8(\mathrm{dp}=19,5)$ e mediana de 69 anos.

\subsubsection{Quanto ao sexo}

Tabela 2 - Distribuição dos pacientes submetidos à TNE em um hospital universitário, no período de 2008/2009, segundo o sexo. São Paulo, 2010

\begin{tabular}{lcc}
\hline Sexo & $\mathbf{n}$ & $\%$ \\
\hline Feminino & 95 & 44,4 \\
Masculino & 119 & 55,6 \\
Total & $\mathbf{2 1 4}$ & $\mathbf{1 0 0 , 0}$ \\
\hline
\end{tabular}


Pelos dados da Tabela 2, observa-se que os pacientes do sexo masculino 119 (55,6\%) foram proporcionalmente maiores do que o feminino.

\subsubsection{Quanto ao local de internação}

Quanto ao local de internação em que os pacientes submetidos à TNE permaneceram, verifica-se a seguir a distribuição dos respectivos locais.

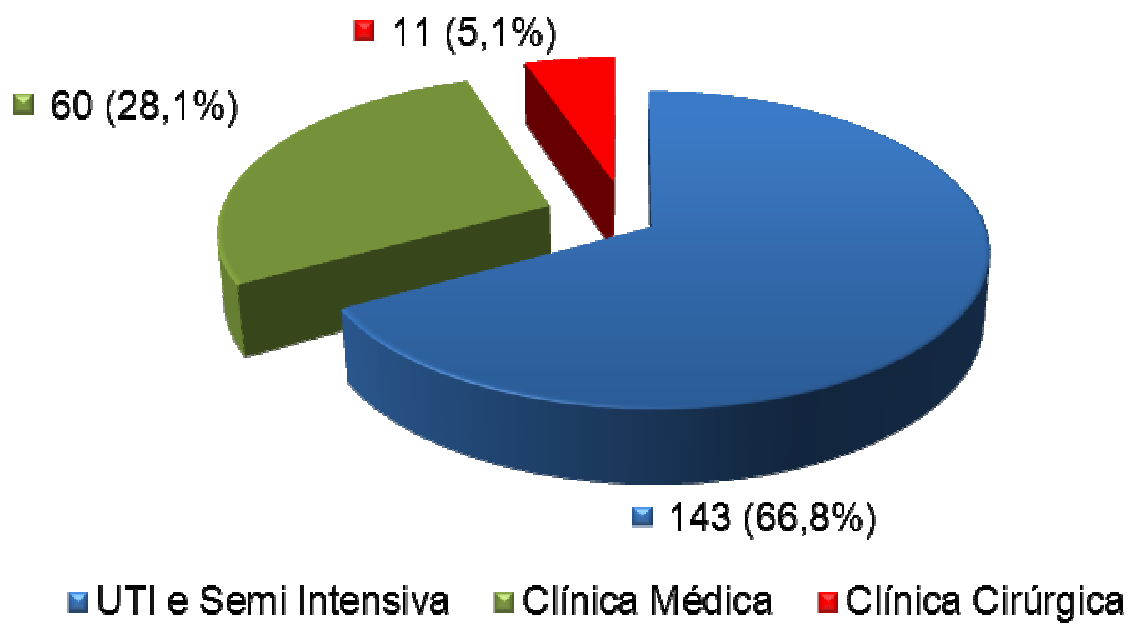

Figura 1 - Distribuição dos pacientes submetidos à TNE $(n=214)$ em um hospital universitário, no período de 2008/2009, segundo o local de internação. São Paulo, 2010

Pelos dados da Figura 1, verifica-se que $143(66,8 \%)$ dos pacientes submetidos à TNE estavam internados nas Unidades de Terapia Intensiva e Semi-Intensiva.

\subsubsection{Quanto às comorbidades e tipo de tratamento recebido}

A seguir, na Tabela 3, estão listadas as comorbidades e suas respectivas ocorrências. 
Tabela 3 - Distribuição das comorbidades apresentadas pelos pacientes submetidos à TNE em um hospital universitário, no período de 2008/2009. São Paulo, 2010

\begin{tabular}{lcc}
\hline Comorbidades & $\mathbf{n}$ & $\%$ \\
\hline Pulmonar & 140 & 20,1 \\
Cardiovascular & 135 & 19,4 \\
Neurológica & 121 & 17,4 \\
Renal & 78 & 11,2 \\
Endócrina & 58 & 8,4 \\
Hematológica & 42 & 6,0 \\
Oncológica & 36 & 5,2 \\
Sepse & 28 & 4,0 \\
Hepática & 24 & 3,5 \\
Ortopédica & 20 & 2,9 \\
Imunológica & 09 & 1,3 \\
Psiquiátrica & 04 & 0,6 \\
Total & 695 & 100,0 \\
\hline
\end{tabular}

De acordo com os dados da Tabela 3, verifica-se a diversidade das comorbidades apresentadas pelos pacientes, sendo as pulmonares com $140(20,1 \%)$ ocorrências, as mais frequentes, seguidas pelas cardiovasculares com 135 (19,4\%) e neurológicas com 121 (17,4\%).

Dos 214 pacientes analisados, $147(68,7 \%)$ foram submetidos a tratamento clínico e 67 (31,3\%), a tratamento cirúrgico. 


\subsubsection{Quanto à necessidade de ventilação mecânica}

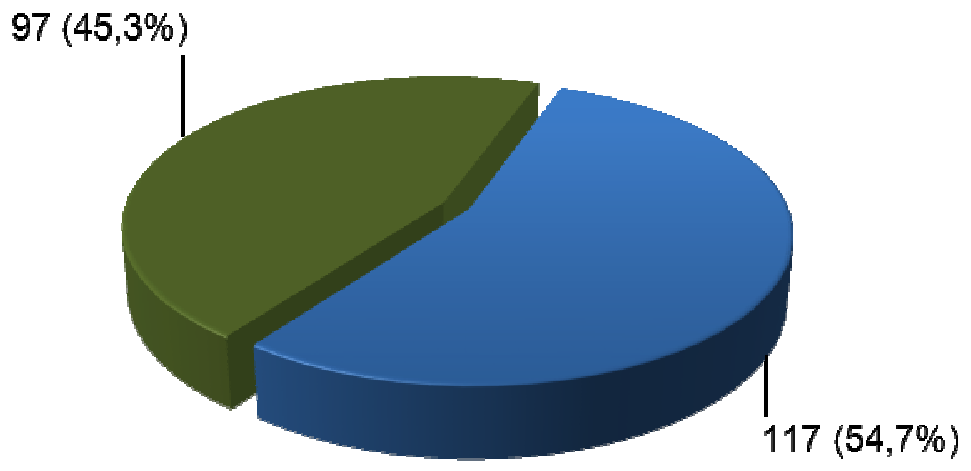

•Ventilação não mecânica $\quad$ Ventilação mecânica

Figura 2 - Distribuição dos pacientes submetidos à TNE $(n=214)$ em um hospital universitário, no período de 2008/2009, segundo o uso de ventilação mecânica. São Paulo, 2010

Pelos dados da Figura 2, verifica-se que $97(45,3 \%)$ pacientes fizeram uso de ventilação mecânica.

\subsubsection{Quanto ao tipo de terapia medicamentosa}

Nos dados da tabela seguinte, serão apresentados os resultados sobre as terapias medicamentosas utilizadas pelos pacientes durante $\mathrm{O}$ período, quando receberam a nutrição enteral. 
Tabela 4 - Distribuição das terapias medicamentosas utilizadas pelos pacientes submetidos à TNE em um hospital universitário, no período de 2008/2009. São Paulo, 2010

\begin{tabular}{lcc}
\hline Terapias medicamentosas & $\mathbf{n}$ & $\%$ \\
\hline Antibiótico & 168 & 33,7 \\
Sedativo/Opioide & 121 & 24,2 \\
Pró-cinético & 87 & 17,4 \\
Droga vasoativa & 60 & 12,0 \\
Anti-inflamatório & 46 & 9,2 \\
Relaxante muscular & 17 & 3,4 \\
Total & 499 & $\mathbf{1 0 0 , 0}$ \\
\hline
\end{tabular}

Pelos dados da Tabela 4, verifica-se que os antibióticos e os sedativos/opioides foram os mais utilizados pelos pacientes.

\subsubsection{Quanto ao tempo de internação}

O tempo de internação dos 214 pacientes em uso da TNE variou, de 2 a 212 dias, média de 23,8 $(\mathrm{dp}=22,4)$ e mediana de 19 dias.

\subsection{Terapia nutricional enteral: tempo de TNE, vias de acesso e métodos de infusão.}

A seguir, serão apresentados os resultados referentes à TNE a que foram submetidos os pacientes do presente estudo. 


\subsubsection{Terapia nutricional enteral, segundo 0 tempo de administração}

Tabela 5 - $\quad$ Distribuição dos pacientes submetidos à TNE $(n=214)$ em um hospital universitário, no período de 2008/2009, segundo o tempo de TNE em semanas. São Paulo, 2010

\begin{tabular}{|c|c|c|}
\hline Tempo de TNE & $\mathbf{n}$ & $\%$ \\
\hline até 1 semana ( $\leq 7$ dias) & 93 & 43,5 \\
\hline até 2 semanas (7 --| 14 dias) & 57 & 26,6 \\
\hline até 3 semanas (14 --| 21 dias) & 27 & 12,6 \\
\hline até 4 semanas (21 --| 28 dias) & 15 & 7,0 \\
\hline até 5 semanas (28 --| 35 dias) & 12 & 5,6 \\
\hline 5 semanas ou mais ( $>35$ dias) & 10 & 4,7 \\
\hline Total & 214 & 100,0 \\
\hline
\end{tabular}

Os dados da Tabela 5 mostram que, grande parte dos pacientes 93 (43,5\%), fez uso da TNE durante um curto período de tempo (até 7 dias).

$\mathrm{Na}$ amostra total analisada, o tempo de uso da nutrição enteral variou de 1 e 189 dias, média de 13,2 dias ( $d p=17,3$ dias) e mediana de 8 dias.

\subsubsection{Terapia nutricional enteral, segundo o tipo de acesso}

Quanto ao tipo de acesso enteral a que os pacientes foram submetidos, verifica-se na figura a seguir. 


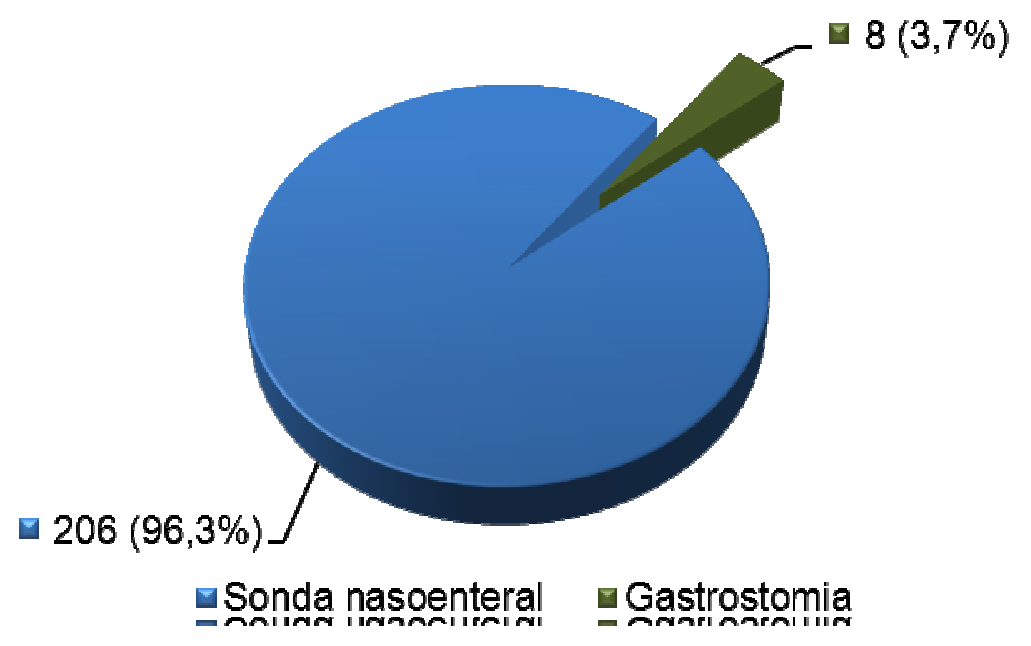

Figura 3 - Distribuição dos pacientes submetidos à TNE em um hospital universitário, no período de 2008/2009, segundo o tipo de acesso enteral. São Paulo, 2010

Referente às vias de acesso enteral verifica-se na Figura 3 que o uso das sondas nasoenterais foi predominante.

4.2.3 Terapia nutricional enteral, segundo o método de infusão: contínuo e intermitente

Tabela 6 - Distribuição dos pacientes submetidos à TNE em um hospital universitário, no período de 2008/2009, segundo o método de infusão da TNE. São Paulo, 2010

\begin{tabular}{lcc}
\hline Métodos de infusão & $\mathbf{n}$ & \% \\
\hline Contínuo & 144 & 67,3 \\
Intermitente & 69 & 32,2 \\
Total & $\mathbf{2 1 3}$ & $\mathbf{9 9 , 5}$ \\
\hline
\end{tabular}

Pelos dados da Tabela 6, observa-se que o método mais utilizado foi o contínuo em 144 (67,3\%) pacientes. Todavia, cabe ressaltar que em um dos pacientes da amostra, o tipo de método de infusão não foi identificado. 


\subsection{Complicações ocorridas durante a TNE}

Dos 214 pacientes em uso da TNE analisados, 14 (6,5\%) não apresentaram nenhuma complicação. Assim, os dados que serão apresentados a seguir, referem-se aos 200 (93,5\%) pacientes, cujas complicações foram identificadas no período de janeiro de 2008 a dezembro de 2009 (Figura 4).

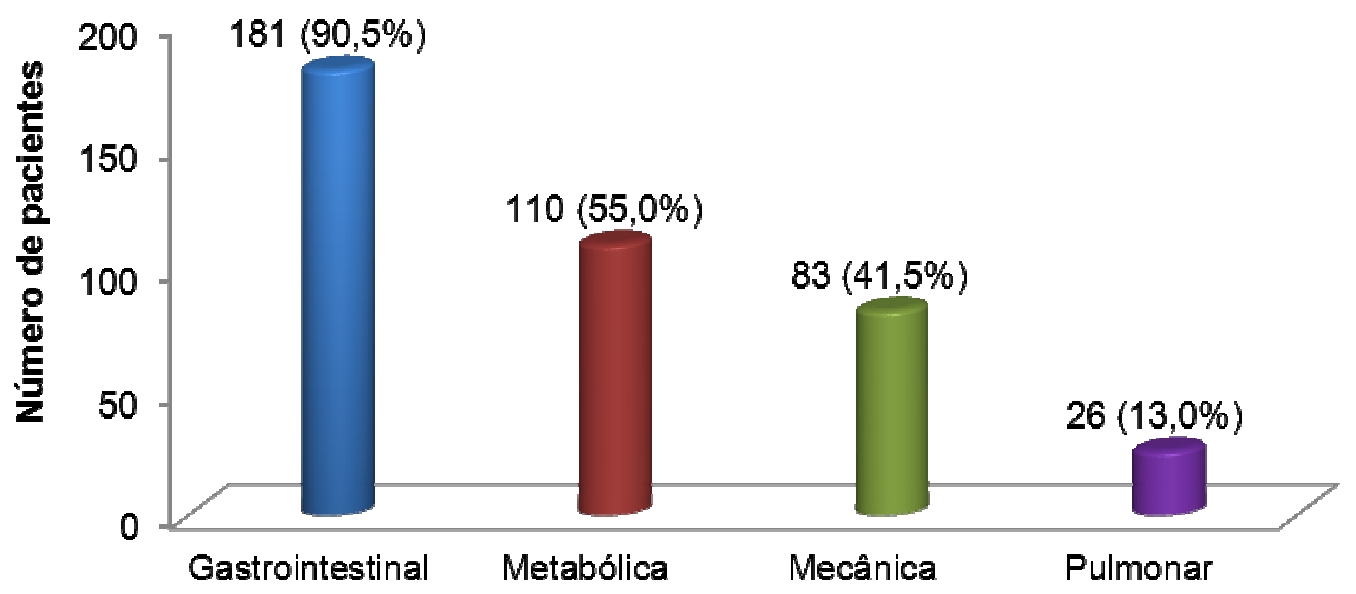

Tipos de complicações

Figura 4 - Distribuição dos pacientes submetidos à TNE com complicações $(n=200)$ em um hospital universitário, no período de 2008/2009, segundo os tipos de complicações. São Paulo, 2010

Dos 200 pacientes que apresentaram complicações, verifica-se, na Figura 4, que houve um predomínio da gastrointestinal em 181 (90,5\%) pacientes. Em menor frequência, aparecem as complicações: metabólica, mecânica e pulmonar, em ordem decrescente. A presença de mais de uma complicação no mesmo paciente foi comumente observada. 


\subsection{Análise da associação entre as complicações ocorridas durante a TNE}

A seguir, serão analisadas as possíveis associações entre as complicações, admitindo-se que a complicação gastrointestinal é o foco principal desta investigação.

\subsubsection{Associação entre as complicações ocorridas durante a TNE, segundo a ocorrência de complicações gastrointestinais.}

A tabela a seguir demonstra as três complicações distribuídas, segundo a ocorrência de complicações gastrointestinais.

Tabela 7 - Distribuição dos pacientes submetidos à TNE em um hospital universitário, no período de 2008/2009, com complicações: metabólica, mecânica e pulmonar $(n=200)$ segundo a ocorrência ou não da complicação gastrointestinal. São Paulo, 2010

\begin{tabular}{|c|c|c|c|c|c|}
\hline \multirow{2}{*}{\multicolumn{2}{|c|}{$\begin{array}{c}\text { Tipos de } \\
\text { Complicações }\end{array}$}} & \multicolumn{2}{|c|}{$\begin{array}{c}\text { Complicação } \\
\text { Gastrointestinal }\end{array}$} & \multirow{2}{*}{ Total } & \multirow{2}{*}{$\mathbf{p}$} \\
\hline & & $\begin{array}{c}\text { Sim } \\
\mathrm{n}(\%) \\
\end{array}$ & $\begin{array}{c}\text { Não } \\
\text { n (\%) }\end{array}$ & & \\
\hline \multirow{3}{*}{ Metabólica } & Sim & 0010011 & & 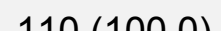 & \multirow{3}{*}{$0,611^{\dagger}$} \\
\hline & sim & प्र० $(89,1)$ & $12(10, y)$ & $170(100,0)$ & \\
\hline & Não & $83(92,2)$ & $07(7,8)$ & $90(100,0)$ & \\
\hline \multirow{2}{*}{ Mecânica } & Sim & $70(84,3)$ & $13(15,7)$ & $83(100,0)$ & \multirow{2}{*}{$0,023^{\ddagger}$} \\
\hline & Não & $111(94,9)$ & $06(5,1)$ & $117(100,0)$ & \\
\hline \multirow{2}{*}{ Pulmonar } & Sim & $24(92,3)$ & $02(7,7)$ & $26(100,0)$ & \multirow{2}{*}{$1,000^{\ddagger}$} \\
\hline & Não & $157(90,2)$ & $17(9,8)$ & $174(100,0)$ & \\
\hline
\end{tabular}

${ }^{\dagger}$ Teste de Qui-Quadrado de Pearson

Pela Tabela 7, verifica-se que a complicação mecânica associa-se inversamente à complicação gastrointestinal $(p=0,023)$. Tanto a complicação metabólica, como a pulmonar não demonstraram associação significativa $(p>0,05)$. Embora não atinja significância estatística, a complicação 
metabólica apresenta comportamento semelhante ao da complicação mecânica.

\subsubsection{Associação entre as complicações: mecânica e metabólica segundo a ocorrência de complicação pulmonar}

A despeito de que não haja evidências que apontem associação entre as três complicações, os da tabela a seguir testam uma associação que pode ser contingencial entre essas variáveis.

Tabela 8 - Distribuição dos pacientes submetidos à TNE em um hospital universitário, no período de 2008/2009, com complicações: mecânica e metabólica $(n=200)$, segundo a ocorrência ou não de complicação pulmonar. São Paulo, 2010

\begin{tabular}{|c|c|c|c|c|c|}
\hline \multirow{3}{*}{\multicolumn{2}{|c|}{$\begin{array}{c}\text { Tipos de } \\
\text { Complicações }\end{array}$}} & \multicolumn{2}{|c|}{ Complicação Pulmonar } & \multirow{3}{*}{ Total } & \multirow{3}{*}{$\mathbf{p}$} \\
\hline & & \multirow{2}{*}{$\begin{array}{c}\text { Sim } \\
n(\%)\end{array}$} & \multirow{2}{*}{$\begin{array}{c}\text { Não } \\
\text { n (\%) }\end{array}$} & & \\
\hline & & & & & \\
\hline \multirow{2}{*}{ Mecânica } & $\operatorname{Sim}$ & $09(10,8)$ & $74(89,2)$ & $83(100,0)$ & \multirow{2}{*}{$0,582^{\dagger}$} \\
\hline & Não & $17(15,3)$ & $100(84,7)$ & $117(100,0)$ & \\
\hline \multirow{2}{*}{ Metabólica } & Sim & $12(10,9)$ & $98(89,1)$ & $110(100,0)$ & \multirow{2}{*}{$0,447^{\dagger}$} \\
\hline & Não & $14(15,6)$ & $76(84,4)$ & $90(100,0)$ & \\
\hline
\end{tabular}
estatisticamente significativa entre ocorrência de complicação pulmonar em relação às complicações: mecânica e metabólica.

\subsubsection{Eventos observados nas complicações}

Os resultados descritos nas figuras seguintes referem-se à descrição geral da quantidade de eventos observados em relação aos tipos 
de complicações apresentadas pelos pacientes submetidos à TNE deste estudo.

Relembrando que serão considerados, para este estudo e descritos anteriormente no método, eventos observados nas complicações. Gastrointestinal: náusea, vômito, refluxo, alto volume residual gástrico (VRG), dor abdominal, distensão abdominal, constipação e diarreia; Pulmonar: presença de aspiração pulmonar; Mecânica: obstrução, deslocamento e saída acidental da sonda enteral, lesão tissular associada ao uso da sonda enteral e infecção perigastrostomia e Metabólica: hiperglicemia.

A ocorrência dos eventos observados nas complicações variou de uma a sete vezes por paciente e a distribuição será apresentada a seguir.

Tabela 9 - $\quad$ Frequência de eventos observados nas complicações encontradas nos pacientes submetidos à TNE em um hospital universitário, no período de 2008/2009. São Paulo, 2010

\begin{tabular}{ccc}
\hline Número de eventos observados & $\mathbf{n}$ & $\mathbf{\%}$ \\
\hline 1 & 38 & 19,0 \\
2 & 40 & 20,0 \\
3 & 53 & 26,5 \\
4 & 34 & 17,0 \\
5 & 24 & 12,0 \\
6 & 07 & 3,5 \\
7 & 04 & 2,0 \\
Total & $\mathbf{2 0 0}$ & $\mathbf{1 0 0 , 0}$ \\
\hline
\end{tabular}

Pela Tabela 9, verifica-se que $53(26,5 \%)$ pacientes apresentaram três eventos observados nas complicações, seguidos de 40 (20,0\%) que apresentaram dois eventos e $39(19,0 \%)$ pacientes com apenas um evento. Vale ressaltar que $4(2,0 \%)$ pacientes apresentaram sete eventos observados nas complicações durante a TNE. 
Do total de eventos observados nas complicações, verificou-se uma variação de 1 a 7 , média de $3(d p=1,5)$ e mediana de 3 eventos por paciente.

Nos resultados a seguir serão descritos os eventos observados para cada uma das complicações: gastrointestinal, metabólica, mecânica e pulmonar.

\subsubsection{Complicação gastrointestinal e eventos observados}

Os eventos observados na complicação gastrointestinal, apresentados pelos pacientes deste estudo estão descritos na tabela a seguir.

Tabela 10 - Frequência dos eventos observados nos 181 casos de complicação gastrointestinal em pacientes submetidos à TNE em um hospital universitário, no período de 2008/2009. São Paulo, 2010

\begin{tabular}{lcc}
\hline Eventos observados & $\mathbf{n}$ & $\mathbf{\%}$ \\
\hline Distensão abdominal & 126 & 33,4 \\
Constipação & 66 & 17,5 \\
VRG & 55 & 14,6 \\
Diarreia & 49 & 13,0 \\
Vômito & 31 & 8,2 \\
Refluxo & 23 & 6,1 \\
Dor abdominal & 18 & 4,8 \\
Náusea & 09 & 2,4 \\
Total & 377 & 100 \\
\hline
\end{tabular}

$\mathrm{Na}$ Tabela 10, observa-se que os pacientes apresentaram mais de um evento observado na complicação gastrointestinal, com o predomínio da distensão abdominal em 126 (33,4\%) pacientes, seguida da constipação em 66 (17,5\%), VRG em 55 (14,6\%) e diarreia em 49 (13,0\%). 


\subsubsection{Complicação metabólica e evento observado}

Neste estudo o evento observado na complicação metabólica foi a hiperglicemia 110 (55,0\%). Os valores encontrados variaram de $147 \mathrm{mg} / \mathrm{dL}$ a $237 \mathrm{mg} / \mathrm{dL}$, com média de 174,2mg/dL (DP= 17,5) e mediana de $170 \mathrm{mg} / \mathrm{dL}$.

\subsubsection{Complicação mecânica e eventos observados}

Os eventos observados na complicação mecânica nos pacientes submetidos à TNE foram cinco, que serão apresentados na Tabela 11.

Tabela 11 - Frequência dos eventos observados nos 83 casos de complicação mecânica em pacientes submetidos à TNE em um hospital universitário, no período de 2008/2009. São Paulo, 2010

\begin{tabular}{lcc}
\hline Eventos observados & $\mathbf{n}$ & $\mathbf{\%}$ \\
\hline Saída não programada da sonda & 74 & 70,5 \\
Obstrução da sonda & 20 & 19,0 \\
Deslocamento da sonda & 05 & 4,8 \\
Infecção periestoma & 05 & 4,8 \\
Lesão nasal & 01 & 0,9 \\
Total & $\mathbf{1 0 5}$ & $\mathbf{1 0 0 , 0}$ \\
\hline
\end{tabular}

Na Tabela 11, observa-se que, dos pacientes que apresentaram complicação mecânica, houve predominância da saída não programada da sonda enteral em 74 (70,5\%) casos, seguida das obstruções em 20 (19,0\%), das infecções perigastrostomias em 5 (4,8\%), dos deslocamentos das sondas enterais em $5(4,8 \%)$ e da lesão nasal caracterizada pela úlcera por pressão em um paciente. 


\subsubsection{Complicação pulmonar e evento observado}

$\mathrm{Na}$ complicação pulmonar, o evento observado refere-se à aspiração pulmonar que ocorreu neste estudo, em 26 pacientes submetidos à TNE. Mas, outros eventos constituintes de certas complicações podem estar relacionados à aspiração pulmonar e estes são testados a seguir, apresentados na tabela 12 .

Tabela 12 - Distribuição dos casos com complicação gastrointestinal (eventos observados), segundo a complicação pulmonar nos pacientes submetidos à TNE em um hospital universitário, no período de 2008/2009. São Paulo, 2010

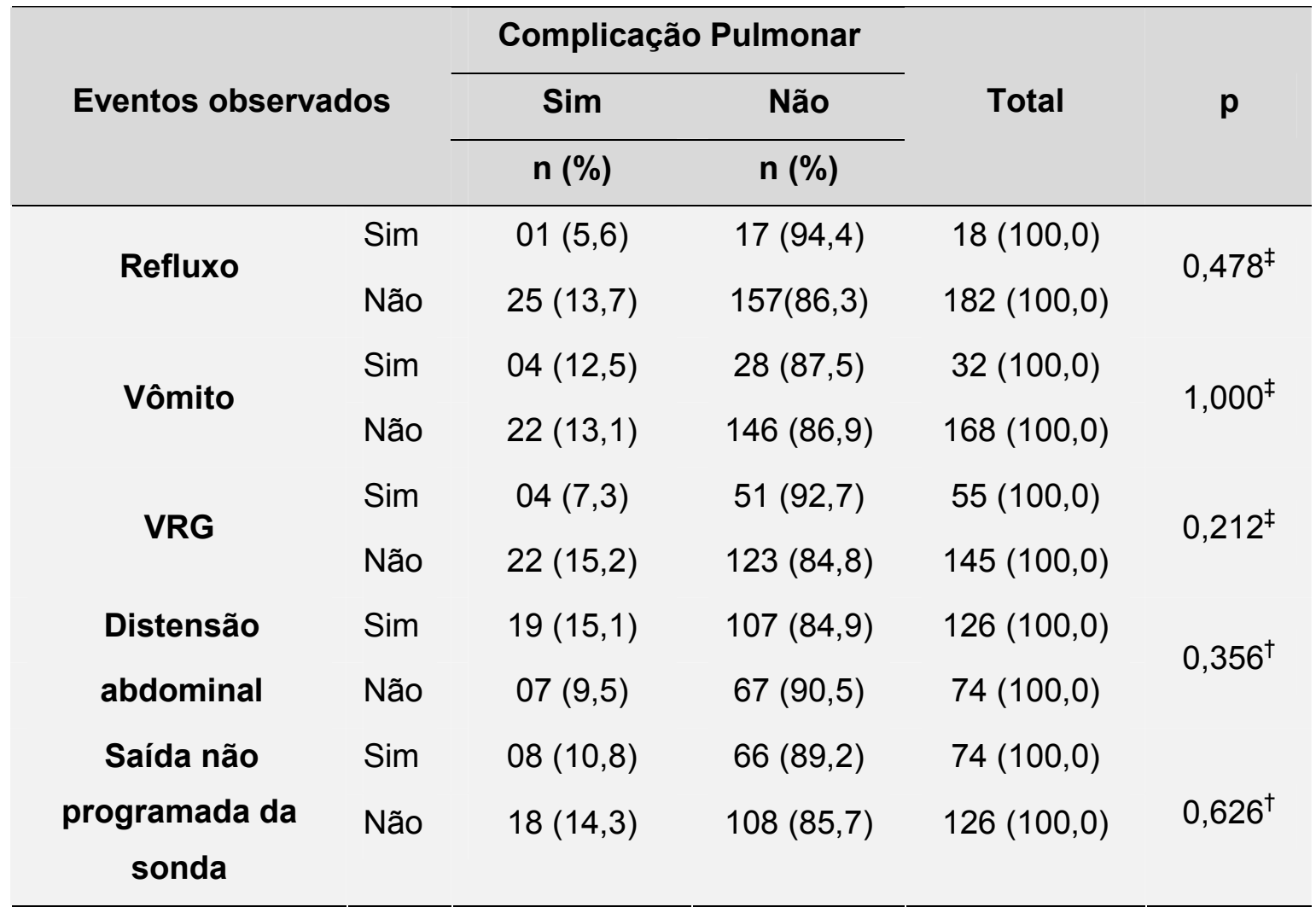

$\mp$ Teste exato de Fisher

† Qui-Quadrado de Pearson

Os resultados dos testes Qui-Quadrado e Fisher observados na

Tabela 12 mostram que não houve relação estatisticamente significativa entre ocorrências de eventos observados, que poderiam ser eventos percebidos no desenvolvimento da complicação pulmonar. 
4.5 Eventos observados nas complicações e métodos de infusão da nutrição enteral e terapia medicamentosa

Os métodos de infusão de nutrição foram analisados em relação à ocorrência das complicações e os dados são apresentados a seguir. 


\subsubsection{Eventos observados nas complicações gastrointestinais e forma de infusão da TNE}

Tabela 13 - Distribuição dos casos com complicação gastrointestinal (eventos observados) nos pacientes submetidos à TNE em um hospital universitário, no período de 2008/2009, segundo o método de infusão da TNE. São Paulo, 2010

\begin{tabular}{|c|c|c|c|c|c|}
\hline \multirow{2}{*}{\multicolumn{2}{|c|}{$\begin{array}{l}\text { Eventos observados à } \\
\text { complicação gastrointestinal }\end{array}$}} & \multicolumn{2}{|c|}{ Método de infusão* } & \multirow[b]{2}{*}{$\begin{array}{l}\text { Total } \\
\text { n (\%) }\end{array}$} & \multirow[b]{2}{*}{$\mathbf{p}$} \\
\hline & & $\begin{array}{c}\text { Intermitente } \\
\mathbf{n}(\%)\end{array}$ & $\begin{array}{c}\text { Contínuo } \\
\mathrm{n}(\%)\end{array}$ & & \\
\hline \multirow{2}{*}{ Náusea } & Sim & $04(44,4)$ & $05(55,6)$ & $09(100,0)$ & \multirow{2}{*}{$0,477^{\ddagger}$} \\
\hline & Não & $61(32,1)$ & $129(67,9)$ & $190(100,0)$ & \\
\hline \multirow{2}{*}{ Dor abdominal } & Sim & $10(55,5)$ & $08(44,4)$ & $18(100,0)$ & \multirow{2}{*}{$0,056^{\dagger}$} \\
\hline & Não & $55(30,4)$ & $126(69,6)$ & $181(100,0)$ & \\
\hline \multirow{2}{*}{ Refluxo } & Sim & $10(43,47)$ & $13(56,5)$ & $23(100,0)$ & \multirow{2}{*}{$0,264^{\dagger}$} \\
\hline & Não & $55(31,3)$ & $121(68,7)$ & $176(100,0)$ & \\
\hline \multirow{2}{*}{ Vômito } & $\operatorname{Sim}$ & $05(16,1)$ & $26(83,9)$ & $31(100,0)$ & \multirow{2}{*}{$0,054^{\dagger}$} \\
\hline & Não & $60(35,7)$ & $108(64,3)$ & $168(100,0)$ & \\
\hline \multirow{2}{*}{ Diarreia } & $\operatorname{Sim}$ & $19(38,8)$ & $30(61,2)$ & $49(100,0)$ & \multirow{2}{*}{$0,381^{\dagger}$} \\
\hline & Não & $46(30,0)$ & $104(69,3)$ & $150(100,0)$ & \\
\hline \multirow{2}{*}{ VRG } & $\operatorname{Sim}$ & $07(12,7)$ & $48(87,3)$ & $55(100,0)$ & \multirow{2}{*}{$0,000^{\dagger}$} \\
\hline & Não & $58(40,3)$ & $86(59,7)$ & $144(100,0)$ & \\
\hline \multirow{2}{*}{ Constipação } & Sim & $13(19,7)$ & $53(80,3)$ & $66(100,0)$ & \multirow{2}{*}{$0,010^{\dagger}$} \\
\hline & Não & $52(39,1)$ & $81(60,9)$ & $133(100,0)$ & \\
\hline \multirow{2}{*}{ Distensão Abdominal } & $\operatorname{Sim}$ & $34(26,7)$ & $92(73,3)$ & $126(100,0)$ & \multirow{2}{*}{$0,037^{\dagger}$} \\
\hline & Não & $31(42,7)$ & $42(53,7)$ & $73(100,0)$ & \\
\hline \multicolumn{6}{|c|}{$\begin{array}{l}{ }^{\ddagger} \text { Teste exato de Fisher } \\
{ }^{\dagger} \text { Teste de Qui-Quadrado de Pearson } \\
{ }^{\star} \text { Missing }\end{array}$} \\
\hline
\end{tabular}


de VRG $(p=0,000)$, constipação $(p=0,010)$ e distensão abdominal $(p=0,037)$, e em todos esses eventos, o método de infusão contínua predominou, com exceção da dor abdominal.

\subsubsection{Evento observado na complicação metabólica e método de infusão da TNE}

A hiperglicemia, evento observado na complicação metabólica, também foi uma variável analisada em relação ao método de infusão, apresentada na tabela a seguir.

Tabela 14 - Distribuição dos casos com complicação metabólica (hiperglicemia), segundo o método de infusão da nutrição enteral nos pacientes submetidos à TNE em um hospital universitário, no período de 2008/2009, São Paulo, 2010

\begin{tabular}{|c|c|c|c|c|c|}
\hline \multirow{2}{*}{\multicolumn{2}{|c|}{$\begin{array}{l}\text { Evento observado na } \\
\text { Complicação Metabólica }\end{array}$}} & \multicolumn{2}{|c|}{ Método de infusão } & \multirow[b]{2}{*}{$\begin{array}{l}\text { Total } \\
\mathrm{n}(\%) \\
\end{array}$} & \multirow[b]{2}{*}{$\mathbf{p}$} \\
\hline & & $\begin{array}{c}\text { Intermitente } \\
\mathbf{n}(\%) \\
\end{array}$ & $\begin{array}{c}\text { Contínuo } \\
\mathrm{n}(\%) \\
\end{array}$ & & \\
\hline \multirow[t]{2}{*}{ Hiperglicemia } & Sim & $31(28,4)$ & $78(71,6)$ & $109(100,0)$ & 0,213 \\
\hline & Não & $34(37,8)$ & $56(62,2)$ & $90(100,0)$ & \\
\hline
\end{tabular}

Teste de Qui-Quadrado de Pearson Missing

Pelos dados da Tabela 14, verifica-se que, pela análise estatística, não houve associação significante entre método de infusão e ocorrência de hiperglicemia $(p=0,213)$.

\subsubsection{Eventos observados na complicação mecânica e método de infusão da TNE}

Os dados da Tabela 15 a seguir mostram a análise estatística entre ocorrência dos eventos observados na complicação mecânica e métodos de infusão utilizados. 
Tabela 15 - Distribuição dos casos com complicação mecânica (eventos observados), segundo o método de infusão da nutrição enteral nos pacientes submetidos à TNE em um hospital universitário, no período de 2008/2009. São Paulo, 2010

\begin{tabular}{|c|c|c|c|c|c|}
\hline \multirow{2}{*}{\multicolumn{2}{|c|}{$\begin{array}{l}\text { Eventos observados na } \\
\text { complicação mecânica }\end{array}$}} & \multicolumn{2}{|c|}{ Método de infusão* } & \multirow{2}{*}{$\begin{array}{l}\text { Total } \\
\mathrm{n}(\%) \\
\end{array}$} & \multirow{2}{*}{$\mathbf{p}$} \\
\hline & & $\begin{array}{c}\text { Intermitente } \\
\mathrm{n}(\%) \\
\end{array}$ & $\begin{array}{c}\text { Contínuo } \\
\mathrm{n}(\%) \\
\end{array}$ & & \\
\hline \multirow{2}{*}{$\begin{array}{l}\text { Deslocamento da } \\
\text { sonda }\end{array}$} & Sim & $04(80,0)$ & $01(20,0)$ & $05(100,0)$ & \multirow{2}{*}{$0,040^{\ddagger}$} \\
\hline & Não & $61(31,4)$ & $133(68,6)$ & $194(100,0)$ & \\
\hline \multirow{2}{*}{$\begin{array}{l}\text { Saída não } \\
\text { programada da sonda }\end{array}$} & Sim & $33(44,6)$ & $41(55,4)$ & $74(100,0)$ & \multirow{2}{*}{$0,005^{\dagger}$} \\
\hline & Não & $32(25,6)$ & $93(74,4)$ & $125(100,0)$ & \\
\hline \multirow{2}{*}{ Obstrução da sonda } & Sim & $05(25,0)$ & $15(75,0)$ & $20(100,0)$ & \multirow{2}{*}{$0,603^{\dagger}$} \\
\hline & Não & $60(33,5)$ & $119(66,5)$ & $179(100,0)$ & \\
\hline \multicolumn{6}{|c|}{$\begin{array}{l}\text { F Teste exato de Fisher } \\
{ }^{\dagger} \text { Teste de Qui-Quadrado de Pearson } \\
{ }^{*} \text { Missing }\end{array}$} \\
\hline \multicolumn{6}{|c|}{$\begin{array}{l}\text { Pelos dados da Tabela } 15 \text {, verifica-se que houve associação } \\
\text { Imente significativa entre a ocorrência de deslocamento da sonda e } \\
\text { os de infusão }(p=0,040) \text {, ocorrendo com menor frequência na }\end{array}$} \\
\hline
\end{tabular}

Da mesma forma, nos casos de saída não programada da sonda, houve uma relação estatisticamente significativa $(p=0,005)$ entre os métodos de infusão da dieta. Verifica-se que entre os 125 casos de não ocorrência desse evento 93 (74,4\%) ocorreram com a infusão contínua. Portanto, podese considerar que o método contínuo tem efeito protetor na manutenção da sonda nasoenteral. 


\subsubsection{Evento observado na complicação pulmonar e método de infusão da TNE}

A seguir, os dados da Tabela 16 demonstram a análise da possível associação entre a complicação pulmonar e o método de infusão da TNE.

Tabela 16 - Distribuição dos casos com complicação pulmonar (evento observado) nos pacientes submetidos à TNE em um hospital universitário, no período de 2008/2009, segundo o método de infusão da TNE. São Paulo, 2010

\begin{tabular}{lccccc}
\hline \multirow{2}{*}{$\begin{array}{c}\text { Evento observado na } \\
\text { Complicação Pulmonar }\end{array}$} & \multicolumn{2}{c}{ Método de infusão } & \\
\cline { 3 - 5 } & & Intermitente & Contínuo & Total & \multirow{2}{*}{ p } \\
\cline { 3 - 5 } & $\mathrm{n} \mathrm{( \% )}$ & $\mathbf{n}(\%)$ & $\mathbf{n ~ ( \% )}$ & \\
\hline \multirow{2}{*}{ Aspiração Pulmonar } & $\operatorname{Sim}$ & $7(26,9)$ & $19(73,1)$ & $26(100,0)$ & \multirow{2}{*}{0,656} \\
& Não & $58(33,5)$ & $115(66,5)$ & $173(100,0)$ & \\
\hline
\end{tabular}

Teste de Qui-Quadrado de Pearson

${ }^{*}$ Missing

Pela Tabela 16, observa-se que a aspiração pulmonar ocorreu com menor frequência no método intermitente de infusão. No entanto, não houve associação estatisticamente significativa desta complicação em relação aos métodos de infusão $(p=0,656)$.

\subsubsection{Terapia medicamentosa e complicações: gastrointestinal e metabólica}

A relação entre os eventos observados nas complicações apresentadas e a terapia medicamentosa utilizada para esses pacientes, foi verificada e apresentada na Tabela 17. 
Tabela 17 - Distribuição dos pacientes que receberam terapia medicamentosa e foram submetidos à TNE em um hospital universitário, no período de 2008/2009, segundo a ocorrência de complicações: gastrointestinal e metabólica. São Paulo, 2010

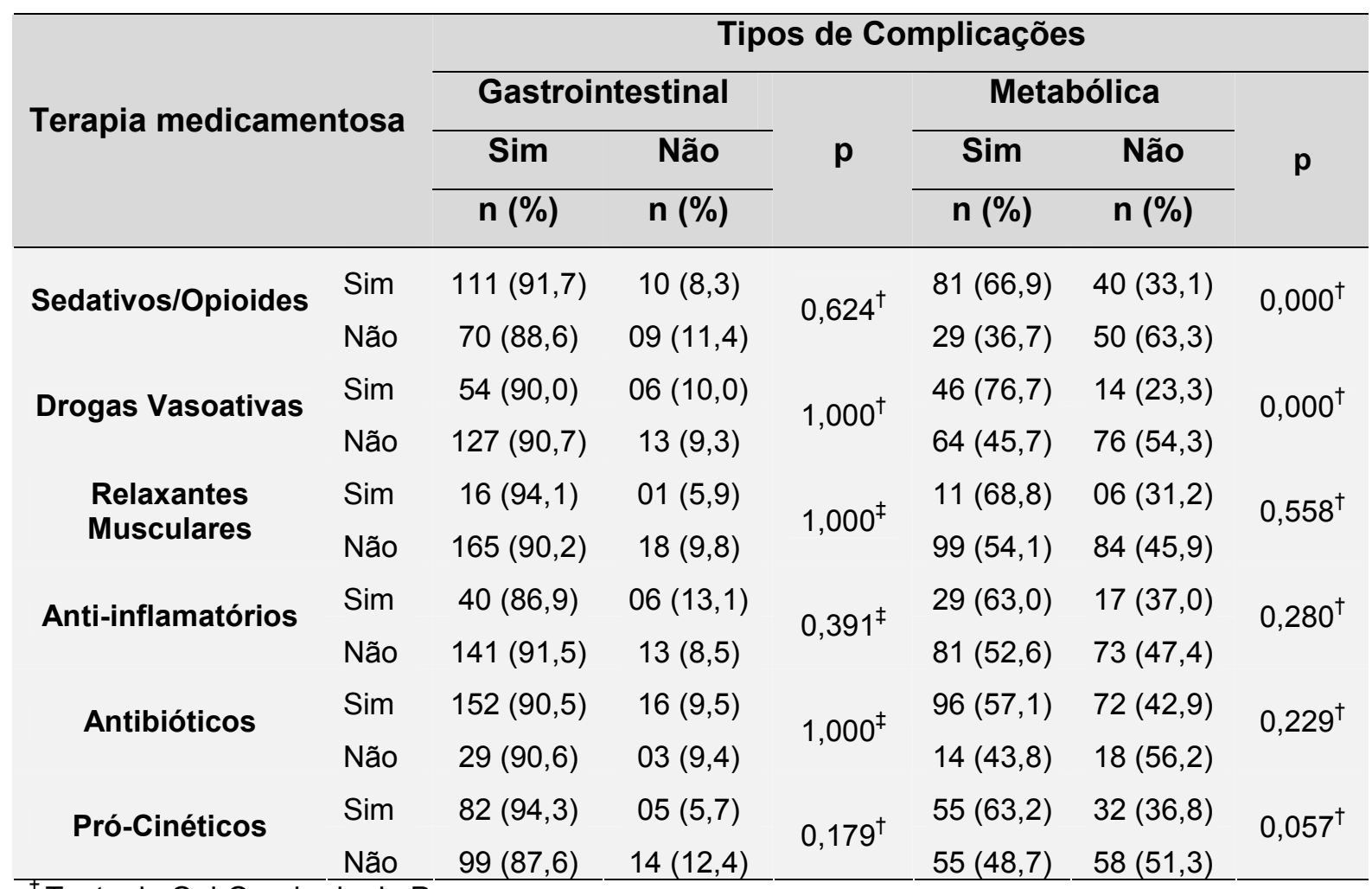

${ }^{\dagger}$ Teste de Qui-Quadrado de Pearson

${ }^{\ddagger}$ Teste exato de Fisher

Na Tabela 17, observa-se que houve associação estatisticamente significativa $(p=0,000)$ nos pacientes com complicação metabólica que fizeram uso de sedativos/opioides e drogas vasoativas. 


\subsubsection{Terapia medicamentosa e complicações: mecânica e pulmonar}

Tabela 18 - Distribuição dos pacientes que receberam terapia medicamentosa e foram submetidos à TNE em um hospital universitário, no período de 2008/2009, segundo a ocorrência de complicações mecânica e pulmonar. São Paulo, 2010

\begin{tabular}{|c|c|c|c|c|c|c|c|}
\hline \multirow{3}{*}{\multicolumn{2}{|c|}{ Terapia medicamentosa }} & \multicolumn{6}{|c|}{ Tipos de Complicações } \\
\hline & & \multicolumn{2}{|c|}{ Mecânica } & \multirow[b]{2}{*}{$\mathbf{p}$} & \multicolumn{2}{|c|}{ Pulmonar } & \multirow[b]{2}{*}{$\mathbf{p}$} \\
\hline & & $\frac{\operatorname{Sim}}{\mathrm{n}(\%)}$ & $\frac{\text { Não }}{\mathrm{n}(\%)}$ & & $\frac{\operatorname{Sim}}{\mathrm{n}(\%)}$ & $\begin{array}{c}\text { Não } \\
\text { n (\%) }\end{array}$ & \\
\hline \multirow{2}{*}{ Sedativos/Opioides } & Sim & $46(39,6)$ & $70(60,4)$ & \multirow{2}{*}{$0,633^{\dagger}$} & $14(12,1)$ & $102(87,9)$ & \multirow{2}{*}{$0,805^{\dagger}$} \\
\hline & Não & $37(44,0)$ & $47(56,0)$ & & $12(14,3)$ & $72(85,7)$ & \\
\hline \multirow{2}{*}{ Drogas Vasoativas } & Sim & $25(42,4)$ & $34(57,6)$ & \multirow{2}{*}{$0,996^{\dagger}$} & $6(10,2)$ & $53(89,8)$ & \multirow{2}{*}{$0,590^{\dagger}$} \\
\hline & Não & $58(41,1)$ & $83(58,9)$ & & $20(14,2)$ & $121(85,8)$ & \\
\hline \multirow{2}{*}{$\begin{array}{l}\text { Relaxantes } \\
\text { Musculares }\end{array}$} & Sim & $06(40,0)$ & $09(60,0)$ & \multirow{2}{*}{$1,000^{\dagger}$} & $01(6,7)$ & $14(93,3)$ & \multirow{2}{*}{$0,698^{\ddagger}$} \\
\hline & Não & $77(41,6)$ & $108(58,4)$ & & $25(13,5)$ & $160(86,5)$ & \\
\hline \multirow{2}{*}{ Anti-inflamatórios } & Sim & $19(44,2)$ & $24(55,8)$ & \multirow{2}{*}{$0,819^{\dagger}$} & $06(11,6)$ & $37(88,4)$ & \multirow{2}{*}{$1,000^{\dagger}$} \\
\hline & Não & $64(40,8)$ & $93(59,2)$ & & $20(12,7)$ & $137(87,3)$ & \\
\hline \multirow{2}{*}{ Antibióticos } & Sim & $70(42,2)$ & $96(57,8)$ & \multirow{2}{*}{$0,816^{\ddagger}$} & $20(12,0)$ & $146(88,0)$ & \multirow{2}{*}{$0,402^{\ddagger}$} \\
\hline & Não & $13(38,2)$ & $21(61,8)$ & & $06(17,6)$ & $28(82,4)$ & \\
\hline \multirow{2}{*}{ Pró-Cinéticos } & Sim & $36(42,9)$ & $48(57,1)$ & \multirow{2}{*}{$0,852^{\dagger}$} & $09(10,7)$ & $75(89,3)$ & \multirow{2}{*}{$0,545^{\dagger}$} \\
\hline & Não & $47(40,5)$ & $69(59,5)$ & & $17(14,7)$ & $99(85,3)$ & \\
\hline
\end{tabular}

${ }^{\dagger}$ Teste de Qui-Quadrado de Pearson

‡ Teste exato de Fisher

Pela Tabela 18, verifica-se que o uso desses medicamentos não se associou estatisticamente com a ocorrência das complicações: mecânica ou pulmonar. 


\section{DISCUSSÃO}

\subsection{Caracterização da amostra}

A casuística desta pesquisa compôs-se de 214 pacientes adultos que fizeram uso de TNE com a faixa etária (Tabela 1) predominante acima de 60 anos $(64,5 \%)$ e média de idade de $64,8(\mathrm{dp}=19,5)$ anos.

Corroborando com a presente investigação, este mesmo resultado foi encontrado em um estudo retrospectivo e descritivo realizado em Córdoba, na Espanha, com 50 pacientes de clínica médica, cuja média de idade foi de 65 anos $^{(10)}$. Em outro estudo, tipo ensaio clínico, com 28 pacientes de uma instituição privada da cidade de São Paulo, foi observado um resultado similar. Nesse trabalho, os autores analisaram os efeitos dos diferentes métodos de infusão para nutrição enteral em pacientes internados em UTI, cuja média de idade foi 64,9 e 69,6 anos aos grupos investigados $^{(15)}$. Da mesma forma, uma pesquisa realizada com 42 pacientes de um hospital no Estado de Santa Catarina, cujo objetivo foi analisar se a dieta prescrita era efetivamente consumida por pacientes que permaneceram em TNE, revelou a mesma tendência, ou seja, a média de idade foi de 64,02 anos $^{(89)}$.

A respeito da importância da idade dos pacientes nesse tipo de abordagem terapêutica, vale acrescentar que pesquisas realizadas no Brasil confirmam o envelhecimento da clientela. Prognosticam, também, que o crescimento da população acima de 65 anos apresentará um potencial crescimento $^{(90)}$ e, provavelmente, representará, aproximadamente, $28 \%$ da população, em $2050^{(91)}$.

No Brasil e em muitos outros países, a população idosa utiliza os serviços hospitalares de maneira mais intensiva que os demais grupos 
etários, originando maiores custos, tratamento mais prolongado e recuperação mais lenta. Como fator complicador, pacientes em faixa etária mais avançada apresentam, com maior frequência, inadequação do estado nutricional. Dessa forma, o fornecimento alimentar a eles deve ser considerado um parâmetro de relevância, como medida profilática à desnutriçao hospitalar. As alterações alimentares em relação aos componentes nutricionais e horários de administração somados à associação de doenças cardíacas, pulmonares e neurológicas são eventos que os deixam mais suscetíveis ao acréscimo de complicações, resultando disso mais intervenções terapêuticas ${ }^{(92)}$.

No que se refere ao sexo (Tabela 2), verificou-se que a maioria dos pacientes era do sexo masculino $(55,6 \%)$ em concordância com outras investigações, que confirmam a predominância de homens em suas amostras $^{(15,93--95)}$. Assim como a faixa etária, o sexo também foi predominantemente semelhante a outros estudos nacionais e internacionais realizados sobre TNE.

De fato, os homens utilizam mais os serviços hospitalares do Sistema Único de Saúde, uma realidade decorrente, provavelmente, da carência de ações dos serviços preventivos destinados a eles na juventude. Assim, em virtude da maior fragilidade conferida pelo envelhecimento, incidem-Ihes outras condições mórbidas responsáveis pelo agravo ainda maior do estado de saúde desse sexo ${ }^{(96)}$.

Além disso, os pacientes do serviço público apresentam uma peculiaridade, que é a baixa renda, dificultando a aquisição de medicamentos tão necessários a essa faixa etária para controle das doenças crônicodegenerativas $^{(97)}$. Esse tipo de comportamento foi semelhante ao encontrado com os pacientes em TNE da instituição, local da pesquisa, cujos pacientes apresentaram idades mais elevadas e, predominantemente, eram do sexo masculino. As doenças crônicas que foram observadas na população estudada também podem estar em concordância com essas características. 
No que diz respeito às unidades de internação (Figura 1), a maioria dos pacientes permaneceram em Semi-Intensiva e UTI (66,8\%), seguida da clínica médica $(28,1 \%)$, o que está em concordância, em relação à proporção, com os achados de um estudo comparativo que teve como objetivo a avaliar as condutas nutricionais em pacientes com TNE de dois hospitais públicos. A maioria dos pacientes (77\%) de um dos hospitais analisados estava internada na UTI e $22 \%$ deles na clínica médica ${ }^{(98)}$. Outras pesquisas também ilustram essa tendência ${ }^{(95,99,100)}$, a despeito de que existam na literatura científica estudos nacionais e internacionais, que realizaram pesquisas com pacientes em TNE internados em unidades clínicas $^{(89,93,101)}$.

Referente às comorbidades (Tabela 3), houve predomínio das pulmonares $(20,1 \%)$ e cardiovasculares $(19,4 \%)$, seguidas das neurológicas $(17,4 \%)$. Em dois estudos, houve concordância com o achado, cujos pacientes eram somente de UTI e com predominância das comorbidades pulmonares, neurológicas e cardiológicas ${ }^{(100,102)}$. Entretanto, diferiu de outro estudo, que analisou 205 pacientes em TNE sob ventilação mecânica, em que as comorbidades neurológicas (16\%) e pulmonares (15\%) predominaram, e as cardiovasculares foram verificadas em apenas $4 \%$ dos pacientes $^{(81)}$.

A Associação de Medicina Intensiva Brasileira (AMIB) ${ }^{(103)}$ cita que as causas de admissão mais frequentes nas UTIs brasileiras são as doenças cardiovasculares e respiratórias, em concordância com o l Consenso Brasileiro de Nutrição e Disfagia em Idosos Hospitalizados, no qual consta que as doenças pulmonares são responsáveis por cerca de 55\% das internações hospitalares de pacientes idosos e, dentre as mais prevalentes, estão as cardiovasculares, que agravam a morbidade e mortalidade ${ }^{(104)}$.

Quanto ao tipo de tratamento, $68,7 \%$ dos pacientes foram submetidos a tratamento clínico, resultado proporcionalmente similar ao encontrado em um estudo do tipo ensaio clínico, no qual $63 \%$ de 125 pacientes críticos em TNE com alto VRG receberam tratamento clínico ${ }^{(94)}$. 
Acredita-se que, frente ao apresentado pelos autores descritos anteriormente e ao encontrado neste estudo, a existência de doenças crônicas preexistentes somadas aos diversos fatores de risco, como a idade elevada, uso de terapia farmacológia e ventilatória podem agravar as condições clínicas do doente e contribuir para ocorrência de diversas complicações. Muitas vezes, a piora da condição clínica do paciente exige o uso de ventilação mecânica e drogas para seu restabelecimento. Entretanto, os efeitos adversos dessas terapias podem propiciar complicações. No presente estudo, a ventilação mecânica (Figura 2) foi observada em 45,3\% dos pacientes, enquanto os antibióticos $(33,7 \%)$ e sedativos/opioides $(24,2 \%)$, (Tabela 4$)$, também foram administrados na maior parte deles.

No estudo que analisou 205 pacientes em ventilação mecânica sob TNE, a antioticoterapia foi utilizada em todos os doentes, enquanto os sedativos opioides foram usados somente em 35\% deles. Os antibióticos não foram considerados como potenciais fatores de risco para esses pacientes, pois eles têm um papel importante no tratamento de pacientes sob ventilação invasiva. Entretanto, quando associados às múltiplas drogas podem potencializar prejuízos ao organismo ${ }^{(81)}$, mas o objetivo do estudo não contemplou essa variável.

Em pacientes sob ventilação mecânica, a TNE deve ser estabelecida precocemente, com a finalidade de se evitar efeitos colaterais como a inanição clínica, atrofia dos músculos respiratórios, redução de proteína sérica e a imunidade celular, além de comprometer a oxigenação celular. No intuito de manter o paciente ventilado mecanicamente, o uso de sedativos e drogas vasoativas e inotrópicas são instituídos em alguns casos. Mas, podem ocorrer prejuízos em decorrência dos efeitos adversos desses medicamentos, dentre eles, a alteração do fluxo e da perfusão vascular periférica afetando adversamente a motilidade gastrointestinal e o esvaziamento gástrico ${ }^{(36,39)}$.

O tempo de internação hospitalar dos pacientes em TNE teve uma média de 23,8 dias. Resultado semelhante foi observado em um estudo 
prospectivo randomizado que analisou comparativamente 164 pacientes em TNE para avaliar o alcance da meta nutricional de pacientes vítimas de trauma admitidos em UTI nos EUA, cujo tempo médio verificado foi de 21,2 e 20,1 dias entre os grupos investigados, de acordo com o método de infusão da dieta ${ }^{(99)}$. Diferindo desses resultados, os pacientes submetidos à TNE em uma unidade clínica apresentaram o tempo médio de 6 dias $^{(10)}$.

\subsection{Caracterização da terapia nutricional enteral}

A TNE faz parte da rotina de tratamento de pacientes hospitalizados que estão impossibilitados de utilizar a via oral para se alimentar, sobretudo, em unidades de cuidados intensivos e semi-intensivos. No presente estudo, o tempo médio da TNE foi de 13,2 dias. Em um estudo prospectivo observacional com 116 pacientes e duração de 4 anos, identificou que, a média foi de 12,5 dias, muito próxima à da presente pesquisa $^{(100)}$.

$\mathrm{Na}$ totalidade dos pacientes, 93 (43,5\%) receberam a nutrição por até 7 dias (Tabela 5). Esta alta proporção induz à sugestão de que uma parcela desses doentes pode não ter entrado no regime de TNE com previsão mínima de 5 a 7 dias, recomendadas por alguns serviços ${ }^{(6,19)}$.

Em relação ao tipo de via de acesso enteral (Figura 3), a sonda nasoenteral foi predominante em $96,3 \%$ dos pacientes. Semelhante resultado foi observado em um estudo prospectivo com 42 pacientes em um hospital de grande porte, no qual $95 \%$ deles fizeram uso da $\mathrm{SNE}^{(89)}$.

Segundo "Guideline" de terapia nutricional ${ }^{(27)}$, o período da TNE pode ser classificado em curto e longo prazo. $\mathrm{O}$ curto prazo é considerado até 4 semanas e, o longo prazo, acima deste período. Em geral, a TNE de curto prazo é realizada por meio de SNE para diminuir o índice de complicações. Já as ostomias são indicadas para TNE à longo prazo, por permitirem maior tempo de permanência da TNE e minimizarem os riscos 
inerentes ao uso prolongado de SNE, tais como: lesão nasal, risco de aspiração e estresse psicológico com prejuizo da autoimagem. A Agência Nacional de Vigilância Sanitária (ANVISA) define TNE de longo prazo, como a manutenção do estado nutricional normal e de reabilitação de pacientes em termos de recuperação física e social ${ }^{(20)}$.

A estimativa de tempo prolongado da TNE é um fator determinante da escolha da gastrostomia, em pacientes que estejam impedidos em ingerir a alimentação por via oral, seja ela pela dificuldade de deglutição, doenças neurológicas, neurovegetativas, neoplasias, traumas e disfagias $^{(43)}$. Dessa forma, acredita-se que a pouca utilização das gastrostomias no presente estudo pode ser justificada pelo tempo médio de TNE de 13,2 dias.

\subsection{Complicação gastrointestinal e eventos observados}

As complicações selecionadas para o estudo foram as mais frequentes descritas na literatura ${ }^{(2,13)}$ e foram identificadas pela ocorrência de 15 tipos de eventos observados que as caracterizaram. Além do que verificou-se que os pacientes sofreram mais de um tipo de evento diferente (Tabela 9), sendo em média de 3 por paciente. Assim, apesar dos comprovados benefícios da terapia nutricional enteral, a ocorrência de complicações é possível e deve ser criteriosamente observada e controlada, por poder ocasionar intolerância alimentar e interferir negativamente na recuperação do doente, aumentar o tempo de internação e os custos hospitalares $^{(50)}$.

Dessa forma, frente à avaliação retrospectiva das informações contidas em prontuários, identificou-se que as complicações acometeram $200(93,5 \%)$ pacientes. Pela análise de associação entre os quatro tipos de complicações verificou-se que não houve evidências de relação absoluta para ocorrência entre elas. 
A complicação gastrointestinal foi a mais observada (Figura 4), em $181(90,5 \%)$ dos pacientes que apresentaram um total de 377 eventos observados (Tabela 10). Em concordância com a proporcionalidade, em um estudo prospectivo com 60 pacientes em TNE, a complicação gastrointestinal ocorreu em $51 \%$ dos casos. Admite-se que essa complicação seja desenvolvida em decorrência da alteração da motilidade gastroduodenal e, em pacientes graves, é inerente às condições clínicas. $O$ índice de utilização da TNE é considerado alto nessas unidades e seu gerenciamento é complexo pela à instabilidade clínica e intervenções medicamentosas, que esses pacientes são submetidos, limitando em algumas situações, a tolerância da dieta enteral ${ }^{(105)}$.

Em pesquisa com pacientes de clínica médica de um hospital público do Rio Grande do Sul, a complicação gastrointestinal ocorreu em $17 \%$ de 22 pacientes internados submetidos à nutrição enteral ${ }^{(101)}$. Outro estudo, que teve como objetivo identificar a complicação gastrointestinal em uma população de 262 pacientes em TNE, observou que 29\% deles apresentaram essa complicação, com presença de constipação, diarreia, retorno gástrico e vômito; concluiu que essa ocorrência não levou a inadequação da oferta nutricional enteral ${ }^{(106)}$.

Entre os eventos observados nessa complicação, a presença de distensão abdominal tem sido relatada como uma das mais frequentes ${ }^{(13)} \mathrm{e}$, em qualquer caso, é um sinal de alerta da incapacidade do tubo digestivo em processar os substratos. Nesses casos, faz-se obrigatório avaliar o paciente e a possível suspensão da dieta e restituí-la precocemente, após descartar alterações significativas ${ }^{(45)}$. Esse tipo de complicação, quando associado ao uso da nutrição enteral, geralmente, é decorrente da má absorção de nutrientes, administração rápida de fórmulas resfriadas e administração de grandes volumes em períodos curtos ${ }^{(13)}$.

Por outro lado, tendo em vista a diversidade de complicações e dos seus eventos observados, torna-se fundamental identificá-las, além de conhecer sua prevalência para o melhor gerenciamento das possíveis 
causas. Assim, neste estudo, verificou-se nos pacientes com complicação gastrointestinal que a distensão abdominal foi o evento mais frequente ocorrendo em $33,4 \%$ dos pacientes (Tabela 10). Uma pesquisa que acompanhou a TNE em 18 pacientes em pós operatório de cirurgia colorretal, identificou que a distensão abdominal ocorreu em $88 \%$ dos casos e, destes, $4 \%$ apresentaram náusea e $22 \%$, vômito ${ }^{(107)}$. Um estudo que teve a finalidade de avaliar as complicações decorrentes de nutrição enteral em 64 pacientes cardiopatas mostrou que $29 \%$ deles evoluíram com distensão abdominal associada ao vômito em $11 \%$ dos casos e concluiu que essas ocorrências contribuíram para o não benefício do suporte enteral ${ }^{(44)}$.

A distensão abdominal foi a segunda mais frequente em $9(32 \%)$ dos 28 pacientes analisados, em um estudo tipo ensaio clínico que investigou os benefícios dos métodos de infusão, e, em 5 casos a administração da nutriçao enteral era intermitente, porém esta ocorrência não determinou a suspensão da nutrição. A autora conclui que a causa mais provável foi o gotejamento da dieta ${ }^{(15)}$.

A redução da velocidade da nutrição enteral pode ser necessária em pacientes graves em consequência da própria evolução clínica, porque estes podem apresentar disfunções gastrointestinais, como a distensão abdominal, redução dos ruídos hidroaéreos ou náuseas, levando ao aumento de resíduo gástrico e intolerância alimentar ${ }^{(1)}$.

Neste estudo, o método infusão contínua foi utilizado na maioria dos pacientes (Tabela 6) inclusive nos que apresentaram complicação gastrointestinal como a distensão abdominal. Entretanto, cabe ressaltar que para verificar a eficácia deste método frente o controle das complicações seria necessário investigar outros aspectos que podem ter interferido diretamente nesse quadro, como a hemodinâmica do paciente e a formulação enteral.

A constipação (Tabela 10) foi a segunda mais frequente $(17,5 \%)$ dos eventos observados na complicação gastrointestinal. Pesquisa realizada para avaliar complicação gastrointestinal em 77 pacientes internados em UTI 
que receberam TNE, verificou que essa complicação ocorreu em todos os pacientes, sendo a constipação a mais frequente $(36 \%)$. Os autores concluíram que, embora tenha ocorrido alta prevalência dessa complicação na população, esta não foi acompanhada de inadequação da oferta nutricional $^{(106)}$.

A constipação é comumente identificada nos pacientes hospitalizados, sobretudo naqueles que são limitados ao leito, que fazem uso de sedativos opioides, dentre outros medicamentos que alteram a motilidade gastrointestinal. Sua incidência é bastante variável e isto pode estar atribuído à carência de uma definição específica adotada entre os profissionais das diversas instituições hospitalares para avaliar esse quadro ${ }^{(52)}$.

O desenvolvimento de gastroparesia e ileoparesia pode caracterizar esse quadro e prejudicar a progressão do suporte nutricional. Isso pode dificultar a meta nutricional estimada pela via enteral e piorar o prognóstico ${ }^{(52)}$. O uso de dietas com baixa quantidade de resíduos e a inatividade dos pacientes são considerados fatores que reduzem o número de evacuações ${ }^{(108)}$.

Em UTI, os pacientes são identificados como os de alto risco para constipação em decorrência do estado de choque que causa hipoperfusão esplênica e distúrbio hidroeletrolítico. Além disso, drogas usadas para analgesia, como os opiodes, promovem a diminuição do fluxo sanguíneo, perfusão e motilidade intestinal. Um estudo comparativo e prospectivo demonstrou que, dos 106 pacientes analisados, 68\% apresentaram constipação e, destes, a TNE foi utilizada em 19\% dos casos, demonstrando ter sido um fator protetor, pois diminuiu a incidência de constipação em relação ao total de pacientes. Outros aspectos observados nos pacientes constipados foi o uso de antibioticoterapia (75\%), sedativos opioides (64\%) e ventilação mecânica (72\%). Em relação à mortalidade hospitalar (63\%) e na UTI $(72 \%)$, a maior incidência foi encontrada nos pacientes constipados ${ }^{(54)}$. Mesmo sendo complicação comumente observada, sabe-se que ela age 
negativamente no prognóstico e sobrevida dos pacientes, porém é possível concluir que exista um fator causal relacionado diretamente a essa complicação ${ }^{(36,53)}$.

O alto VRG é comumente observado em pacientes em uso da TNE com complicação gastrointestinal e, no presente estudo, ocorreu em $14,6 \%$ dos casos (Tabela 10). A ocorrência é referida em outros estudos. Uma pesquisa vinculada a esse quesito com pacientes de UTI e teve por objetivos analisar os efeitos da infusão contínua e intermitente para TNE, identificou que $46 \%$ dos pacientes tiveram VRG, e este foi um dos motivos que determinou a suspensão da dieta ${ }^{(15)}$. Dos 37 pacientes que fizeram parte de um estudo retrospectivo, que avaliou a relação do volume prescrito versus administrado, o VRG foi observado em $40 \%$ dos casos, constituindo um dos eventos que dificultou o alcance da meta nutricional ${ }^{(109)}$. Um estudo prospectivo controlado com pacientes com traumatismo crânioencefálico que receberam TNE, cujo objetivo foi avaliar os resultados do uso de prócinético, verificou que $36 \%$ dos doentes apresentaram alto VRG e concluiu que o uso do medicamento foi adequado, considerando os benefícios apresentados durante sua recuperação dos mesmos ${ }^{(110)}$.

Embora os volumes de referência adotados como parâmetro para mensuração do VRG apresentem variabilidade na literatura (150 a $400 \mathrm{ml})^{(15,109,110)}$, pesquisas mostram que essa ocorrência é um agravante, pois pode acarretar a aspiração brônquica e, consequentemente, Pneumonia Aspirativa, interferindo negativamente na evolução do paciente ${ }^{(15,50,110)}$. No presente estudo, o volume médio de VRG observado foi de 703,1ml. Autores demonstram que volumes acima de $200 \mathrm{ml}$ são marcadores de alerta para potenciais complicações graves ${ }^{(67,94)}$.

A mensuração do VRG é necessária e sua verificação deve ser realizada ao menos a cada 4 a 6 horas para o monitoramento de intolerância e maiores complicações como a gastroparesia que predispôe a aspiração pulmonar em pacientes que apresentam a aspiração pulmonar ${ }^{(111)}$. 
O aumento do VRG é um determinante para maiores complicações. Portanto, o resíduo gástrico precisa ser monitorado criteriosamente, a partir do momento em que a nutrição enteral é instalada. Vale ainda ressaltar que a conduta deve ser mantida e a avaliação desses volumes deve ser realizada em conjunto com outros parâmetros de função instestinal e adequação da fórmula enteral.

O tipo de monitoramento para o controle do VRG utilizado na instituição sede não fez parte do objetivo do estudo. Entretando, observouse que este era realizado com maior frequência na UTI e Semi-Intensiva. A experiência clínica mostra que a falta de definição do que seja realmente um alto volume residual gástrico, além de seu aspecto, pode limitar a avaliação dessa complicação e determinar uma conduta inadequada. Mesmo com ressalvas, esses parâmetros devem ser devidamente registrados, para que haja compreensão e a devida avaliação entre os profissionais que monitoram a TNE.

Neste estudo, o refluxo ocorreu em $6,1 \%$ dos pacientes analisados (Tabela 10). Uma pesquisa que acompanhou 16 pacientes portadores de doenças crônicas associadas aos quadros de disfagia e desnutrição, identificou a ocorrência de retardo do esvaziamento gástrico e vômitos em $37 \%$ dos casos. O estudo enfatiza que é uma ocorrência de desordem comum e de difícil controle e revela que a prática da mensuração pode prevenir maiores complicações, inclusive, as Pneumonias Aspirativas que são recorrentes, independente do período do dia que o paciente recebe a dieta ou do método de infusão(112). A administração contínua da nutrição enteral induz a menor refluxo gastroesofageano, mas pode aumentar a incidência de colonização gástrica e pneumonia por aspiração ${ }^{(44)}$. No presente estudo, a utilização do método de infusão da dieta enteral não demonstrou ser eficaz para o controle dessa complicação (Tabela 16).

A ocorrência de refluxo e alto VRG alerta para complicações maiores. Assim, o controle da cabeceira e decúbito do paciente e o posicionamento da sonda são intervenções, que devem ser criteriosamente 
acompanhadas. Um protocolo para o controle de volume é necessário para direcionar o momento de descarte ou reintrodução do $\mathrm{VRG}^{(94)}$, além da pausa alimentar em algumas situações ${ }^{(15)}$. Estas medidas visam a contribuir para o melhor aproveitamento da oferta nutricional e gerenciamento de potenciais complicações.

Um "Guideline" sobre TNE para pacientes adultos hospitalizados afirma que o refluxo e o alto VRG são comuns nos pacientes que fazem uso dessa terapia, especialmente, quando permanecem em posição supina que predispõe ao retorno do conteúdo gástrico em decorrência da presença da sonda enteral que estimula a diminuição da função do esfíncter gastroesofágico. Em relação ao decúbito, este deve permanecer em $30^{\circ}$ ou mais para minimizar os riscos de aspiração pulmonar. A administração da nutrição enteral pelo método contínuo é um outro aspecto importante a ser considerado pois, embora forneça um volume menor e mais lento, é utilizado frequentemente no período noturno, o que prejudica a acidificação gástrica proporcionando a colonização bacteriana e migração esofágica. Já o posicionamento pós-pilórico da sonda enteral diminui os riscos para essas complicações, porém não elimina o problema ${ }^{(67)}$.

A diarreia em pacientes com TNE é considerada o evento mais frequente da complicação gastrointestinal em diversos estudos nacionais $(8,15,44,95,109,115,116)$ e internacionais ${ }^{(50,67,71,99,110,113,114,117-122)}$. No presente estudo, a ocorrência de diarreia foi observada em 13,0\% dos pacientes (Tabela 10), diferindo do encontrado na literatura. Um estudo prospectivo controlado que objetivou acompanhar as possíveis consequências aos pacientes com TNE a longo prazo por gastrostomia, demonstrou que a diarreia foi mais elevada no grupo que recebeu antibótico $(p=0,32)^{(114)}$. Em outra pesquisa com pacientes submetidos ao controle do VRG, a diarreia foi observada em $38 \%$ desses pacientes internados na UTI ${ }^{(93)}$.

Embora a diarreia seja referida nos estudos, como um evento gastrointestinal da TNE, segundo um estudo a esse respeito, em apenas $20 \%$ dos casos a nutrição enteral foi, de fato, responsável por essa 
ocorrência. Em 61\%, a causa principal foi a reação medicamentosa e em $17 \%$, a infecção por Clostridium Difficile ${ }^{(123)}$.

Para o presente estudo não houve problema para entender o que seria diarreia, pois, na instituição, essa definição é padronizada nos impressos de controles de ingesta e eliminações fisiológicas, usados pela equipe de enfermagem, facilitando a leitura dessa informação. Entretanto, na prática clínica, é notório que os profissionais não sabem distinguir a diferença entre os episódios de fezes líquidas e a diarreia, e essa interpretação é transcrita para os registros. É um aspecto que deve ser trabalhado intensamente com os profissionais de saúde, sobretudo, com a equipe de enfermagem. Ademais, é importante ressaltar ser fundamental diferenciar a diarreia provocada pelo uso da nutrição enteral das terapêuticas usuais que alteram a motilidade gastrointestinal. A falta de esclarecimentos pode sugerir ações e condutas inadequadas como a suspensão da dieta sem maiores investigações do real problema.

Vômito (8,2\%), dor abdominal (4,8\%) e náusea (2,4\%) foram eventos menos frequentes no presente estudo (Tabela 10).

O vômito em pacientes com TNE é largamente referido na literatura ${ }^{(8,15,44,94,107,110,114,116,118,119,122)}$. Dentre as principais razões atribuídas pelos respectivos autores, destacam-se a gravidade e o uso de agentes medicamentosos que diminuem a motilidade gastrointestinal. A ocorrência de vômito está, geralmente, relacionada a outros eventos gastrointestinais, como a intolerância alimentar, náusea, refluxo, VRG, distensão abdominal, constipação e diarreia.

Uma pesquisa que analisou pacientes sob ventilação mecânica, observou que o vômito e o VRG levaram à interrupção da nutrição enteral, e a posição dos pacientes no leito favoreceu essa ocorrência: a posição em prona propiciou mais eventos $(82 \%)$ frente à supina $(49 \%)$. Tal resultado salienta a necessidade do uso de pró-cinéticos e do posicionamento da sonda transpilórica nos pacientes em posição prona ${ }^{(124)}$. Em um estudo 
japonês, dois dos 140 pacientes disfágicos, que utilizaram gastrostomia, apresentaram aspiração pulmonar sendo o vômito a principal razão ${ }^{(125)}$.

A dor abdominal, ocorrida em $4,8 \%$ dos pacientes desta pesquisa (Tabela 10), também foi observada em um estudo comparativo com pacientes de clínica médica, que avaliou os efeitos adversos à ingestão de suplementos nutricionais em relação à nutrição enteral, e seis (30\%) dos 20 pacientes com TNE tiveram dores abdominais. Além disso, $45 \%$ dos pacientes apresentaram também diarreia e $10 \%$ náuseas e vômitos. Ainda assim os autores concluem que, embora os pacientes que receberam suplementação, tiveram menos efeitos adversos em relação aos com nutrição enteral, estes apresentaram parâmetros antropométricos desfavoráveis para a intervenção. Tais resultados podem estar atribuídos à doença de base, erros de avaliações antropométricas ou a formulação alimentar utilizada, em razão da relutância dos profissionais em iniciar precocemente a nutrição enteral, mesmo que os suplementos nutricionais, em muitas situações, sejam ineficazes para melhorar o estado nutricional dos pacientes hospitalizados ${ }^{(115)}$.

Referente à náusea ocorrida na minoria dos pacientes $(2,4 \%$ Tabela 10), acredita-se que, possívelmente, mais pacientes tiveram esse sintoma, visto a dimensão dos eventos observados na complicação gastrointestinal verificada nos pacientes do presente estudo. No entanto, os resultados referentes à náusea tornam-se aceitáveis, pois o sintoma é de difícil interpretação para aqueles que prestam assistência aos pacientes, sobretudo naqueles impossibilitados de se comunicar, como os intubados. Considerando que este é um estudo retrospectivo, os registros correspondentes ao quadro ficam limitados pela falta de parâmetros claros que a diagnostique. 


\subsection{Complicação metabólica e evento observado}

A complicação metabólica é decorrente da resposta ao estresse, tornando o paciente mais suscetível à infecção ${ }^{(44)}$. Por essa razão, este é um fator de risco que contribui para um agravo clínico, como desequilíbrio ácidobásico, aumento da resistência a medicamentos ${ }^{(50)}$ e impossibilidade de fornecer adequado aporte nutricional ao doente ${ }^{(102)}$.

Pacientes não diabéticos apresentam hiperglicemia pelo aumento dos níveis de hormônios contrarregulatórios e citocinas em decorrência do estresse metabólico. A hiperglicemia pode ser um sinal de infecção ou inflamação, pelo uso de medicamentos imunossupressores, corticosteróides, agentes anestésicos e sedativos comumente utilizados em UTI, ou decorrentes da provisão excessiva de calorias nos casos de suporte nutricional enteral e parenteral ${ }^{(126)}$.

A TNE pode causar uma variedade de problemas metabólicos pelas ofertas deficientes ou excessos de fluidos, eletrólitos, vitaminas e oligoelementos. Entre $10 \%$ a $30 \%$ dos pacientes submetidos à TNE, apresentam hiperglicemia e podem precisar de agentes antiglicemiantes ou insulinoterapia antes ou durante a terapia nutricional. Nesses casos, deve-se atentar, para que a nutrição enteral não seja interrompida radicalmente e ocasione hipoglicemia, sobretudo nos pacientes que já são dependentes de agentes antiglicemiantes $^{(67)}$.

A hiperglicemia por não ser diretamente relacionada à intolerância alimentar, muitas vezes, é sub-relatada ${ }^{(50)}$. No presente estudo, a hiperglicemia ocorrida em $55,0 \%$ dos casos (Figura 4) teve um valor médio de $174,19 \mathrm{mg} / \mathrm{dL}$, e o mínimo observado foi de $147 \mathrm{mg} / \mathrm{dL}$. Ao acompanhar a complicação gastrointestinal em 132 pacientes com TNE, verificou-se que $34 \%$ deles apresentaram hiperglicemia associada com diarreia e constipação, mas não foi encontrada relação com a formulação enteral (com ou sem fibra, normo ou hipercalórica) utilizada. Os autores recomendam que 
o controle da glicemia capilar faça parte do plano de cuidado básico da enfermagem que presta assistência aos pacientes em $\operatorname{TNE}^{(108)}$.

Alguns autores vêm investigando a influência da hiperglicemia no desenvolvimento de refluxo e alto VRG, pois exerce uma função importante na diminuição da motilidade gastrointestinal, gerando retardo do esvaziamento gástrico. Por essa razão, recomenda-se o gerenciamento dessa complicação, por meio do controle frequente de glicemia nos pacientes críticos $^{(94)}$. Este fato foi investigado e descrito em uma revisão sistemática e de metanálise revelou que o controle do nível glicêmico $<110 \mathrm{mg} / \mathrm{dL}$ mostrou-se ser um fator redutor de morbidade e mortalidade nos pacientes cirúrgicos, não diabéticos submetidos à insulinoterapia na $\mathrm{UTI}^{(127)}$. Outra pesquisa revelou que valores de níveis glicêmicos $>150 \mathrm{mg} / \mathrm{dL}$ estiveram associados à elevada mortalidade nos pacientes internados na UTI ${ }^{(65)}$.

Portanto, o desenvolvimento da hiperglicemia não resulta do uso da nutrição enteral, mas, sim, das doenças de base do paciente ou da instabilidade hemodinâmica apresentada. Mesmo não tendo por objetivo analisar os aspectos clínicos, nota-se que sua ocorrência foi muito elevada $(55,0 \%)$ do que no descrito na literatura científica ${ }^{(67)}$. Acredita-se que a ocorrência de hiperglicemia nos pacientes do presente estudo teve origens diversas, pois, a maior parte deles manteve-se internada nas unidades de cuidados intensivos e semi-intensivos sob ventilação mecânica, apresentou doenças crônicas e recebeu drogas que propiciam reações adversas ao organismo, conforme descritas anteriormente.

\subsection{Complicação mecânica e eventos observados}

A complicação mecânica apresentou 105 eventos, constituindo-se na segunda complicação que apresentou o maior número de eventos observados (Tabela 11). Um total de $83(41,5 \%)$ pacientes foi vitimado por essa complicação (Figura 4). 
Em um estudo retrospectivo, 11\% dos 37 pacientes internados em UTI tiveram complicação mecânica, que esteve associada a diferentes fatores que interferiram na administração correta da nutrição enteral e limitaram o alcance da meta nutricional ${ }^{(109)}$. Conclusão semelhante foi demonstrada em um estudo de coorte prospectivo com 78 pacientes, na qual a complicação mecânica ocorreu em $12 \%$ dos casos, promovendo atraso importante no reinício da TNE. O estudo também concluiu que, em muitos casos, essas complicações eram evitáveis ${ }^{(128)}$.

A saída não programada da sonda enteral, que ocorreu com considerável frequência neste estudo (Tabela 11), também foi identificada em pesquisa que analisou pacientes cardiopatas, dos quais $29 \%$ perderam a sonda acidentalmente ${ }^{(44)}$. Por meio de indicadores de qualidade, as saídas acidentais das sondas foram acompanhadas em pacientes de UTI e verificou que esta teve uma incidência que variou de 0,13\% a 0,22\%. Concluindo que a baixa taxa de notificação pode estar relacionada somente à contabilização daquelas saídas em que a repassagem da sonda foi necessária ${ }^{(100)}$. Em um estudo prospectivo no qual pesquisadores acompanharam por 2 anos pacientes internados em UTI, foi observado que a saída não programada da sonda aumentou consideravelmente de $5 \%$ para $21 \%$. O achado esteve associado a períodos que corresponderam antes e após a implantação de um protocolo de TNE e conclui-se que o aumento dessa complicação mecânica pode ser justificado pelo uso de sonda de baixa qualidade utilizado no mês seguinte à implantação do protocolo ${ }^{(102)}$. Em $27 \%$ de 228 pacientes, a saída acidental da sonda enteral associou-se estatisticamente com a idade dos pacientes, sendo mais frequente naqueles com idade inferior a 50 $\operatorname{anos}^{(129)}$.

Situação semelhante foi encontrada em pacientes internados em UTI onde o deslocamento da sonda enteral ocorreu em $25 \%$ deles, e $7 \%$ ocorreram pela retirada pelo próprio paciente e, em apenas $3 \%$, resultaram na suspensão da dieta ${ }^{(15)}$. 
Uma investigação sobre a adequação da nutrição enteral, complicação e satisfação de pacientes oncológicos, observou-se que os deslocamentos das sondas, seguidos das saídas acidentais ocorreram em 12 dos 18 pacientes com SNE e em nove dos 15 pacientes com gastrostomia. Embora os deslocamentos tenham ocorrido com maior frequência naqueles com SNE, não houve diferença em relação às condições clínicas e qualidade de vida entre os pacientes. Quanto à adequação nutricional, também não houve diferença entre os grupos, porém os custos dos pacientes com gastrostomias foram mais elevados ${ }^{(130)}$. A perda de gastrostomia pode ocorrer em $46 \%$ dos casos em geral. Entretanto, podem ser minimizadas com a colocação de botons e supervisão periódica do tubo ${ }^{(31)}$. No presente estudo, o deslocamento foi observado em 5 (4,8\%) dos casos (Tabela 11), resultado inferior ao encontrado na literatura.

O deslocamento da sonda enteral é caracterizado por sua manipulação direta em razão dos procedimentos ou agitação do paciente. Dentre as causas que favorecem este evento, estão a fixação inadequada da sonda, tosse e vômito, aspiração oro/nasotraqueal ${ }^{(73)}$. Por essa razão, é recomendado o controle radiológico do posicionamento da sonda, após sua passagem $^{(27)}$, sempre que se execute uma extubação traqueal, além de ter como parâmetro a demarcação da sonda na porção externa da narina para facilitar a avaliação ${ }^{(73)}$.

Estudo retrospectivo, publicado em 2004, fundamentado em registros de sondas que foram passadas entre 2000 e 2003, verificou-se que, dos 87 de 683 pacientes, a SNE foi locada nos brônquios e em nove deles, o posicionamento resultou em pneumotórax. A presença da SNE já é um fator de risco para deslocamento, e este aumenta, consideravelmente, o de pneumotórax, pois a ponta da sonda apresenta rigidez suficiente para perfurar o pulmão. Os autores ainda acrescentaram que $32 \%$ dos 87 pacientes tiveram mais de um deslocamento da sonda e identificaram que a chance de pneumotórax foi de $5 \%$ para $36 \%$ naqueles pacientes com mais de três deslocamentos. Os autores concluíram que os deslocamentos das sondas são mais prováveis no período noturno (16\%) do que de dia (4\%) e 
pela ocorrência frequente de deslocamentos o controle por meio de radiografias é necessário, além dos registros precisos em relação à mensuração do posicionamento sonda enteral ${ }^{(131)}$.

A mobilização da sonda enteral que resulta na saída não programada, é um evento comum na prática clínica, porém é subnotificado dificultando a avaliação das reais consequências desse fato. A falha da notificação pode ser decorrente do medo da possível punição ou pela falta de perceber a importância do fato. A realidade deve ser mudada com intenso treinamento de pessoal e utilização de indicadores de qualidade que permitam avaliar os resultados inadequados e compará-los com os achados de outras instituições.

A obstrução da SNE correspondeu a 19,0\% (20 casos) dos eventos observados na complicação mecânica no presente estudo (Tabela 11), não se assemelhou aos resultados encontrados no estudo que analisou as complicações durante a vigência da TNE em pacientes internados em UTI, no qual a obstrução ocorreu em apenas um caso, sendo resolvida prontamente sem suspender a nutrição enteral ${ }^{(15)}$. O mesmo evento, ocorrido em $10 \%$ dos 42 pacientes em TNE contribuiu para o atrazo da oferta enteral em um estudo que objetivou identificar se a dieta enteral prescrita era de fato infundida ${ }^{(89)}$.

Muitas vezes, a causa da obstrução da sonda enteral é desconhecida. Entretanto, acredita-se que o evento seja provocado pela elevada quantidade de medicamentos, que é administrada ao mesmo tempo, baixa infusão da nutrição enteral, interação medicamentosa ${ }^{(1)}$ e técnica ineficiente de irrigação ${ }^{(15,75)}$. Além disso, admite-se que a obstrução pode estar relacionada ao acúmulo de resíduos da fórmula enteral e gástrico no lúmen da sonda, em decorrência da alta osmolaridade ou aspiração do conteúdo gástrico ou enteral ${ }^{(15,44)}$; a formação de complexos insolúveis de fórmula-medicamento; a maceração inadequada de comprimidos injetados pela sonda e a precipitação da fórmula em razão da acidez do conteúdo gástrico $^{(1,70)}$. 
A habilidade em desobstruir a sonda evita situações de saídas não programadas. A maior pressão conferida por uma seringa de menor calibre facilita a desobstrução, por deslocar o conteúdo oclusor restaurando a permeabilidade do lúmen da sonda. Os movimentos bruscos não devem ser realizados, a fim de evitar risco de rompimento da sonda ${ }^{(15)}$.

A oclusão da sonda enteral pode interromper a terapia nutricional, como a administração dos medicamentos prescritos por essa via. Cada medicamento, devidamente diluído, deve ser administrado separadamente para evitar possíveis interações e oclusão, impedindo que a TNE seja interrompida por motivos considerados evitáveis ${ }^{(24,30)}$. O melhor método e periodicidade para irrigação da sonda enteral também necessita ser avaliado a cada mudança na prescrição.

A prescrição de medicamentos pela sonda de alimentação requer cuidados, para que o medicamento atinja sua finalidade, tais como: o posicionamento da sonda, considerando onde ocorrerá a ação do medicamento; efeitos fármacos-nutrientes, para planejar os intervalos e evitar risco de precipitações e obstruções, trituração permitida para o medicamento e administração individual, além da irrigação da sonda enteral com água (20 a $30 \mathrm{~mL}$ ) para manter sua permeabilidade. Essas regras simples evitam problemas e fazem parte de uma boa prática clínica ${ }^{(132)}$.

Além disso, a repassagem de uma nova sonda implica desconforto para o paciente, risco de posicionamento acidental no trato respiratório e custos adicionais, envolvendo materiais e exames radiológicos $^{(75)}$. Cada vez que é necessária a repassagem da sonda, 0 paciente é submetido ao prolongado período de jejum, além de ficar impossibilitado de receber medicamentos por esta via de acesso, favorecendo sua baixa oferta nutricional e, conseqüente, prejuízo a seu restabelecimento.

Embora haja uma vasta literatura abordando a incompatibilidade e a obstrução da sonda enteral, é imprescindível o desenvolvimento de pesquisas sobre esse fato que envolve o nível de conhecimento dos 
profissionais sobre essa ocorrência. Vale lembrar que essa via de acesso é muito utilizada como primeira opção em pacientes hospitalizados, por diversos fatores, dentre eles, o menor risco de infecção.

A implementação de protocolos para os cuidados com a sonda e administração da dieta e medicamentos é fundamental para possibilitar menores riscos e maior êxito do suporte nutricional prescrito.

Referente à infecção perigastrostomia que foi verificada em cinco casos (Tabela 11) no presente estudo, correspondendo a uma minoria $(4,8 \%)$ entre os eventos observados na complicação mecânica. A literatura revela incidência dessa complicação entre $2 \%$ e $67 \%{ }^{(79,125,130,133-136)}$.

Um estudo retrospectivo realizado, cujo objetivo foi avaliar a reabilitação de pacientes submetidos à gastrostomia, identificou que quatro dos 193 pacientes que possuíam tal via evoluíram com infecção periestoma, necessitando de tratamento clínico intra-hospitalar ${ }^{(133)}$. Outra pesquisa, com 80 pacientes crônicos com disfagia, analisou duas diferentes técnicas para realização de gastrostomia e observou que a infecção ocorreu em cinco pacientes 3 dias após a colocação do tubo, e a maior parte deles foi submetida à técnica que evidenciaria menores riscos ${ }^{(134)}$. Os autores de um estudo comparativo verificaram a presença dessa complicação em $27 \%$ dos pacientes, com culturas positivas. Entretanto sugeriram que, para a confirmação das reais causas da infecção, devem ser realizados exames clínicos $^{(130)}$.

No presente estudo, não foram identificadas as técnicas utilizadas para realização das gastrostomias nem 0 motivo que levou ao desenvolvimento das infecções. Vale salientar que os autores citados anteriormente utilizaram, em suas pesquisas, tanto a técnica de gastrostomia percutânea endoscópica como outras, cujos resultados das complicações não diferiram muito entre eles.

A literatura demonstra que a gastrostomia endoscópica percutânea submete o paciente a menores riscos, porém não é isenta de 
complicações. São divididas em menores e ocorrem entre $7 \%$ a $10 \%$ dos casos, na qual a infecção local é a mais comum. As maiores e mais raras ocorrem entre $1 \%$ a $2 \%$ como a Pneumonia Aspirativa que pode acarretar a morte ${ }^{(31)}$. Essas infecções podem ser causadas por lesões e/ou higienização inadequada. Outros problemas comumente encontrados são as obstruções que podem ser evitadas por meio de irrigações periódicas entre a administração da dieta e o medicamento ${ }^{(30)}$.

Apesar do que foi descrito, as ostomias alimentares apresentam vantagens frente à sonda nasoenteral: menor risco de refluxo de dieta e aspiração, facilidade para o próprio paciente administrar a nutrição enteral, além de manter a aparência e preservar a autoimagem àqueles que utilizam a TNE por longo prazo ${ }^{(34)}$.

Por fim, a lesão nasal, a úlcera por pressão, provocada pela fixação incorreta da sonda, foi observada em um paciente (Tabela 11). Em um estudo prospectivo, esse evento ocorreu em $29 \%$ dos 48 pacientes com SNE internados em UTI. Constatou-se que a primeira úlcera por pressão nasal foi no $9^{a}$ dia de uso da SNE. Desses casos, em 92\% uma das asas do nariz ulcerou e em $8 \%$, as duas. Em $55 \%$ dos casos, as úlceras evoluíram para estágio II. Dentre as variáveis analisadas, foi identificado que do total de pacientes que desenvolveu úlcera, 33\% receberam sedativos, 31\% noradrenalina, 35\% ventilação mecânica e $40 \%$ tinham anemia. Os autores concluíram que as lesões tiveram origem iatrogênica, como umidade e fricção da fixação, além de fatores intrínsecos como o estado nutricional, medicamentos que promoveram diminuição da resistência periférica e a idade. Ainda foi concluído que nenhum fator pode ser considerado preditor isolado para essa complicação, devendo, portanto, intensificar as medidas preventivas aos pacientes que usam a $\mathrm{SNE}^{(137)}$.

A fixação da sonda pode ser um dos motivos, em razão da tração exercida na asa da narina para fixá-la, promovendo isquemia local, ulceração e necrose ${ }^{(138)}$. Outros autores ainda alertam que essa ocorrência 
pode ser causada pelo calibre grosso ou pela pouca flexibilidade da sonda ${ }^{(2,13)}$.

\subsection{Complicação pulmonar e evento observado}

A complicação pulmonar é considerada de maior gravidade na $\operatorname{TNE}^{(2,78)}$, caracterizada pela aspiração do conteúdo gástrico ou de dieta ${ }^{(13)}$, pelo retardo do esvaziamento gástrico e íleo paralítico, que não é raro, sobretudo em pacientes com afecções neurológicas ou gravemente doentes $^{(2)}$. Muitas vezes, a aspiração pulmonar é insidiosa, manifestando-se como Pneumonia Aspirativa, que apresenta mortalidade entre $17 \%$ a $62 \%^{(111)} \mathrm{e}$, em pacientes submetidos à TNE, pode variar entre $2 \%$ a $10 \%{ }^{(13)}$.

Neste estudo, a aspiração pulmonar ocorreu em 26 casos, correspondendo a $13,0 \%$ do total de pacientes com complicações (Figura 4). Nos prontuários desses pacientes, não foram identificados resultados de exames para confirmar se a causa originou da microaspiração da nutrição enteral. Ainda assim, foi considerada a presença da complicação na vigência das informações contidas na evolução médica que sugerissem que a TNE pudesse ter sido o fator determinante.

No estudo longitudinal randomizado com 123 pacientes disfágicos foi verificado que a Pneumonia Aspirativa foi diagnosticada predominantemente em pacientes com SNE quando comparada aos sem SNE. Os autores concluíram que, em pacientes com doenças cerebrovascular e disfagia o uso de SNE pode influenciar na piora do quadro clínico do doente, pois sua presença promove o acúmulo de secreção orofaríngea, diminuição do reflexo de tosse, inabilidade de proteção das vias aéreas e aumento do $\mathrm{pH}$ intragástrico, promovendo a contaminação bacteriana. Dessa forma, seu uso deveria ser mais restrito e devidamente avaliado $^{(79)}$. Em outra pesquisa, a aspiração pulmonar ocorreu em $16 \%$ dos pacientes submetidos à esofagectomia, ainda assim concluiu que esse resultado esteve abaixo do esperado, considerando-se os benefícios 
observados em relação à prevenção de infecção pós-operatória, que estava sendo investigada ${ }^{(139)}$.

Em estudo com pacientes em TNE, vítimas de trauma neurológico e com retardo do esvaziamento gástrico, verificou-se que a aspiração pulmonar ocorreu em 10\% deles, não havendo associação significativa entre a ocorrência da complicação e uso de pró-cinético. Os autores atribuíram a complicação diretamente às condições clínicas dos pacientes. Ainda assim reforçam que o uso do pró-cinético auxilia na motilidade gástrica em pacientes com risco de aspiração pulmonar, mas seu benefício está associado ao monitoramento das complicações e ao posicionamento da sonda enteral ${ }^{(110)}$.

Em um estudo com 288 pacientes em TNE internados em um hospital universitário, a Pneumonia Aspirativa ocorreu em 24\% daqueles doentes, que foram acompanhados até o $3^{\circ}$ mês e $12 \%$ dos acompanhados por 6 meses. Afirmam os autores que a infecção respiratória após a introdução da SNE, provavelmente, foi associada à aspiração da dieta ${ }^{(129)}$.

A aspiração ocorre com frequência sem evidência de vômitos, refluxo ou quaisquer outros sinais gástricos, e é reconhecida pelo desenvolvimento de sinais clínicos que evidenciam o comprometimento respiratório. Dentre os fatores de risco para seu desenvolvimento, incluem idade, déficits neurológicos, higienização oral inadequada e uso de medicamentos que diminuem a motilidade gastrointestinal ${ }^{(30)}$. A motilidade gastrointestinal dos pacientes também deve ser avaliada, pois seu funcionamento moderado ou prejudicado associado a outros fatores de risco aumenta ainda mais o grau de risco para aspiração. O posicionamento da sonda é um importante aspecto a ser investigado nesses casos, pois a sonda enteral pode se deslocar acidentalmente, após ser corretamente posicionada. Não é incomum que a sonda seja tracionada pelo paciente confuso ou que haja deslocado acidentalmente durante algum procedimento, sem demonstrar mudança no comprimento externo ${ }^{(111)}$. 
Para prevenir tal ocorrência, recomenda-se a implantação de medidas e ações baseadas em alto grau de evidência, como a confirmação do posicionamento da sonda enteral pelo controle radiológico, mensuração do comprimento externo da sonda, como um marcador secundário (da narina a extremidade da sonda) e avaliação de intolerâncias pela verificação do volume residual gástrico ${ }^{(2)}$, higienização oral eficaz, uso de agentes prócinéticos e manutenção do decúbito elevado de $30^{\circ}$ a $45^{\circ}(13,30,78,111)$, além do rigoroso cuidado da enfermagem na administração da TNE e monitorização dos pacientes, reduzindo ou evitando a ocorrência de aspiração pulmonar ${ }^{(2)}$.

Pelos dados dos prontuários desta casuística verificou-se que o registro do grau da elevação da cabeceira (não foi objetivo da pesquisa) não é uma prática comum entre os profissionais de enfermagem da instituição, local da pesquisa. Isso demonstra a necessidade de reforçar o treinamento do profissional de enfermagem em relação a possíveis complicações ocasionadas pela falha na assistência ao paciente sob TNE.

\subsection{Associação entre as complicações}

Os quatro tipos de complicações poderiam apresentar relação de interdependência, isto é, a ocorrência de um tipo poderia amenizar a de outro tipo de complicação ou, agir de forma contrária, predispondo ao aparecimento de outra complicação.

Para essa abordagem, como se verifica nos dados da Tabela 7 e 8, as complicações foram estudadas de forma comparativa. Verifica-se que a complicação mecânica, a única a ter comportamento diferente, associa-se inversamente a complicação gastrointestinal $(p=0,023)$. Nota-se que, dentre 181 casos com complicação gastrointestinal, apenas 70 tiveram a complicação mecânica e dos 19 casos sem complicação gastrointestinal, 13 (mais de dois terços) tiveram complicação mecânica. A ótica de uma análise lógica, esta constatação é frágil e deve-se, provavelmente, à mera 
casualidade em razão da grande prevalência de complicação gastrointestinal (181 casos do total de 200 com complicações).

A complicação metabólica teve comportamento semelhante ao da complicação mecânica, embora não tenha atingido significado estatístico $(p=0,611)$. A complicação pulmonar não demonstrou associação significativa $(p>0,05)$ em relação à gastrointestinal. Na Tabela 8 , verifica-se que não houve associação estatisticamente significativa entre ocorrência de complicação pulmonar em relação às complicações mecânica e metabólica.

Portanto, vale consignar que as complicações apresentaram tendência uniforme de ocorrências, não havendo interferência siginificativa de uma complicação sobre a outra. Indubitavelmente, o alto número simultâneo de complicações (Tabela 9) e a grande prevalência de casos com complicação gastrointestinal (Figura 4) são as variáveis que determinaram estes resultados.

\subsection{Influência dos eventos observados nas complicações: gastrointestinal e mecânica na complicação pulmonar}

Conforme foi aludido na introdução deste trabalho, a complicação pulmonar é temida por ser considerada a de maior gravidade em TNE, sobretudo em pacientes incapacitados de tolerar a alimentação gástrica, no qual o risco de aspiração pulmonar é ainda maior ${ }^{(2,45,78)}$.

Em razão de essa complicação relacionar-se à aspiração de conteúdo gástrico e/ou de dieta para a árvore brônquica e tendo como fatores de risco vários eventos observados nas complicações, como alto VRG, vômitos, refluxos, retardo do esvaziamento gástrico, saída não programada da sonda ${ }^{(13,79)}$ tornou-se imperioso uma avaliação desse quesito. Entretanto, nos dados da Tabela 12, nota-se que nenhum dos eventos testados (refluxo, vômito, alto VRG, distensão abdominal e saída não programada da sonda) associou-se à complicação pulmonar. 


\subsection{Eventos observados nas complicações: métodos de infusão da nutrição enteral}

Além das variáveis apresentadas, foram analisados os métodos de infusão utilizados para administração da TNE e as terapias medicamentosas que poderiam representar risco para a tolerância alimentar, em decorrência de seus efeitos adversos, além de serem citados na literatura, como fatores envolvidos na ocorrência de complicações em pacientes, que são submetidos à TNE.

O método de infusão da nutrição enteral foi um fator analisado no presente estudo, em decorrência de sua ampla utilização no âmbito hospitalar. A infusão da TNE pelo método contínuo tem sido empregada no intuito de controlar um gotejamento mais lento e fornecer volumes reduzidos de dieta, favorecendo um melhor esvaziamento gástrico e possibilitando a tolerância gradual da nutrição com melhor absorção dos nutrientes, além de reduzir o risco de distensão gástrica, náusea, vômito, refluxo e aspiração pulmonar $^{(70)}$.

Neste estudo, destaca-se que a maior frequência de eventos foi: náusea, refluxo, vômito, VRG, diarreia, constipação, distensão abdominal, hiperglicemia, saída não programada da sonda e aspiração pulmonar ocorreram nos pacientes, cuja nutrição enteral foi fornecida pelo método contínuo (Tabelas 13, 14 e 15). Entretanto, houve associação estatisticamente significativa apenas nos casos de alto VRG, constipação e distensão abdominal em relação ao uso desse método.

Em um estudo comparativo randomizado com 74 pacientes em TNE (37 pelo método contínuo e 37 pelo intermitente) não foi observada redução do quadro de diarreia nos pacientes que receberam a nutrição enteral pelo método contínuo, no $1^{\circ}$ dia $(12$ vs $10, p=0,18)$ e no $5^{\circ}$ dia ( 5 vs $4, p=0,83$ ). Concluiu ainda que não houve benefícios do método no controle da complicação nos respectivos pacientes. De forma diversa aos resultados da presente pesquisa, nos casos de VRG, verificou-se que o método 
contínuo foi melhor na administração da TNE para controlar a complicação, porém, sem existência de associação significativa ${ }^{(140)}$.

Em relação à complicação pulmonar, nesta pesquisa (Tabela 16) foi observada ausência de associação entre aspiração pulmonar e método de infusão. Sobre o assunto, uma pesquisa evidenciou que 54\% dos pacientes internados em UTI, que estavam sob ventilação mecânica e que receberam TNE pelo método contínuo, desenvolveram pneumonia, por manterem o pH gástrico elevado e aumento da colonização bacteriana no período noturno e o índice de mortalidade neste grupo foi de $46 \%$. Os autores concluíram que a chance de mortalidade para os pacientes em ventilação mecânica que mantiveram o método contínuo de infusão foi de 1,6 vezes maior ${ }^{(141)}$. Em vista disso, pode-se afirmar que o método contínuo não é recomendado para administração noturna em pacientes com risco de aspiração, pois a infusão contínua da dieta, sem pausa, dificulta a redução da população bacteriana intragástrica. A pausa noturna é necessária, pois, o pH gástrico, não sendo bloqueado pela dieta, cai para níveis bactericidas, auxiliando no controle do desenvolvimento de infecções nosocomiais ${ }^{(67)}$.

\subsection{Eventos observados nas complicações: terapia medicamentosa}

$\mathrm{Na}$ prática clínica, alguns medicamentos são utilizados com frequência, embora sejam indicados para a terapêutica, podem potencializar as complicações pelos seus efeitos adversos e prejudicar a TNE. Assim, verificou-se que os pacientes hiperglicêmicos, que fizeram uso de sedativos/opioides, foram predominantemente maiores $(66,9 \%)$, e esse evento observado indicou a existência de associação significativativa (Tabela 17).

O uso de drogas vasoativas também se associou à ocorrência de hiperglicemia $(p=0,000)$. Em relação a esse tópico, é evidente que a normalização da glicemia não se relaciona com o uso dessas drogas mas, 
sim, com a estabilização hemodinâmica do doente. Entretanto, a relação desses medicamentos com a hiperglicemia ocorre de forma indireta, visto que o aumento nos níveis glicêmicos é uma alteração adaptativa decorrente do estresse, presente na instabilidade hemodinâmica ${ }^{(142,143)}$.

As outras complicações em relação às demais terapias medicamentosas não apresentaram associação significativa pela análise realizada (Tabela 17 ).

\subsection{1 À guisa de sinopse, limitações e perspectivas}

Ao iniciar o presente estudo, procurou-se identificar as complicações mais frequentes ocorridas durante a vigência da TNE e que tivessem relação direta com a assistência de enfermagem a fim de que os resultados encontrados contribuíssem para elaboração dos diagnósticos de enfermagem a esses pacientes. No entanto, o número de casos com complicações foi exorbitante, atingindo a quase totalidade da casuística, obviamente relacionado com as condições clínicas dos pacientes, desde a internação, tornando a tarefa muito complexa.

O perfil apresentado pelos pacientes do presente estudo corrobora outros estudos e explica plenamente a magnitude das complicações computadas nesta casuística de um Hospital Universitário de São Paulo. O fato da população situar-se, majoritariamente, na faixa da terceira idade compatibiliza-se com os riscos impostos àqueles que necessitam da TNE, em sua maioria admitida em UTI e Unidade de Cuidados Semi-intensivos. Portanto, é plausível que as complicações, nesse grupo de sujeitos, sejam inexoravelmente prevalentes em grande proporção. Em face disso, é obviamente aceitável que, nessa vertente, os cuidados dos profissionais envolvidos devam ser altamente diferenciados. Para esses trabalhadores, o treinamento e o embasamento teórico e prático são essenciais para o bom termo da TNE. 
A análise das complicações e de suas relações entre si e entre os diversos eventos observados demonstrou a mutualidade de ocorrências e a alta prevalência concomitante de vários desses fenômenos, sem a caracterização de influências de uma sobre a outra, com poucas exceções (método de infusão e hiperglicemia). A imponderabilidade das ações voltadas à melhoria da assistência a esse grupo de pacientes de altíssimo risco de morbidade e mortalidade tornou-se patente. A literatura dá amplo respaldo aos achados da presente investigação, havendo poucas divergências e, no cômputo final, pode-se considerar que houve convergência de resultados. Entre os achados em oposição à literatura, destacam-se os piores resultados da infusão contínua da TNE em relação ao VRG, constipação e distensão abdominal. Entretanto, em relação à complicação mecânica, o método contínuo exerceu um efeito protetor.

Causou surpresa também a ausência de associação entre os eventos observados às complicações: gastrointestinal e pulmonar (Tabela 12), visto que há longa data admite-se como certa essa relação. Nesta composição, a baixa prevalência da aspiração pulmonar em relação aos eventos observados na caracterização das complicações gastrointestinais pode explicar os resultados contraditórios emanados desta pesquisa.

A despeito de esta pesquisa clínica apresentar-se como um estudo observacional e retrospectivo, especificamente para esta casuística, ostenta conotação de um estudo exploratório, descritivo em função das características peculiares do Serviço Universitário e do ineditismo desta abordagem. Pode-se admitir que a caracterização da amostra deste estudo seja muito útil, pois demonstra com detalhes o perfil da clientela usuária de TNE, nesse Serviço, tópico importante para a assistência de Enfermagem. Da mesma forma, a constatação da presença maciça de complicações esclarece, com veemência, a gravidade do quadro clínico dos pacientes em TNE. No entanto, é indubitável a presença de vários vieses que podem limitar o poder discriminatório de alguns resultados obtidos. Certamente, para se elaborar grupos de sujeitos de pesquisa com amostragens robustas demanda muito tempo, especialmente, em pacientes com necessidade de 
TNE. Melhor seria um estudo multicêntrico e de execução prospectiva, com possibilidades de generalização das conclusões obtidas.

Frente ao exposto, as perspectivas de novos estudos direcionam o pesquisador para busca de outros enfoques relacionados aos cuidados de Enfermagem destinados a esse grupo de pacientes. As lacunas observadas e os questionamentos não foram plenamente esclarecidos, ao revés, outros podem ser elaborados em função dos resultados emanados da presente pesquisa. As contradições permanecem, ainda, sem resposta. Por outro lado, para o aprimoramento das ações educativas, a presente contemporaneidade repleta de tecnologia avançada requer atualizações em todos os campos, incluindo esta tela. A atenção constante para as inovações que surgem nesse terreno são inquestionavelmente fundamentais, para se galgar um salto qualitativo na assistência a esses pacientes. 


\section{CONCLUSÕES}

O presente estudo permitiu as seguintes conclusões:

1) Quanto à caracterização da amostra

a) Perfil dos pacientes:

a.1) A maioria foi do sexo masculino (55,6\%); idade média de 64,8 anos, mediana de 69 anos;

a.2) A maioria foi internada para tratamento clínico $(68,7 \%)$; a comorbidade mais frequente foi a pulmonar $(20,1 \%)$ seguida pela cardiovascular $(19,4 \%)$ e pela neurológica $(17,4 \%)$;

a.3) Foram internados em sua maioria na UTI e na semiintensiva $(66,8 \%)$.

b) Terapia nutricional

b.1) Quanto à duração, a média de TNE foi de 13,2 dias com variação de 1 a 189 dias; mediana de 8 dias, e 43,5\% receberam a terapia por até uma semana;

b.2) Quanto a via de acesso, houve predomínio de SNE $(96,3 \%)$;

b.3) Em relação ao método de infusão, a maioria recebeu de forma contínua $(67,3 \%)$. 
2) Quanto às complicações da terapia nutricional enteral (TNE), foi observado um total de 400. Os pacientes (200) foram distribuídos da seguinte forma:

a) Complicação gastrointestinal: 181 (90,5\%);

b) Complicação metabólica: 110 (55,0\%);

c) Complicação mecânica: 83 (41,5\%);

d) Complicação pulmonar: 26 (13,0\%).

3) Quanto à associação entre as complicações entre si:

a) Houve associação inversa significativa da complicação mecânica com a gastrointestinal;

b) Não houve associação entre outras complicações.

4) Quanto à associação dos eventos observados na complicação gastrointestinal com a complicação pulmonar: não houve associação significativa.

5) Quanto à influência do método de infusão da TNE (intermitente e contínua) sobre os eventos observados nas complicações:

a) A complicação gastrointestinal associou-se significativamente nos seguintes eventos: VRG, constipação e distensão abdominal, com vantagens para a infusão intermitente nos três eventos;

b) Houve associação significativa com a complicação mecânica nos seguintes eventos: deslocamento da sonda e saída não 
programada da sonda, com vantagens para a infusão contínua nos dois eventos;

c) Não houve influência do tipo de infusão da TNE com as complicações: metabólica e pulmonar.

6) Quanto à influência das drogas administradas sobre os eventos observados nas complicações

a) A administração de sedativos/opioides e de drogas vasoativas associou-se diretamente com a complicação metabólica;

b) Nenhum grupo de drogas associou-se às complicações: gastrointestinal, mecânica e pulmonar. 


\section{REFERÊNCIAS}

1. Matsuba CST. Obstrução de sondas nasoenterais em pacientes cardiopatas [dissertação]. São Paulo: Universidade Federal de São Paulo; 2003.

2. Coppini L, Waitzberg DL. Complicações em nutrição enteral. In: Waitzberg DL. Nutrição oral, enteral e parenteral. $4^{a}$ ed. São Paulo: Atheneu; 2009. v.1. p. 907-17.

3. Metheny NA, Clouse RE, Chang YH, Stewart BJ, Oliver DA, Kollef MH. Tracheobronchial aspiration of gastric contents in critically ill tube-fed patients: frequency, outcomes, and risk factors. Crit Care Med. 2006;34(4):1007-15.

4. Waitzberg DL, Raslan M, Ravacci GR. Desnutrição: prevalência e metabolismo. In: Waitzberg DL. Nutrição oral, enteral e parenteral na prática clínica. $4^{\mathrm{a}}$ ed. São Paulo: Atheneu; 2009. v.1. p. 535-56.

5. Waitzberg DL, Caiaffa WT, Correia MITD. Inquérito brasileiro de avaliação nutricional hospitalar (IBRANUTRI). Rev Bras Nutr Clín. 1998;13(1):30-40.

6. Garita FS, Cukier C, Magnoni CD.Indicações e prescrição da terapia nutricional. In: Matsuba CST, Magnoni CD. Enfermagem em terapia nutricional. São Paulo: Sarvier; 2009. p. 35-55.

7. Freitas MI, Marchini JS. A enfermagem em terapia nutricional. In: Matsuba CST, Magnoni CD. Enfermagem em terapia nutricional. São Paulo: Sarvier; 2009. p.1-26.

8. Teixeira ACC, Caruso L, Soriano FG. Terapia nutricional enteral em unidade de terapia intensiva: infusão versus necessidades. Rev Bras Ter Intensiva. 2006;18(4):331-37.

9. Acosta-Escribano J, Fernandez-Vivas M, Carmona TG, Cartula-Such J, Garcia-Martinez M, Menendez-Mainer A, et al. Gastric versus transpyloric feeding in severe, traumatic brain injury: a prospective, randomized trial. Intensive Care Med. 2010;36(9):1532-39. 
10. Belletti GA, Gómez J, Yorio MA. Caracteristicas de los pacientes internados con alimentacion enteral de un servicio de clínica medica. Rev Fac Cienc Méd. 2005;62(3):12-8.

11. Santos DMV, Ceribelli MIPF. Enfermeiros especialistas em terapia nutricional no Brasil: onde e como atuam. Rev Bras Enferm. 2006;59(6):757-61.

12. Mello ED, Beghetto MG, Teixeira LB, Luft VC. Desnutrição hospitalar: cinco anos após o IBRANUTRI. Rev Bras Nutr Clín. 2003;18(2):65-9.

13. Serpa LF, Fini A, Fantuchi J. Complicações e condutas em terapia nutricional. In: Matsuba CST, Magnoni CD. Enfermagem em terapia nutricional. São Paulo: Sarvier; 2009. p.163-82.

14. Leandro-Merhi VA, Morete JL, Oliveira MRM. Avaliação do estado nutricional precedente ao uso de nutrição enteral. Arq Gastroenterol. 2009;46(3):219-24.

15. Serpa LF. Complicações da nutrição enteral em pacientes de UTI: comparação entre os métodos de administração contínua e intermitente [dissertação]. São Paulo: Escola de Enfermagem, Universidade de São Paulo; 2001.

16. Waitzberg DL, Alves CC. Nutrição enteral. In: Martins MA, Carrilho FJ, Alves VAF. Clínica médica: doenças do aparelho digestivo, nutrição e doenças nutricionais. São Paulo: Manole; 2009. v. 4. p. 610-24.

17. Campos ACL, Branco AB, Matias JEF. Fístulas digestivas e terapia nutricional. Acta Gastroenterol Latinoam. 2007;37(2):118-25.

18. Wu GH, Wu ZH, Wu ZG. Effects of bowel rehabilitation and combined trophic therapy on intestinal adaptation in short bowel patients. World $\mathrm{J}$ Gastroenterol. 2003;9(11):2601-04.

19. Baxter YC, Waitzberg DL. Alimentação enteral. In: Mura JDP, Silva SMC. Tratado de alimentação, nutrição \& dietoterapia. São Paulo: Roca; 2007. p. 873-82.

20. Brasil. Agência Nacional de Vigilância Sanitária (ANVISA). Resolução n. 63 , de 6 de julho de 2000. Regulamento técnico para fixar requisitos mínimos exigidos para a terapia nutricional enteral. 
[internet], Brasília, 2000 [citado em 2010 mai 25]. Disponível em: http://www.anvisa.gov.br/legis/resol/2000/63_00rdc.htm.

21. Miyadahira AMK. Princípios da assistência de enfermagem na nutrição enteral. Rev Paul Enferm. 1984;4(2):62-8.

22. Sant'anna LC. Composição das fórmulas enterais. In: Matsuba CST, Magnoni CD. Enfermagem em terapia nutricional. São Paulo: Sarvier; 2009. p. 56-74.

23. Baxter YC, Waitzberg DL. Fórmulas enterais: complexidade de nutrientes e categorização. In: Mura JDP, Silva SMC. Tratado de alimentação, nutrição \& dietoterapia. São Paulo: Roca; 2007. p. 883-92.

24. Magnuson BL, Clifford TM, Hoskins AL, Bernard AC. Enteral nutrition and drug administration, interactions, and complications. Nutr Clin Pract. 2005;20(6):618-24.

25. Matsuba CST, Moraes HM. Interações droga-nutrientes e suas implicações na assistência de enfermagem. In: Matsuba CST, Magnoni CD. Enfermagem em terapia nutricional. São Paulo: Sarvier; 2009. p. 145-65.

26. Azevedo SO, Escudeiro CL. Suporte nutricional em enfermagem: uma revisão de literatura. Enferm Atual. 2009;50(1):17-21.

27. American Society for Parenteral and Enteral Nutrition (ASPEN). Acess for administration of nutrition support. JPEN J Parenter Enteral Nutr. 2002;26(1 Suppl):33SA-4SA.

28. Junior JCM, Moreira LFS. Vias de acesso para terapia nutricional In: Cukier C, Magnoni D. Perguntas e respostas em nutrição clínica. São Paulo: Roca; 2001. p. 45-58.

29. Cunha SFC. Terapia nutricional enteral. In: Marchini JSI, Vannucchi H. Nutrição clínica: nutrição e metabolismo. Rio de Janeiro: Guanabara Koogan; 2007. p. 78-95.

30. Gavi S, Hensley J, Cervo F, Nicastri C, Fields S. Management of feeding tube complications in the long term care resident. Ann Long Term Care. 2008;16(4):28-32. 
31. Minicucci MF, Silva GF, Matsui M, Inque RMT, Zornoff LAM, Matsubara LS, et al. O uso da gastrostomia percutânea endoscópica. Rev Nutr. 2005;18(4):553-59.

32. París AS, Lázaro J, Guallar A, Gracia P, Carveni A, Albero R. Nutrición enteral continua frente a nutrición en bolo: efectos sobre el péptico $C$ urinário. Med Clin. 2005;124(16):613-5.

33. Rainho MS. Dispositivos para implementação da nutrição enteral. In: Waitzberg DL. Nutrição oral, enteral e parenteral na prática clínica. São Paulo: Atheneu; 2001. p. 697-712.

34. Unamuno MRDL, Marchini JS. Sonda nasogástrica/nasoentérica: cuidados na instalação, na administração da dieta e prevenção de complicações. Medicina (Ribeirão Preto). 2002;35(1):95-101.

35. Hermann AP, Cruz EDA. Enfermagem em nutrição enteral: investigação do conhecimento e da prática assistencial em hospital de ensino. Cogitare Enferm. 2008;13(4):520-5.

36. Mutlu GM, Mutlu EA, Factor P. GI complications in patients receiving mechanical ventilation. Chest. 2001;119(4):1222-41.

37. Heydrich J. Padrão de prescrição, preparo e administração medicamentos em usuários de sonda de nutrição internados em um hospital universitário [dissertação]. Porto Alegre: Universidade Federal do Rio Grande do Sul; 2006.

38. Boullata JI. Medication administration through feeding tubes. Am J Health Syst Pharm. 2010;67(1):23.

39. Abrams AC. Farmacoterapia clínica: princípios para prática clínica. $7^{a}$ ed. Rio de Janeiro: Guanabara Koogan; 2006. Analgésicos opioides e antagonistas opioides; p. 79-98.

40. Abrams AC. Farmacoterapia clínica: princípios para prática clínica. $7^{a}$ ed. Rio de Janeiro: Guanabara Koogan; 2006. Antibacterianos macrolídeos e diversos; p. 551-67.

41. Filho JPPM, Barczinsski T, Hashimoto CL. Doença do refluxo gastroesofágico. In: Martins MA, Carrilho FJ, Alves VAF. Clínica 
médica: doenças do aparelho digestivo, nutrição e doenças nutricionais. São Paulo: Manole; 2009. p. 60-9.

42. Matias JEF, Campos ACL. Complicações da terapia nutricional enteral e parenteral. In: Cukier C, Magnoni D. Perguntas e respostas em nutrição clínica. São Paulo: Roca; 2001. p. 347-56.

43. Ribeiro P. Nutrição enteral em situações de instabilidade hemodinâmica e fluxo sanguíneo limítrofe. In: Azevedo JRA, Loss SH, Ferro HC. Nutrição parenteral e enteral em UTI. São Paulo: Atheneu; 2001. p. $150-9$.

44. Alves VGF, Chiesa CA, Silva MHN, Soares RLS, Rocha EEM, Gomes MV. Complicações do suporte nutricional em pacientes cardiopatas em uma unidade de terapia intensiva. Rev Bras Nutr Clin. 1999;14(3):135-44.

45. Ferreira IKC. Terapia nutricinal em unidade de terapia intensiva. Rev Bras Ter Intensiva. 2007;19(1):90-7.

46. Desachy A, Clavel M, Vuagnat A, Normand S, Gissot V, François B. Initial efficacy and tolerability of early enteral nutrition with immediate or gradual introduction in intubated patients. Intensive Care Med. 2008;34(6):1054-9.

47. Reid C. Frequency of under-and overfeeding in mechanically ventilated ICU patients: causes and possible consequences. J Hum Nutr Diet. 2006;19(1):13-22.

48. MCClave SA, Snider HL. Clínical use of gastric residual volumes a mointor for patients on enteral tube feeding . JPEN J Parenter Enteral Nutr. 2002;26(6 Suppl):S43-S50.

49. Troncon LEA. Gastroparesias: revisão de aspectos relacionados ao conceito, à etiopatogenia e ao manejo clínico. AMB Rev Assoc Med Bras. 1997;43(3):228-36.

50. Castrao DLL, Freitas MM, Zaban ALRS. Terapia nutricional enteral e parenteral: complicações em pacientes críticos - uma revisão da literatura. Comun Ciênc Saúde. 2009;20(1):65-74. 
51. Escribano JA, Vivas MF, Carmona TG, Caturla-Such J, Garcia-Martinez $M$, Menendez-Mainer A, et al. Gastric versus transpyloric feeding in severe traumatic brain injury: a prospective, randomized trial. Intensive Care Med. 2010;36(9):1532-9.

52. Azevedo RP, Freitas FGR, Ferreira EM, Machado FR. Constipação intestinal em terapia intensiva. Rev Bras Ter Intensiva. 2009;21(3):32431.

53. Silva CFB, Damião AOMC, Sipahi AM. Constipação intestinal. In: Martins MA, Carrilho FJ, Alves VAF. Clínica médica: doenças do aparelho digestivo, nutrição e doenças nutricionais. São Paulo: Manole; 2009. p. 160-9.

54. Nassar AP Jr, Silva FMQ, Cleva R. Constipation in intensive care unit: Incidence and risk factors. J Crit Care. 2009;24(4):630.9-630.12.

55. Mostafa SM, Bhandari S, Ritchie G, Gratton N, Wenstone R. Constipation and its implications in the critically ill patient. $\mathrm{Br} \mathrm{J}$ Anaesth. 2003;91(6):815-9.

56. Wiesen P, Van Gossum A, Preiser JC. Diarrhoea in the critically ill. Curr Opin Crit Care. 2006;12(2):149-54.

57. Leite AZA. Diarreia crônica e má absorção In: Martins MA, Carrilho FJ, Alves VAF. Clínica médica: doenças do aparelho digestivo, nutrição e doenças nutricionais. São Paulo: Manole; 2009. p. 150-9.

58. Caruso L. Distúrbios do trato digestório. In: Cuppari L. Guia de nutrição clínica no adulto: guia de medicina ambulatorial e hospitalar. São Paulo: Manole; 2005. p. 221-42.

59. Kelly CP, Pothoulakis C, LaMont JT. Clostridium difficile colitis. N Engl J Med. 1994;330(4):257-62.

60. Chang VT, Nelson K. The role of physical proximity in nosocomial diarrhea. Clin Infect Dis. 2000;31(3):717-22.

61. Sérvulo LB, Pinheiro BV, Lima PFH, Chebli FJM. Diarreia nosocomial em unidade de terapia intensiva: incidência e fatores de risco. Arq Gastroenterol. 2008;45(2):117-23. 
62. Kyne L, Sougioultzis S, McFarland LV, Kelly CP. Underlying disease severity as major risk factor for nosocomial clostridium difficile diarrhea. Infect Control Hosp Epidemiol. 2002;23(11):653-9.

63. Whelan K, Judd PA, Preedy VR, Taylor MA. Enteral feeding: the effect on faecal output, the faecal microflora and SCFA concentrations. Proc Nutr Soc. 2004;63(1):105-13.

64. Anker SD, John M, Pedersen PU, Raguso C, Cicoira M, Dardai E, et al. ESPEN guidelines on enteral nutrition: cardiology and pulmonology. Clin Nutr. 2006;25(2):311-8.

65. Mebis L, Gunst J, Langouche L, Vanhorebeek I, Van den Berghe G. Indication and practical use of intensive insulin therapy in the critically ill. Curr Opin Crit Care. 2007;13(4):392-8.

66. Marik PE, Raghavan M. Stress-hyperglycemia, insulin and immunomodulation in sepsis. Intensive Care Med. 2004;30(5):748-56.

67. Stroud M, Duncan H, Nightingale J. Guidelines for enteral feeding in adult hospital patients. Gut. 2003;52 (Supl 7):vii1-vii12.

68. Robinson LE, Soeren MHV. Insulin resistance and hiperglycemia in critical ilness. AACN Clin Issues. 2004;15(1):45-62.

69. Ceribelli MIPF, Malta MA. Inserção da sonda nasogástrica: análise dos pontos de referência. Rev Bras Nutr Clín. 2006;21(1):54-9.

70. Fujino $\mathrm{V}$, Nogueira LABNS. Terapia nutricional enteral em pacientes graves: revisão de literatura. Arq Ciênc Saúde 2007;14(4):220-6.

71. Parrish CR. Enteral feeding: the art and the science. Nutri Clin Pract. 2003;18(1):76-85.

72. Carvalho RT, Taquemori LY. Nutrição e hidratação. In: Oliveira RA. Cuidado paliativo. São Paulo: CREMESP; 2008. p. 221-71.

73. Bourgault AM, Ipe L, Weaver J, Swartz S, O'Dea PJ. Development of evidence-based guidelines and critical care nurses knowledge of enteral feeding. Crit Care Nurse. 2007;27(4):17-29. 
74. Poltronieri MJA. Eventos adversos na administração de dieta enteral em unidade de terapia intensiva: análise comparativa entre o volume prescrito e o administrado [dissertação]. São Paulo: Escola de Enfermagem, Universidade de São Paulo; 2006.

75. Lima G, Negrini NMM. Assistência farmacêutica na administração de medicamentos via sonda: escolha da forma farmacêutica adequada. Einstein (São Paulo). 2009;7(Pt 1):9-17.

76. Kohl CL, Keithley JK. Enteral nutrition. Potencial complications and patient monitoring. Nurs Clin North América. 1989;24(2):339-53.

77. Thomson FC, Naysmith MR, Lindsay A. A managing drug therapy in patients receiving enteral and parenteral nutrition. Hosp Pharm. 2000;7(6):155-64.

78. American Association of Critical Care Nurses (AACN). Verification of feeding tube placement. Columbia: AACN; 2009. p. 1-4.

79. Gomes GF, Campos ACL, Pisani JC, Macedo EDF, Ribas JMF, Malafaia $\mathrm{O}$, et al. Sonda nasoenteral, aspiração traqueal e pneumonia aspirativa em pacientes hospitalizados com doença cérebro-vascular complicada por disfagia orofaríngea. ABCD Arq Bras Cir Dig. 2003;16(4):189-92.

80. Carrilho CMD, Grion CMC, Carvalho LM, Grion AS, Matsuo T. Ventilator-associated pneumonia in surgical intensive care unit. Rev Bras Ter Intensiva. 2006;18(1):38-44.

81. Apostolopoulou E, Bakakos P, Katostaras T, Gregorakos-Athens L, Grecce. Incidence and risk factors for ventilator-associated pneumonia in 4 multidisciplinary intensive care units in Athens, Greece. Respir Care. 2003;48(7):681-8.

82. Bento ALP, Schieferdeker MEM, Campos AC. Qualidade de vida em terapia nutricional enteral domiciliar: doente e cuidador. Rev Bras Nutr Clín. 2005;20(4):287-92.

83. Boog MCF, Silva JB. Percepções de enfermeiras no processo de cuidado nutricional. Rev Bras Nutr Clín. 2001;16(1):17-22. 
84. Conselho Federal de Enfermagem (COFEN). Resolução n. 277, de 16 de junho de 2003. Dispõe sobre a ministração de nutrição parenteral e enteral [Internet]. Brasília; 2003. [citado em 2010 set 11]. Disponível em: http://site.portalcofen.gov.br/node/4313.

85. Bolfarine $\mathrm{H}$, Bussab WO. Elementos de amostragem. São Paulo: Edgard Blücher; 2005. p. 126-34.

86. Filho JWF, Leuck MP, Levandovski RM. Manuseio de complicações nutricionais no paciente grave. In: Waitzberg DL. Nutrição oral, enteral e parenteral na prática clínica. $4^{a}$ ed. São Paulo: Atheneu; 2009. v. 2. p. 1965-86.

87. Braunschweig C, Jensen GL. Hyperglycemia, nutrition support and acute illness. JPEN J Parenter Enteral Nutr. 2006;30(2):175-6.

88. Kirkwood BR, Sterne JAC, Malden M. Essential medical statistics. $2^{a}$ ed. London: Blackwell Science; 2003. Chi-square tests for $2 \times 2$ and larger contingency tables; p. 165-76.

89. Campanella LCA, Silveira BM, Rosário Neto O, Silva AA. Terapia nutricional enteral: a dieta prescrita é realmente infundida? Rev Bras Nutr Clin. 2008;23(1):21-5.

90. Instituto Brasileiro de Geografia e Estatística (IBGE). Censo demográfico de 2009. [Internet], Brasília. [citado em 2011 jan. 27]. Disponível em: http://www.ibge.gov.br/home/mapa site/mapa site.php\#populacao.

91. Nasri F. O envelhecimento populacional no Brasil. Einstein (São Paulo). 2008;6 (Supl 1):S4-S6.

92. Gaino NM, Leandro-Merhi VA, Oliveira MRM. Idosos hospitalizados: estado nutricional, dieta, doença e tempo de internação. Rev Bras Nutr Clin. 2007;22(4):273-9.

93. Finco C, Magnanini P, Sarzo G, Vecchiato M, Luongo B, Savastano S, et al. Prospective randomized study on perioperative enteral 
immunonutrition in laparoscopic colorectal surgery. Surg Endosc. 2007;21(7):1175-9.

94. Juvé-Udina ME, Valls-Miró C, Carreño-Granero A, Martinez-Estalella $\mathrm{G}$, Monterde-Prat D, Domingo-Felici CM, et al. To return or to discard? randomized trial on gastric residual volume management. Intensive Crit Care Nurs. 2009;25(5):258-67.

95. Watanabe S, Cukier C, Civelli S, Catalini LA, Muroya C. Impacto do sistema de infusão de dieta enteral sobre infecção respiratória e diarreia. Rev Bras Nutr. 2008;23(1):46-50.

96. Nunes A. O envelhecimento populacional e as despesas do sistema único de saúde. [citado em 2011 mar. 01]. Disponível em:

http://www.ipea.gov.br/sites/000/2/livros/idososalem60/Arq 21 Cap 13 .pdf.

97. Maués CR, Rodrigues SMC, Cardoso HC, Cardoso HM, Junior JEBF, Ribeiro VC. Epidemiologia de idosos internados na enfermaria de clínica médica de hospital público. Rev Para Med. 2007;21(3):31-6.

98. Nozaki VT, Peralta RM. Adequação do suporte nutricional enteral: comparação em dois hospitais. Rev Nutr. 2009;22(3):341-50.

99. MacLeod JB, Lefton J, Houghton D, Roland C, Doherty J, Cohn SM, et al. Prospective randomized control trial of intermitent versus continuos gastric feeds for critically III trauma patients. J Trauma. 2007;63(1):5761.

100. Cartolano FDC, Caruso L, Soriano FG. Terapia nutricional enteral: aplicação de indicadores de qualidade. Rev Bras Ter Intensiva. 2009;21(4):376-83.

101. Fernandes DD, Ghisleni DR, Colpo E, Lopes LFD, Rubin BA. Aporte nutricional em pacientes em terapia nutricional enteral exclusiva: recomendado x recebido. Rev Bras Nutr Clin. $2009 ; 24(2): 85-92$

102. Aranjues AL, Teixeira ACC, Caruso L, Soriano FG. Monitorização da terapia nutricional enteral em UTI: indicador de qualidade? Mundo Saúde. 2008;32(1):16-23. 
103. Associação de Medicina Intensiva Brasileira (AMIB). $2^{\circ}$ Anuário Brasileiro de Unidade de Terapia Intensiva. São Paulo: AMIB; 2004.

104. Najas M, coordenador. I Consenso brasileiro de nutrição e disfagia em idosos hospitalizados. São Paulo: Manole; 2011. p. 3-4.

105. Engel JM, Muhling J, Junger A, Karcher B, Hempelmann G. Enteral nutrition practice in a surgival intensive care unit: what proportion energy expenditure is delivered enterally? Clin Nutr. 2003;22(2):18792.

106. Oliveira SM, Burgos MGPA, Santos EMC, Prado LVS, Petribú MMV, Bomfim FMTS. Complicações gastrointestinais e adequação calóricoprotéica de pacientes em uso de nutrição enteral em uma unidade de terapia intensiva. Rev Bras Ter Intensiva. 2010;22(3):270-3.

107. Soop M, Carlson GL, Hopkinson J, Clarke S, Thorel A, Nygren J, Ljungqvist $\mathrm{O}$. Randomized clínical trial of the effects of immediate entral nutrition on metabolic responses to major colorectal surgery in an anhanced recovery protocol. Br J Surg. 2004;91(9):1138-45.

108. Pancorbo-Hidalgo PL, Gárcia-Fernandez FP, Ramírez-Pérez C. Complications associated with enteral nutrition by nasogastric tube in an internal medicine unit. J Clin Nurs. 2001;10(4):482-90.

109. Rodriguez KA, Pereira NMP, Valle J. Avaliação da terapia nutricional enteral no paciente crítico relacionado a dieta prescrita e administrada em pacientes internados em um centro de terapia semi-intensiva. Rev Cient HCE. 2004;(2):135-40.

110. Nursal TZ, Erdogan B, Noyan, Cekinmez M, Atalay B, Bilgin N. The effect of metoclopramide on gastric emptying in traumatic brain injury. J Clin Neurosci. 2007;14(4):344-8.

111. Metheny NA. Preventy respiratory complications of tube-feedings: evidence-based practice. Am J Crit Care. 2006;15(4):360-9.

112. Castel H, Tiengou LE, Besancon I, Joubert C, Fatome A, Piquet MA. What is the risk of noturnal supine enteral nutrition? Clín Nutri. 2005;24(6):1014-8. 
113. Pearce CB, Duncan HD. Enteral feeding nasogastric, nasojejunal, percutaneous endoscopic gastrotomy ou jejunostomy: its indications and limitations. Postgrad Med J. 2002;78(918):198-204.

114. Scott F, Beech R, Smedley F, Timmis L, Stokes E, Jones P, et al. Prospective, randomized, controlles, single-blind trial of the costs end consequences of suystematic nutrition team follow-up over 12 month after percutaneous endoscopic gastrostomy. Nutrition. 2005;21(1112):1071-7.

115. Sicchieri JMF, Unamuno MRDL, Marchinni JS, Cunha SFC. Evolução antropométrica e sintomas gastrointestinais em pacientes que receberam suplementos nutricinais ou nutrição enteral. Rev Assoc Med Bras. 2009;55(2):149-52.

116. Borges RM, Nonino-Borges CB, Campos AD, Basile-Filho A. Incidência de complicações em terapia nutricional enteral de pacientes em estado grave. Rev Bras Ter Intensiva. 2005;17(2):98103.

117. Eatock FC, Chong P, Menezes N, Murray L, Mckay CJ, Carter CR, et al. A randomized study of early nasogastric versus nasojejunal feeding in severe acute pancreatitis. Am J Gastroenterol. 2005;100(2):432-9.

118. Ferreras N, Artigas V, Cardona D, Rius X, Trias M, González JA. Effect of early postoperative enteral immunonutrition on wound healing in patients undergoing surgery for gastric cancer. Clin Nutr. 2005;24(1):55-65.

119. Tien YW, Yang CY, Wu YM, Hu RH, Lee PH. Enteral nutrition and biliopancreatic diversion effectively minimize impacts of gastroparesis after pancreaticoduodenectomy. J Gastrointest Surg. 2009;13(5):92937.

120. Luis DA, Izaola I, Cuellar L, Terroba MC, Martin T, Aller R. Clínical and biochemical outcomes after a randomized trial with a high dose of enteral arginine formula im postsurgical head and neck cancer patients. Eur J Clin Nutr. 2007;61(2):200-4.

121. Casas-Rodera P, Gómez-Candela C, Benítez S, Mateo R, Armero M, Castillo R,Culebras JM. Immunoenhanced entral nutrition formulas in head and neck cancer surgery: a prospective, randomyzed clínical trial. Nutr Hosp. 2008;23(2):105-10. 
122. Lobo DN, Willians RN, Welch NT, Aloysius MM, Nunes QM, Padmanabhan J, et al. Early postoperative jejunostomy feeding with an immune modulating diet in patients undergoing resectional surgery for upper gastrointestinal câncer: a prospective, randomized, controlled, double-bkind study. Clin Nutr. 2006;25(5):716-26.

123. Diener JRC, Silva DM, Tomelin P, Silveira LMP. Manual de terapia de nutrição parenteral e enteral. Florianópolis: Universidade Federal de Santa Catarina; 2001. p. 1-27.

124. Reignier J, Thenoz-Jost N, Fiancette M, Legendre E, Lebert C, Bontemps $\mathrm{F}$, et al. Early enteral nutrition in mechanically ventilated patients in the prone position. Crit Care Med. 2004;32(1):94-9.

125. Horiuchi A, Nakayama Y, Tanaka N, Fuji H, Kajiyama M. Prospective randomized trial comparing the direct method using a $24 \mathrm{fr}$ bumperbutton-type device with the pull method for percutaneous endoscopic gastrostomy. Endoscopy. 2008;40(9):722-6.

126. Montori VM, Bistrian BR, McMahon MM. Hyperglycemia in Acutely III Patients. JAMA. 2002;288(17):2167-69.

127. Pittas AG, Siegel RD, Lau J. Insulin therapy and in-hospital mortality in critically ill patients: systematic review and meta-analysis of randomized controlled trials. JPEN J Parenter Enteral Nutr. 2006;30(2):164-72.

128. Santana-Cabrera L, Shanahan-Navarro GO, Garciá-Martul M, Ramiréz-Rodriguez $A$, Sánchez-Palacios $M$, Hernández-medina $E$. Calidad del soporte nutricional artificial en una unidad del cuidados intensivos. Nutr Hosp. 2006;21(6):661-6.

129. Carey TS, Hanson L, Garrett JM, Lewis C, Phifer N, Cox CE, et al. Expectations and outcomes of gastric feeding tubes. Am J Med. 2006;119(1):527.e11-527.e16.

130. Corry J, Poon W, McPhee N, Milner AD, Cruickshank D, Porceddu SV, et al. Randomized study of percutaneous endoscopic gastrostomy versus nasogastric tubes for enteral feeding en head and neck cancer 
patients treated with (chemo) radiation. J Med Imag Rad Oncol. 2008;52(5):503-10.

131. Marderstein EL, Simmons RL, Ochoa JB. Patient safety: effect of institutional protocols on adverse events related to feeding tube placement in the critically ill. J Am Coll Surg. 2004;199(1):39-47.

132. Gorzoni ML, Torre AD, Pires SL. Medicamentos e sondas de nutrição. Rev Assoc Med Bras. 2010;56(1):17-21.

133. lizuka M, Reding M. Use of percutaneous endoscopic gastrostomy feeding tubes and functional recovery in stroke rehabilitation: a casematched controlled study. Arch Phys Med Rehabil. 2005;86(5):1049-52.

134. Horiuchi A, Nakayama Y, Fujii H, Kajiyama M. Endoscopic holderassisted percutaneous endoscopic gastrostomy placement: results of a prospective, randomized comparison study. Gastrointest Endosc. 2006;64(4):627-31.

135. Sedlack RE, Pochron NL, Baron TH. Percutaneous endoscopic gastrostomy placement without skin incision: results of a randomized trial. JPEN J Parenter Enteral Nutr. 2006;30(3):240-5.

136. Han-Geurts IJM, Hop WC, Verhoef C, Tran KTC, Tilanus HW. Randomized clínical trial comparing feeding jejunostomy with nasoduodenal tube placement in patients undergoing oesophagectomy. Br J Surg. 2007;94(1):31-5.

137. Esperón Güimil JA, Freire Rodríguez M, Escudero Quiñones AI, Ocampo Piñeiro A, Pernas Silva CT, González González M, et al. Sondas endonasales como causa de las úlceras por presión en el paciente crítico. Enferm Intensiva. 2009;20(1):10-8 .

138. Ciosak SI. Cuidados de enfermagem na nutrição enteral. In: Waitzberg DL. Nutrição oral, enteral e parenteral. $4^{a}$ ed. São Paulo: Atheneu; 2009. v. 1. p. 894-905.

139. Sakurai Y, Masui T, Yoshida I, Tonomura S, Shoji M, Nakamura Y, et al. Randomized clínical trial of the effects of perioperative use of immune-enhancing enteral formula on metabolic and immunological status in patients undergoing esophagectomy. World J Surg. 2007;31(11):2150-7. 
140. Lee JS, Auyeung TW. A comparison of two feeding methods in the alleviation of diarrhoea in older tube-fed patients: a randomised controlled trial. Age Ageing. 2003;32(4):388-93.

141. Jacobs S, Chang RWS, Lee R, Bartlett FW. Continuous enteral feeding: a major cause of pneumonia among ventilated intensive care unit patients. JPEN J Parenter Enteral Nutr. 1990;14(4):353-6.

142. Salvalaggio PRO, Perosa M, Figueiró JM. Otimização do uso dos enxertos pancreáticos no Brasil. JBT J Bras Transpl. 2005;8(3):390-5.

143. Leite AS. Morbidade e mortalidade de pacientes com choque séptico tratados com noradrenalina: estudo multicêntrico [tese]. Belo Horizonte: Universidade Federal de Minas Gerais, 2009. 


\section{APÊNDICE}

\section{INSTRUMENTO DE COLETA DE DADOS}

\section{Complicações e fatores associados}

$\mathrm{N}^{\circ}$ do instrumento:

$\mathrm{RH}:$

Idade (anos):

Sexo: (1) fem (2) masc

Tempo de internação (dias):

Destino: (1) alta (2) óbito (3) transferência

Unidade de internação:
(1) clínica médica
(2) clínica cirúrgica
(3) UTI
(4)
semiintensiva

Comorbidades:

\section{Aspectos nutricionais:}

Tempo de TNE: (dias) Suspensão da dieta: (dias)

Retornou a TNE após: dias Motivos da suspensão:

Via de acesso enteral

\begin{tabular}{|l|l|l|l|l|}
\hline Data & & & & \\
\hline Sonda naso/oroenteral & & & & \\
\hline 1. Pré-pilórico & & & & \\
2. Pós-pilórico & & & & \\
3. Sem registro & & & & \\
\hline Gastrostomia & & & & \\
\hline
\end{tabular}


Método de infusão da TNE

\begin{tabular}{|l|l|l|l|l|}
\hline \multicolumn{1}{|c|}{ Data } & & & & \\
\hline (1) Intermitente & & & & \\
\hline (2) Contínuo & & & & \\
\hline
\end{tabular}

\section{Complicação Gastrointestinal}

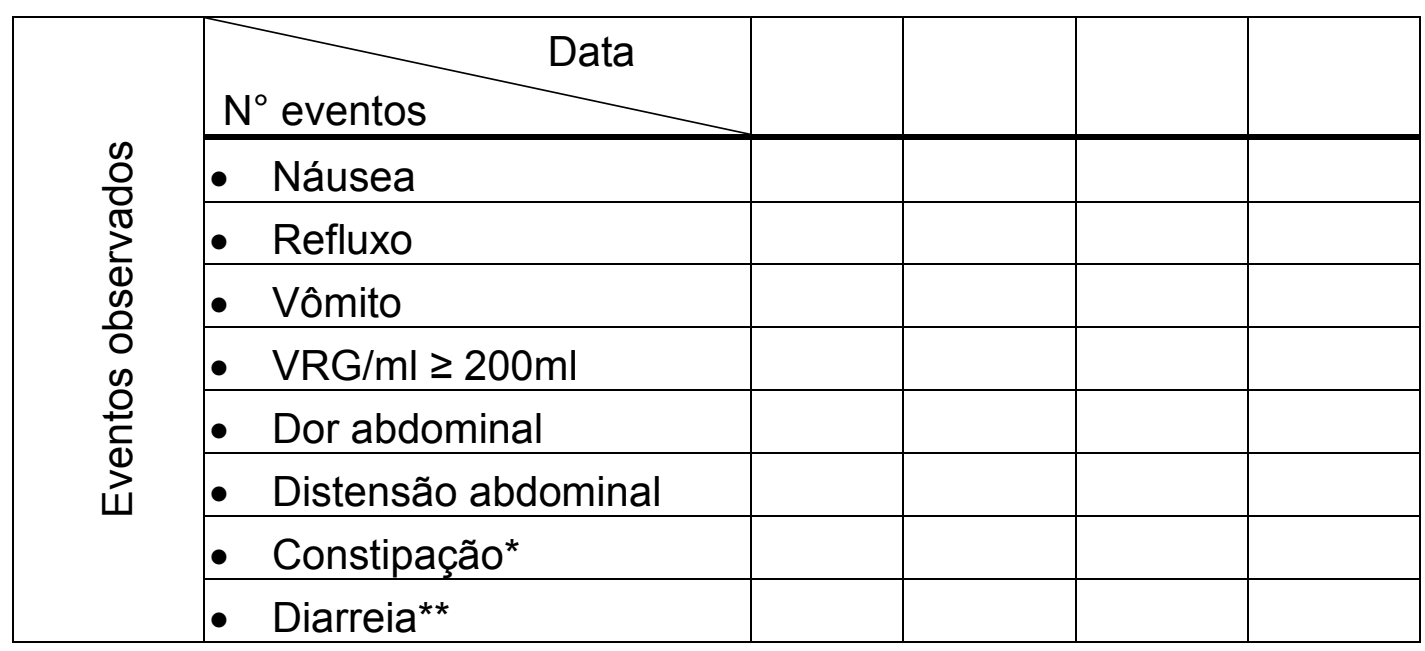

* evacuação ausentes $\geq 3$ dias.

** $\geq 3$ episódios de fezes líquidas ou semilíquidas/24hs.

\section{Complicação Metabólica}

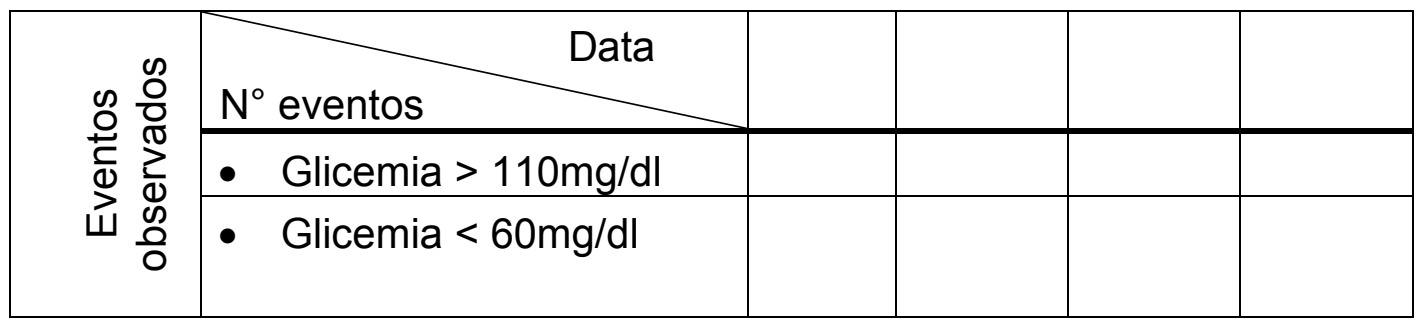

\section{Complicação Mecânica}

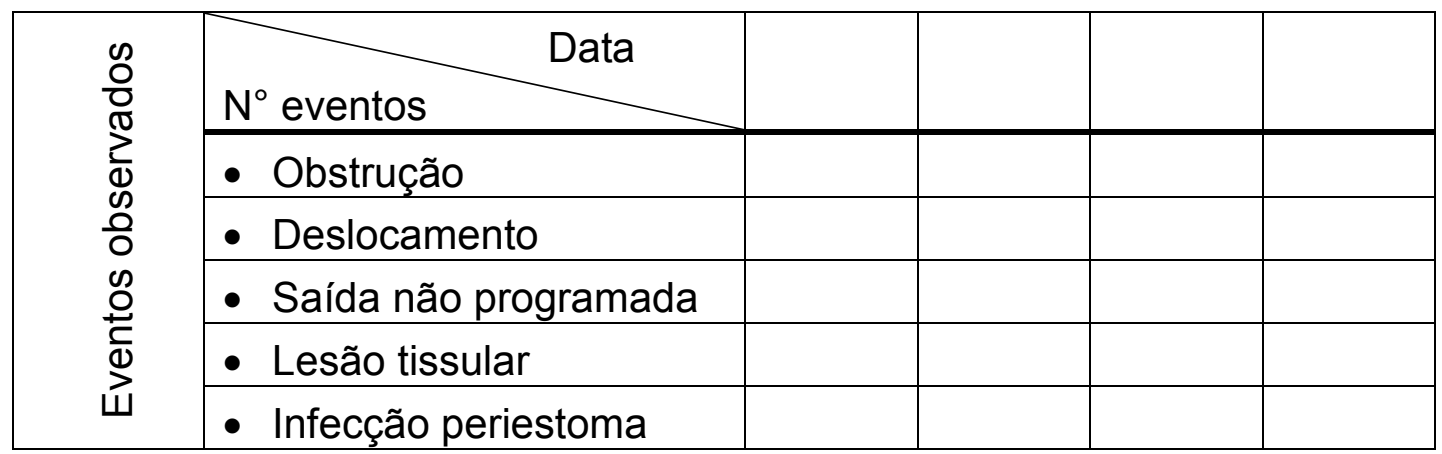




\section{Complicação Pulmonar}

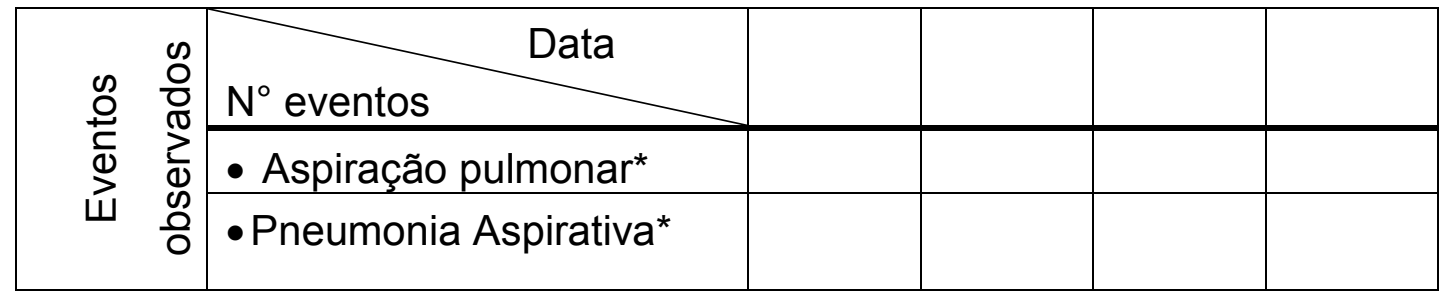

* após introdução da TNE

Informações de terapêuticas complementares

Ventilação Mecânica

\begin{tabular}{|l|l|l|l|l|}
\hline Data & & & & \\
\hline (1) Sim & & & & \\
\hline (2) Não & & & & \\
\hline
\end{tabular}

Terapêutica medicamentosa

\begin{tabular}{|l|l|l|l|l|}
\hline \multicolumn{1}{|c|}{ Data } & & & & \\
\hline - Sedativos/Opioide & & & & \\
\hline - Drogas Vasoativas & & & & \\
\hline - Relaxante Muscular & & & & \\
\hline - Antiinflamatório & & & & \\
\hline - Antibiótico & & & & \\
\hline - Pró-cinético & & & & \\
\hline
\end{tabular}




\section{ANEXO}

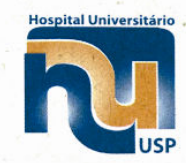

São Paulo, 24 de abril de 2010.

$I^{m o(a)} . S^{r(a)}$

Profa. Dra. Ana Maria Kazue Miyadahira

Departamento de Enfermagem Médico Cirúrgica

Escola de Enfermagem

UNIVERSIDADE DE SÃO PAULO

REFERENTE: Projeto de Pesquisa "Intercorrências com sonda gastrointestinal para aporte nutricional: fatores relacionados" - Registro CEP-HU/USP: 968/09 Registro SISNEP CAAE: 0083.0.198.196-09.

\section{Prezada Professora}

O Comitê de Ética em Pesquisa do Hospital Universitário da Universidade de São Paulo, em reunião ordinária realizada no dia 9 de abril de 2010, analisou e APROVOU a solicitação feita por V.Sa. através do documento datado de 31 de março de 2010, referente à mudança do título do Estudo para "Complicações e fatores de risco da nutrição enteral em pacientes adultos internados em um hospital universitário do Município de São Paulo".

Atenciosamente,

$$
\text { Dr. Maurício Seckler }
$$

Coordenador do Comitê de Ética em Pesquisa Hospital Universitário da Univensidade de São Paulo 